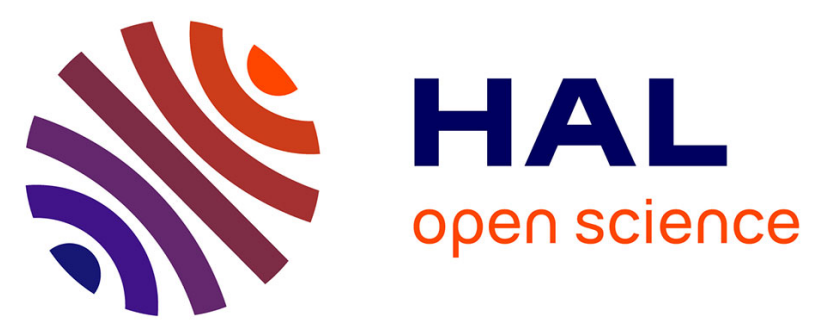

\title{
Cerpegin-derived furo[3,4-c]pyridine-3,4(1H,5H)-diones enhance cellular response to interferons by de novo pyrimidine biosynthesis inhibition
}

Simon Hayek, Nicolas Pietrancosta, Anna Hovhannisyan, Rodolphe Alves de Sousa, Nassima Bekaddour, Laura Ermellino, Enzo Tramontano, Stéphanie Arnould, Claude Sardet, Julien Dairou, et al.

\section{To cite this version:}

Simon Hayek, Nicolas Pietrancosta, Anna Hovhannisyan, Rodolphe Alves de Sousa, Nassima Bekaddour, et al.. Cerpegin-derived furo[3,4-c]pyridine-3,4(1H,5H)-diones enhance cellular response to interferons by de novo pyrimidine biosynthesis inhibition. European Journal of Medicinal Chemistry, 2020, 186, pp.111855. 10.1016/j.ejmech.2019.111855 . hal-02372490

\section{HAL Id: hal-02372490 \\ https://hal.science/hal-02372490}

Submitted on 25 Jan 2020

HAL is a multi-disciplinary open access archive for the deposit and dissemination of scientific research documents, whether they are published or not. The documents may come from teaching and research institutions in France or abroad, or from public or private research centers.
L'archive ouverte pluridisciplinaire HAL, est destinée au dépôt et à la diffusion de documents scientifiques de niveau recherche, publiés ou non, émanant des établissements d'enseignement et de recherche français ou étrangers, des laboratoires publics ou privés. 
1 Cerpegin-derived furo[3,4-c]pyridine-3,4(1H,5H)-diones enhance cellular

Simon Hayek $^{1}$, Nicolas Pietrancosta ${ }^{1}$, Anna A. Hovhannisyan ${ }^{2}$, Rodolphe Alves de Sousa ${ }^{1}$,

Nassima Bekkadour ${ }^{1}$, Laura Ermellino ${ }^{1,3}$, Enzo Tramontano ${ }^{3}$, Stéphanie Arnould ${ }^{4}$, Claude

Sardet $^{4}$, Julien Dairou ${ }^{5}$, Olivier Diaz ${ }^{6}$, Vincent Lotteau ${ }^{6}$, Sébastien Nisole ${ }^{7}$, Gagik Melikyan²*,

Jean-Philippe Herbeuval ${ }^{1}$, Pierre-Olivier Vidalain ${ }^{1 *}$

$9 \quad{ }^{1}$ Chimie et Biologie, Modélisation et Immunologie pour la Thérapie (CBMIT), Laboratoire de 10 Chimie et Biochimie Pharmacologiques et Toxicologiques, Université Paris Descartes, CNRS 11 UMR 8601, Paris, France.

${ }^{2}$ Department of Organic Chemistry, Yerevan State University, Yerevan, Armenia.

3 Laboratory of Molecular Virology, Department of Life and Environmental Sciences,

14 University of Cagliari, Cagliari, Italy

$15{ }^{4}$ Institut de Recherche en Cancérologie de Montpellier, INSERM U1194, Université de 16 Montpellier, Institut Régional du Cancer de Montpellier, Montpellier, France

$17{ }^{5}$ Chimie Bio-inorganique des Dérivés Soufrés et Pharmacochimie (CBDSP), Laboratoire de Chimie et Biochimie Pharmacologiques et Toxicologiques, Université Paris Descartes, CNRS UMR 8601, Paris, France.

${ }^{6}$ Centre International de Recherche en Infectiologie, INSERM U1111, CNRS UMR5308, Université Lyon 1, ENS de Lyon, Lyon, France

$22{ }^{7}$ Institut de Recherche en Infectiologie de Montpellier CNRS UMR 9004, Université de 23 Montpellier, Montpellier, France

\section{* Corresponding authors:}

Pierre-Olivier Vidalain (pierre-olivier.vidalain@inserm.fr)

Current address : Centre International de Recherche en Infectiologie (CIRI), INSERM U1111, CNRS UMR5308, Université Lyon 1, ENS de Lyon, 21 Avenue Tony Garnier - 69365 Lyon Cedex 07, France

Gagik Melikyan (gagik.melikyan@yahoo.com)

Keywords: Interferon, pyrimidine biosynthesis, cerpegin, DHODH, DNA damage response 


\section{ABSTRACT}

2 There is an increasing interest in the field of cancer therapy for small compounds targeting

3 pyrimidine biosynthesis, and in particular dihydroorotate dehydrogenase (DHODH), the fourth

4 enzyme of this metabolic pathway. Three available DHODH structures, featuring three

5 different known inhibitors, were used as templates to screen in silico an original chemical

6 library from Erevan University. This process led to the identification of P1788, a compound

7 chemically related to the alkaloid cerpegin, as a new class of pyrimidine biosynthesis inhibitors.

8 In line with previous reports, we investigated the effect of P1788 on the cellular innate immune

9 response. Here we show that pyrimidine depletion by P1788 amplifies cellular response to both

10 type-I and type II interferons, but also induces DNA damage as assessed by $\gamma \mathrm{H} 2 \mathrm{AX}$ staining.

11 Moreover, the addition of inhibitors of the DNA damage response led to the suppression of the

12 P1788 stimulatory effects on the interferon pathway. This demonstrates that components of the

13 DNA damage response are bridging the inhibition of pyrimidine biosynthesis by P1788 to the

14 interferon signaling pathway. Altogether, these results provide new insights on the mode of

15 action of novel pyrimidine biosynthesis inhibitors and their development for cancer therapies. 


\section{INTRODUCTION}

DNA and RNA syntheses require large amounts of purine and pyrimidine nucleosides as precursors. This makes quickly dividing cells highly dependent on de novo nucleoside biosynthesis, whereas quiescent and slowly growing cells essentially rely on intracellular recycling of nucleosides or their uptake from extracellular fluids. Consequently, cancer cells are particularly sensitive to nucleoside biosynthesis inhibitors such as 5-fluorouracil, methotrexate, or 6-mercaptopurine, which are extensively used in clinical practice. Among antimetabolites that are currently investigated for their antitumoral properties, molecules targeting dihydroorotate dehydrogenase (DHODH), the fourth enzyme of de novo pyrimidine biosynthesis, are the subject of intense research [1-3]. In this metabolic pathway, three enzymatic steps are required to convert glutamine, aspartate, and bicarbonate into dihydroorotate (DHO), which is the substrate for DHODH [3]. Its oxidation by DHODH leads to orotate, which is converted into uridine monophosphate (UMP) that serves as a precursor for cytidine and thymidine biosynthesis. This makes DHODH a rate-limiting enzyme in the biosynthesis of pyrimidine nucleosides, and a potential target for antimetabolite development. In the 90s, brequinar, a potent DHODH inhibitor passed pre-clinical studies, and was evaluated for its antitumor properties in multiple phase-I and phase-II trials [1-3]. However, severe adverse effects and a lack of efficacy in patients with different types of solid tumors stopped its development. This setback also led to the disregard of DHODH inhibition as a valuable strategy for anticancer therapies. Concomitantly, teriflunomide, another DHODH inhibitor, and its related prodrug (leflunomide), were evaluated successfully and approved for the treatment of rheumatoid arthritis and later on for multiple sclerosis despite significant side effects [1-3]. This drug was shown to impair the proliferation of immune cells by inhibiting pyrimidine biosynthesis. It also interferes through tyrosine kinase inhibition and Aryl Hydrocarbon Receptor (AhR) activation, which altogether contribute to its immunosuppressive 
1 properties [4]. Despite the failure of brequinar in past clinical studies, recent publications

2 renewed interest in DHODH as a target in cancer therapy and both old and recent series of

3 DHODH inhibitors were shown to have promising antitumor properties. This was demonstrated

4 in various in vivo models when administered alone or in combination with other drugs, in

5 particular in acute myeloid leukemia (AML), neuroblastoma, PTEN (Phosphatase and TENsin

6 homolog) mutant triple negative breast cancer cells, and KRAS (V-Ki-ras2 Kirsten rat sarcoma

7 viral oncogene homolog) mutant pancreatic cancer cells [5-14]. Several DHODH inhibitors,

8 including brequinar, leflunomide and new molecules such as BAY2402234 or PTC299, are

9 currently being evaluated in clinical trials for cancer therapy $[15,16]$. Some pyrimidine

10 biosynthesis inhibitors also exhibit broad-spectrum antiviral activity in vitro [1-3,17-19] and in

11 vivo [20-22], opening new fields of application for this class of antimetabolites. In this context,

12 the identification of novel DHODH inhibitors with original chemical and pharmacological

13 properties has become a priority to overcome the limitations of existing molecules [23-27].

14 Beyond its cytostatic effects, DHODH inhibition is known to have a strong impact on

15 gene expression, cell metabolism, and differentiation [5,12,14,15,28]. Our team is interested in

16 the existing relationships between pyrimidine biosynthesis and the activation of innate

17 immunity, with a specific focus on the interferon (IFN) response. IFN- $\alpha / \beta$ (or type I IFNs) are

18 key antiviral and antitumoral cytokines that are produced by both immune and non-immune

19 cells. They are released upon stimulation by viral PAMPs (Pathogen-Associated Molecular

20 Patterns) such as double-stranded RNA molecules, or cellular DAMPs (Damage-Associated

21 Molecular Patterns) including DNA breaks. Once bound to their target receptors, IFN- $\alpha / \beta$

22 mobilize the JAK (Janus Kinase) and STAT (Signal Transducers and Activators of

23 Transcription) signaling cascade to induce a large panel of target genes, the ISGs (Interferon-

24 Stimulated Genes), which encode numerous antiviral and antitumoral factors. IFNs and ISGs

25 are therefore essential for the innate immune response against viruses and for the control of 
1 carcinogenesis $[29,30]$. Most interestingly, it is now well documented that pyrimidine

2 biosynthesis inhibitors (i) induce some ISGs by a non-canonical and IFN-independent pathway,

3 and (ii) enhance the expression of IFNs and ISGs when induced by viruses or viral PAMPs

4 such as double-stranded RNA molecules [22,31-41]. Data from the literature suggest that

5 DHODH inhibitors amplify the cellular response to type I IFNs, but this was only shown using

6 a reporter gene containing Interferon-Stimulated Response Elements (ISRE) driving

7 transcription of luciferase and never explored in detail $[32,34]$. The mechanism by which the

8 inhibition of pyrimidine biosynthesis promotes the expression of IFNs and ISGs remains poorly

9 understood and thus needs to be further documented [22,32,36,40,41]. The positive interaction

10 between the inhibition of pyrimidine biosynthesis and the innate immune response likely

11 contributes to the antiviral activity of DHODH inhibitors and it is tempting to speculate that it could also participate to the antitumor effect of these molecules as well.

DHODH, anchored by its N-terminal extremity to the internal mitochondrial membrane, uses flavin mononucleotide (FMN) and ubiquinone (or coenzyme $\mathrm{Q}_{10}$ ) as cofactors in a twostep redox reaction. Ubiquinone is usually located in the mitochondrial membrane. Close contact between DHODH and the membrane allows ubiquinone to shuttle into a hydrophobic channel of this enzyme in order to contact FMN as recently modelled [42]. A majority of DHODH inhibitors that have been described in the literature compete with ubiquinone for binding to this channel, and interact with a limited number of well-characterized residues [13]. Here, we took advantage of three high-definition structures available in the Protein Data Bank (PDB) for human DHODH bound to unrelated inhibitors to develop and benchmark a pipeline for in silico screening (4OQV, 3KVJ, 4RR4). This led to the identification of P1788, a compound featuring structural components of the plant alkaloid cerpegin $[43,44]$, as a new class of pyrimidine biosynthesis inhibitors. We then used this compound to establish that cellular response to both type-I and II IFNs is amplified in cell cultures where pyrimidine 
1 biosynthesis is blocked. We provide evidence that pyrimidine biosynthesis inhibition by P1788

2 activates the DNA damage response to amplify the interferon response. Altogether, our results

3 reinforce the link between this metabolic pathway and the innate immune response and its

4 therapeutic potential in various acute and chronic diseases.

5

6

7

\section{MATERIALS AND METHODS}

\section{Chemical syntheses}

All solvents and chemicals were purchased from the Armenian Institute of Applied Chemistry (ARIAC). Dimethylformamide (DMF), dimethylacetal (DMA) and xylene were dried using standard. ${ }^{1} \mathrm{H}$ NMR and ${ }^{13} \mathrm{C}$ NMR spectra were recorded in deuterated dimethyl sulfoxide (DMSO-d6) at ambient temperature using a $500 \mathrm{MHz}$ nuclear magnetic resonance (NMR) spectrometer equipped with a $5 \mathrm{~mm}$ cryogenically cooled probe ${ }^{1} \mathrm{H} /{ }^{13} \mathrm{C} /{ }^{2} \mathrm{D}$ optimized for carbon-13 detection with z-gradients. The chemical shifts were reported in ppm downfield from tetramethylsilane (TMS). For compounds P2702, P2703, P2705 and P2706, ${ }^{1} \mathrm{H}$ NMR and ${ }^{13} \mathrm{C}$ NMR spectra were recorded with a Varian Mercury 300 spectrometer operating at $300 \mathrm{MHz}$ and $75 \mathrm{MHz}$ with TMS as internal standard in $\mathrm{DMSO}-\mathrm{d}_{6} / \mathrm{CCl}_{4}$ solution at $303 \mathrm{~K}$. Electrospray ionization (ESI) and high resolution mass spectrometry (HRMS) analyses were conducted using a Thermo Scientific High Resolution Exactive Orbitrap Mass spectrometer. The measurements were performed on the NMR platform and Mass spectrometry platform of UMR8601 CNRS laboratory. Elemental analyses were carried out by the CNRS microanalysis service at Gif-sur-Yvette. Melting points were determined on a Kofler hot-stage microscope and are uncorrected.

\section{Procedure for the Synthesis of Cerpegin N-Substituted Derivatives.}

The general procedure used for the synthesis of substituted cerpegin analogs was described in our previous reports [43,45]. Initial (E)-ethyl 4-(2-(dimethylamino)vinyl)-5,5disubstituted-2-oxo-2,5-dihydrofuran-3-carboxylates (II) were synthesized according to 
1 previously described methods [43-46]. Briefly, condensation of 2-oxo-2,5-dihydrofurans (I; 10

$2 \mathrm{mmol})$ and DMF/DMA (1.44 $\mathrm{ml} ; 12 \mathrm{mmol})$ was achieved in $3 \mathrm{~h}$ in boiling anhydrous xylene

3 (10 ml) to give the corresponding compounds (II) in yields of up to 80-90\% (Scheme 1). In a

4 flask fitted with a reflux, compound (II) $(10 \mathrm{mmol})$ and the corresponding amine (40 mmol)

5 were mixed in anhydrous xylene $(7 \mathrm{~mL})$. In the case of amines with low boiling points (bp

$6<100^{\circ} \mathrm{C}$ ) the reaction was undertaken without xylene using an excess of amine. The mixture

7 was boiled for $15 \mathrm{~h}$ (extra $2 \mathrm{~h}$ after cessation of dimethylamine evolution), cooled to room

8 temperature, and $5 \mathrm{~mL}$ of light petroleum was added. The resulting precipitates were filtered,

9 washed with ether and dried. Yields and physical data of the resulting compounds are provided

10 in Supplementary Materials and Methods.

\section{Synthesis of N-cyclopropyl-4-methyl-2-oxo-1-oxaspiro[4.5]dec-3-ene-3-carboxamide} (P2708).

A mixture of ethyl 4-methyl-2-oxo-1-oxaspiro[4.5]dec-3-ene-3-carboxylate (2.38 g; 10 mmol) and cyclopropylamine $(0.9 \mathrm{~mL} ; 13 \mathrm{mmol})$ in ethanol $(1 \mathrm{~mL})$ was left at room temperature $20 \mathrm{~h}$. The resulting precipitate was filtered, washed with cold ether and recrystallized from ethanol. Yields and physical data of the resulting compound are provided in Supplementary Materials and Methods.

\section{In silico screening}

The in silico docking was performed with Discovery Studio (Discovery Studio

21 Modeling Environment, release 4.5; Dassault Systemes BIOVIA: San Diego, 2015) as an interface to LibDock, a docking algorithm developed by Diller and Merz [47]. LibDock uses protein site features called HotSpots which are tagged as polar or apolar. Prior to the docking procedure, the receptor HotSpot file was calculated. In parallel, ligands were prepared (i.e. 
1 ligand conformations were generated for each ligand structure by high-temperature molecular

2 dynamics using the BEST algorithm. The different conformations of ligands were placed into

3 the active site and HotSpots were matched as triplets. After a manual optimization and curation

4 step, the ligand poses were scored. Because ligand hydrogens were removed during the docking

5 process, they were added back to the ligand poses and optimized by minimization. The ligand

6 poses with the highest LibDock scores were retained and clustered according to their binding

7 mode.

\section{Cells and culture conditions}

Cells were cultured at $37^{\circ} \mathrm{C}$ and $5 \% \mathrm{CO}_{2}$ in Dulbecco's Modified Eagle's Medium (DMEM; Sigma-Aldrich; D6429) containing 10\% fetal calf serum (FCS; Sigma-Aldrich; F0804), penicillin and streptomycin. Experiments were performed on HEK-293 cells stably transfected with the ISRE-Luciferase reporter gene (ISRE-Luc), with or without NanoLuc as an additional reporter gene $[32,48]$. ISRE-Luc and ISG expression levels were unaffected by the presence of this additional reporter gene, and data from cells with or without NanoLuc were treated indifferently. Human peripheral blood mononuclear cells (PBMC) from one healthy 17 donor were isolated by density centrifugation with Lymphoprep medium (StemCell Technologies) from leucocytes concentrates obtained when plateletpheresis was performed (Etablissement Français du Sang; Paris; France). To activate PBMCs, cells were treated for 24 $\mathrm{h}$ with the TLR7/8 ligand R848 at $5 \mu \mathrm{g} / \mathrm{ml}$ (Sigma Aldrich) and supernatants were harvested.

21 Cytokine expression levels were assessed using the LEGENDplex Human Anti-Virus Response 22 Panel (BioLegend). Results are presented in Supplementary Table I.

\section{Reagents, cytokines and small compounds}


Firefly luciferase expression in culture wells was measured using the Bright-Glo

2 (Promega) or Britelite plus reagents (PerkinElmer), according to the manufacturer's

3 recommendations. Cellular viability was determined by quantification of adenosine

4 triphosphate (ATP) in culture wells using the CellTiter-Glo assay (Promega). Bioluminescence

5 was measured for $0.1 \mathrm{~s}$ with a luminometer (EnSpire; PerkinElmer). Recombinant IFN- $\alpha$ was

6 from Sigma-Aldrich or PBL Assay Science. Recombinant IFN- $\gamma$ was from Roussel Uclaf (a

7 kind gift of Dr. Mounira Chelbi-Alix) or Miltenyi Biotech. Uridine, orotate, dihydroorotate,

8 PF477736 (Checkpoint Kinase 1 inhibitor), mirin (MRE11 inhibitor), C646 (P300/CREB-

9 Binding Protein inhibitor), teriflunomide, brequinar, and mitoxantrone were all from Sigma

10 Aldrich. Vidofludimus was from Selleckchem. AZD6738 (Ataxia telangiectasia and Rad3-

11 related kinase inhibitor) was from Euromedex.

Metabolite analysis

Nucleoside/nucleotide quantification in HEK-293 cells was performed by highperformance liquid chromatography (HPLC)-coupled spectrophotometry as previously described in [38]. Experimental details are provided in the "Supplementary Materials and 17 Methods".

Gene expression analysis by RT-qPCR.

ISG expression levels were determined by Reverse Transcription and quantitative Polymerase Chain Reaction (RT-qPCR) as follows. Total RNAs were extracted from $2 \times 10^{5}$ cells using the RNeasy Micro kit including DNase (Qiagen). Reverse transcription of cellular RNA into cDNA was achieved using the RevertAid H Minus first-strand cDNA synthesis kit 24 (Thermo Scientific). Real-time PCRs were performed in duplicate using the Takyon ROX SYBR MasterMix dTTP blue kit (Eurogentec) and a 7900HT Fast RT-PCR system (Applied 
1 Biosystems). Transcripts were quantified using the following program: $3 \mathrm{~min}$ at $95^{\circ} \mathrm{C}$, followed

2 by 35 cycles of $15 \mathrm{~s}$ at $95^{\circ} \mathrm{C}, 25 \mathrm{~s}$ at $60^{\circ} \mathrm{C}$, and $25 \mathrm{~s}$ at $72^{\circ} \mathrm{C}$. For each transcript, CT values

3 were normalized both to the expression levels of RPL13A (60S ribosomal protein L13a) and

4 unstimulated control samples using the $2^{-\Delta \Delta C T}$ method. The primers used for the quantification

5 of transcripts are presented in Supplementary Table II.

6

$\gamma H 2 A X$ immunostaining

Cells were harvested after $24 \mathrm{~h}$ of culture, washed with PBS, trypsinized and fixed for 30 min in paraformaldehyde (PFA 4\%). Cells were washed and permeabilized with Perm Buffer III (BD Biosciences) for $5 \mathrm{~min}$. After one washing step, cells were stained with a mouse monoclonal anti- $\gamma \mathrm{H} 2 \mathrm{AX}$ antibody (1/400 dilution, 3F2 Clone, ThermoFisher) or a matching isotypic control in phosphate-buffered saline (PBS) $+2 \%$ bovine serum albumin (BSA). After $45 \mathrm{~min}$ at $4^{\circ} \mathrm{C}$, cells were washed again and incubated with a secondary Alexa Fluor 488conjugated goat anti-mouse antibody (1/500, A21121, ThermoFisher). Cells were washed after 45 min at $4^{\circ} \mathrm{C}$ of incubation, and analyzed by flow cytometry using a FACSCanto II (BD

16 Biosciences).

\section{RESULTS}

\section{In silico identification of DHODH inhibitors.}

Ubiquinone is a rather large cofactor made of a 1,4-benzoquinone and a tail of 10

21 isoprenyl chemical subunits (Fig. 1A). The structure of human DHODH bound to ubiquinone,

22 or its reduced form ubiquinol, has not been resolved yet. However, more than 50 co-structures of human DHODH featuring chemical inhibitors are available in the PDB. The vast majority of

24 these inhibitors were found to bind a hydrophobic funnel localized at the contact interface of 25 DHODH with the mitochondrial membrane. This lipophilic pocket was considered as the 
1 binding site for ubiquinone allowing a direct contact with FMN at its extremity as recently

2 modelized by Costeira-Paulo J. et al [42]. As shown in Fig. 1A, our molecular docking protocol

3 confirmed that ubiquinone perfectly fits within this binding pocket. We also validated that

4 Arg136, which is essential for DHODH activity and mutated in patients with Miller syndrome,

5 interacts with one of the keto groups of ubiquinone as reported in [42]. To perform the

6 molecular docking-based screening, we selected in PDB three available high-resolution

7 structures of DHODH binding chemically-unrelated inhibitors: 4OQV, 3KVJ and 4RR4

$8 \quad[49,50]$. These structures were not selected on the basis of the activity of the compounds, but

9 because the compounds display different binding modes to human DHODH. Indeed, all three

10 compounds are interacting with Arg136 and FMN in the hydrophobic funnel but the rest of the

11 interactions with DHODH are highly diverse (Fig. 1B). This provided three slightly different

12 DHODH structures to undertake an in silico screening. To benchmark our screening protocol,

13 we showed that algorithm-based docking of each inhibitor perfectly matched the corresponding

14 X-ray derived DHODH structure as assessed by a low Root-Mean-Square Deviation (RMSD)

15 comparison (Fig. 1B).

16 The virtual high-throughput screening (vHTS) was performed on a set of 1,587

17 compounds from Yerevan State University, a chemical library that encompasses a large

18 diversity of original structures. To ensure a time/precision ratio compatible with vHTS, we used

19 a protocol in which amino acid side chains of the protein are left flexible only around the

20 binding site, and we tested 10 random conformers for each ligand. The resulting ligand poses

21 were further filtered to select compounds expected to bind Arg136 and FMN, and then ranked

22 according to their docking scores as described in the Material and Methods section. The entire

23 library was screened against the three selected DHODH structures. Finally, a total of 26, 49,

24 and 55 compounds respectively fulfilled our criteria when using the 4OQV, 3KVJ and 4RR4

25 structures (Fig. 1C). To further increase the stringency of our screening, we selected the 11 
1 compounds identified with at least two of the three abovementioned structures. Interestingly,

2 this subset included two molecules, P2703 and P1788 (Fig. 1D), which featured a 1,1,5-

3 trimethylfuro[3,4-c]pyridine-3,4(1H,5H)-dione component similar to one seen in the alkaloid

4 cerpegin. To our knowledge, such double-ringed structure with two adjacent keto groups

5 contacting Arg136 was new for DHODH inhibitors and thus deserved further investigations.

6

7

Functional validation of selected hits.

Since our main interest in DHODH inhibitors is their capacity to boost the cellular innate immune response, we used a reporter cell line expressing luciferase under the control of five interferon-stimulated response elements (ISRE-Luc) to assess the biological activity of the selected compounds. We and other groups have previously shown that in such a reporter system, cellular response to IFN- $\alpha / \beta$ is amplified by DHODH inhibitors [32,34]. Cells were incubated with increasing concentrations of selected compounds in the presence of recombinant IFN- $\alpha$, and luciferase activity was quantified $24 \mathrm{~h}$ later. Of the 11 compounds tested, 9 were inactive but the two related compounds P2703 and P1788 efficiently increased cellular response to IFN- $\alpha$ (Fig. 2A). To further confirm the inhibition properties of this chemical series, we tested the capacity of P1788 to block cellular proliferation, a phenotype that is also associated with DHODH inhibition. P1788 efficiently inhibited the proliferation of HEK-293 cells when monitored over three days (Fig. 2B).

\section{Structure activity relationships}

To determine some structure activity relationship for this chemical series, and confront them with the docking model determined for P2703 and P1788 (Fig. 1D), we prepared the array of chemical analogs of cerpegin depicted in Fig. 3. Each compound was tested for its ability to boost cellular response to IFN- $\alpha$ using ISRE-Luc reporter cells as shown in Fig. 2A. A dose- 
1 response ranging from 0.8 to $150 \mu \mathrm{M}$ was obtained for each molecule, and the corresponding

2 pEC50s were calculated to compare their biological effect (Fig. 3). Norcerpegin (1,13 dimethylfuro[3,4-c]pyridine-3,4(1H,5H)-dione), the original scaffold of this chemical series, 4 was inactive. The difference of effect seen between P1788 and compounds P2512, P1781 or 5 P2705 demonstrated that a cyclopropyl substituent on the nitrogen was essential. Furthermore, 6 compounds with the larger N-cyclobutyl (P2707), N-cyclopentyl (P1792), or N-cyclohexyl 7 (P1793) groups were also inactive. Similarly, P2706 exhibiting an extended cyclopropylmethyl 8 group showed no activity at tested concentrations. Altogether, these results support our docking 9 model in which this cyclopropyl group fully occupies the DHODH hydrophobic pocket made 10 of FMN, Val134 and Val143 (Fig. 1D). We also found that a double hydrophobic substitution on position 1 of the furopyridine scaffold was essential as seen for compounds featuring a spirocyclopentane (P2717), a spirocyclohexane (P1788) or a phenyl and a methyl group 13 (P2703). This is consistent with our docking model where such substituents interact with Ala59 or Ala55 at the entry side of the hydrophobic pocket (Fig. 1D). Finally, opening the pyridine group as in P2708 also impaired the biological activity of the molecule. This last result is in line with a structuring role for the furopyridine scaffold. Altogether, these results validate our docking model for P2703 and P1788 in the ubiquinone binding pocket of DHODH. To compare the activity of P2703 and P1788 with well-characterized inhibitors of DHODH, teriflunomide, vidofludimus and brequinar were evaluated in the same cellular assay (Fig. 3). Teriflunomide and vidofludimus were significantly more active than P2703 and P1788 (EC50 $=8.9$ and $2.8 \mu \mathrm{M} v s 27$ and $44 \mu \mathrm{M}$, respectively), but all four molecules showed EC50s within the micromolar range. Only brequinar was much more active with an EC50 equal to 56 nM. Because P2703 and P1788 were within a range of activity close to fully optimized molecules like teriflunomide or vidofludimus, we decided to further investigate the properties of these molecules. Although P2703 was slightly more active, P1788 was selected as the 
1 prototype of this chemical series because a larger batch had been produced and was readily 2 available.

\section{P1788 targets the pyrimidine biosynthesis pathway}

To demonstrate that P1788 is indeed targeting the pyrimidine metabolism, we treated cells with this molecule and quantified nucleoside levels by liquid chromatography coupled with spectrophotometry. As shown in Fig. 4A, pyrimidine levels collapsed in P1788-treated cells ( $\mathrm{U}$ and $\mathrm{C}$ ), whereas purine levels were unaffected ( $\mathrm{G}$ and $\mathrm{A})$. This shows that P1788 interferes with pyrimidine homeostasis as expected. We then determined if the amplification of

10 IFN- $\alpha / \beta$ signaling by $\mathrm{P} 1788$ is a consequence of pyrimidine depletion in treated cells. To address this question, cells with the ISRE-Luc reporter gene were treated with recombinant IFN- $\alpha$ and P1788 in the absence or presence of uridine. The addition of uridine completely reverted the effect of $\mathrm{P} 1788$, thus demonstrating that pyrimidine depletion is indeed responsible for the amplified response to IFN- $\alpha$ as shown in Fig. 4B. In order to determine more precisely which step of pyrimidine biosynthesis is inhibited by P1788, the same experiment was performed using a culture medium supplemented with either DHO or orotate (Fig. 4C). While DHO showed no effect on cellular response to IFN- $\alpha$, orotate completely reverted the effect of P1788. As DHO and orotate are respectively the substrate and product of DHODH, these results confirmed that P1788 is inhibiting this critical step of the pyrimidine biosynthesis pathway.

\section{P1788 amplifies cellular response to both type I and type II IFNs}

As stated above, it has previously been shown that DHODH inhibition amplifies cellular response to IFN- $\alpha / \beta[32,34]$. However, this was only documented using an ISRE-Luc reported gene and never validated by the actual monitoring of cellular ISGs. We took advantage of 25 P1788 as a novel inhibitor to address this question. Cells were treated with increasing 
1 concentrations of IFN- $\alpha$ in the absence or presence of P1788, and expression levels of 12 ISGs

2 were determined by RT-qPCR. ISGs were induced by IFN- $\alpha$ alone, but P1788 further enhanced

3 their expression (Fig. 5A). For example, a 4 to 5-fold increase in Mx2 expression level was

4 observed when cells stimulated with IFN- $\alpha$ were co-treated with P1788 (Fig. 5B). Altogether,

5 this confirmed that P1788 can boost the cellular response to IFN- $\alpha$

6 To our knowledge, it is still unknown if pyrimidine biosynthesis inhibitors are also able

7 to amplify the cellular response to IFN- $\gamma$. This is particularly interesting because this cytokine,

8 which is massively produced by Natural Killer (NK) cells and CD8+ T lymphocytes, plays a

9 key role in antitumoral immune responses and adaptive immunity in general. We thus

10 investigated the effects of P1788 on this pathway. Cells with the ISRE-Luc reporter gene were

11 stimulated with recombinant IFN- $\gamma$ in the absence or presence of P1788. As shown in Fig. 6A,

12 the reporter gene was induced by IFN- $\gamma$, and P1788 further increased its expression. To further

13 validate this observation, we collected supernatants of human PBMCs stimulated with R848, a

14 synthetic ligand for TLR7. Such conditioned supernatants contain IFN- $\gamma$ as shown in

15 Supplementary Table I and were used to stimulate cells with the ISRE-Luc reporter gene. P1788

16 strongly increased the cellular response to conditioned supernatants from PBMCs (Fig. 6B).

17 Our results demonstrate that P1788 is able to amplify cellular response to both type I and type

18 II interferons.

Key factors of the DNA damage response link P1788 to the IFN signaling pathway

Pyrimidine depletion by DHODH inhibitors has been shown to block DNA replication, leading to S phase accumulation and the activation of DNA damage response [9] (Fig. 7A). It is also well known that DNA damage are able to prime or induce the IFN response to prevent

24 infections or tumor formation, depending on the cellular system [29,51]. The DNA damage 25 response could therefore functionally link the inhibition of DHODH to the innate immunity as 
1 recently documented by Luthra P. et al [40]. To address this question in our cellular system, we

2 first determined if $\mathrm{P} 1788$ treatment induced the DNA damage response by measuring $\gamma \mathrm{H} 2 \mathrm{AX}$,

3 the phosphorylated form of $\mathrm{H} 2 \mathrm{AX}$ (H2A histone family member X) on serine 139. As shown

4 in Fig. 7B, P1788 induced a significant increase in $\gamma \mathrm{H} 2 \mathrm{AX}$ staining as determined by flow

5 cytometry. Similar $\gamma \mathrm{H} 2 \mathrm{AX}$ levels were achieved with the reference DHODH inhibitor

6 teriflunomide but the signal was much higher with mitoxantrone, a potent topoisomerase II

7 inhibitor that induces massive DNA damage. Furthermore, P1788 effect was neutralized by the addition of uridine, thus implicating pyrimidine depletion in this effect. The inhibition of de novo pyrimidine biosynthesis by $\mathrm{P} 1788$ is therefore associated to the induction of a mild DNA damage response which probably reflects the accumulation of stalled DNA forks in S phase. part of the MRE11/RAD50/NBS1 (MRN) complex, plays an important role in the stabilization, resection, and restart of stalled DNA forks (Fig. 7A). MRE11 also exhibits some endonuclease activity involved in the cleavage and release of single-stranded DNA from the resection site which contributes to IFN activation [52]. We tested the effect of mirin, an inhibitor of the MRE11 nuclease activity, on the cellular response to IFN- $\alpha$ in the absence or presence of P1788. As shown in Fig. 7C, mirin completely abolished the booster effect of P1788 on ISRELuc induction by IFN- $\alpha$. Cellular viability was not affected by this treatment as shown in Supp. Fig. 1A. The Ataxia telangiectasia and Rad3-related kinase (ATR) are co-activated with the MRN complex by single-stranded DNA breaks and then phosphorylate CHK1 (Checkpoint Kinase 1) to block cell cycle progression upon DNA damage [53]. We tested potent inhibitors of either ATR (AZD6738) or CHK1 (PF477736) in our system. ATR or CHK1 inhibitors abolished the effects of P1788 on the IFN- $\alpha$ response, further supporting a role of the DNA damage response as shown in Fig. 7D and E. Interestingly, ATR or CHK1 inhibition also showed significant effects on the cellular response to IFN- $\alpha$ in the absence of P1788. This 
1 suggests that a steady-state activation of ATR and CHK1 in these cells somehow contributes to

2 the IFN response. As stated, these treatments showed limited (AZD6738) or no effect

3 (PF477736) on cellular viability (Supp. Fig. 1B). Finally, we evaluated the contribution of P300

4 and CBP (CREB-Binding protein), two related histone acetyltransferases that are activated

5 downstream of the DNA damage response but also regulate the expression of ISGs. We thus

6 treated cells with C636, a small compound inhibiting both P300 and CBP, and induced the

7 ISRE-Luc reporter gene with IFN- $\alpha$ with or without P1788. As shown in Fig. 7F, the inhibition

8 of P300/CBP slightly decreased cellular response to IFN- $\alpha$, but most importantly abolished the

9 effect of P1788. These results confirm the functional link between the DNA damage response and the IFN-potentiating effect of P1788.

\section{DISCUSSION}

De novo pyrimidine biosynthesis is essential to fulfill the metabolic needs of quickly proliferating cells. As such, there is an increased interest in the field of cancer for molecules blocking critical steps of this enzymatic pathway. Here, we detailed the identification of P1788 and related molecules as a new series of pyrimidine biosynthesis inhibitors. These compounds were selected by virtual screening using three structures of DHODH co-crystallized with chemically distinct inhibitors bound to the ubiquinone/ubiquinol pocket. This approach was previously used by other teams and our results confirm its efficacy [54,57]. We then established the inhibition of pyrimidine biosynthesis pathway in P1788-treated cells by measuring nucleoside levels and using cellular response to IFN- $\alpha$ as a functional readout. The fact that orotate but not DHO nullified the effects of P1788 in this test supports the inhibition of DHODH by this molecule. It is of interest that P1788 and related molecules of this chemical series feature the unique chemical scaffold found in the alkaloid cerpegin (Fig. 3)[43,44]. Cerpegin is found in the Indian plant Ceropegia juncea, which has been used for centuries in folk medicine as a 
1 tranquilizer, anti-inflammatory, analgesic, and anti-ulcer therapy. Modern studies showed that

2 compounds with the cerpegin scaffold inhibit the 20S subunit of the proteasome $[43,45]$. The

3 results described here show that compounds also based on the cerpegin scaffold but with

4 different additional chemical groups inhibit pyrimidine biosynthesis. The two-edged fused

5 polycyclic moieties of this chemical series are actually reminiscent of known DHODH

6 inhibitors, including brequinar, dicoumarol, and DD778 that we recently described [38].

7 Brequinar interacts with Arg136 of DHODH through its carboxylic acid group whereas in

8 dicoumarol, the lactone oxygen atom was suggested to play this role [58]. According to our in

9 silico model, the interaction of P1788 with Arg136 is mediated by the diketone motif. To our

10 knowledge, this mode of interaction was not previously reporter for DHODH inhibitors and

11 clearly distinguishes the P1788 series from known DHODH inhibitors.

12 We took advantage of our lead molecule P1788 to characterize in details the impact of

13 pyrimidine biosynthesis inhibition on cellular response to IFNs. It is well known that DHODH

14 inhibition can (i) induce ISGs independently of IFN production or JAK/STAT signaling and

15 (ii) amplify the expression of both ISGs and IFN genes in response to double-stranded RNA

16 molecules, a viral PAMP that binds and activates RIG-like receptors (RLRs). Literature also

17 suggested that cellular response to type I IFNs is amplified when DHODH is inhibited as

18 assessed with an ISRE-Luc reporter gene [32,34]. Here, we have analyzed a dozen of ISGs by

19 RT-qPCR, and found that their induction by recombinant IFN- $\alpha$ is, as expected, enhanced in

20 the presence of P1788. This illustrates that the cellular stress associated to pyrimidine

21 deprivation is acting at multiple steps of the innate immune response. Most interestingly, we

22 also found that P1788 amplifies cellular response to IFN- $\gamma$. This was shown using purified

23 recombinant IFN- $\gamma$ or conditioned supernatants from activated PBMCs. IFN- $\gamma$ activates a

24 signaling cascade that significantly differs from IFN- $\alpha / \beta$ as it binds a specific receptor

25 (IFNGR1/2) and mobilizes Jak1/Jak2 kinases — as opposed to Jak1/Tyk2 for IFN- $\alpha / \beta$ - to 
1 phosphorylate STAT1. STAT2 is not involved in the signaling cascade induced by IFN- $\gamma$. Our

2 results and the literature suggest that a common mechanism triggered by pyrimidine deprivation

3 amplifies cellular response to both IFN $-\alpha / \beta$, IFN- $\gamma$, and RLR ligands. IFNs rely on STAT1/2

4 for gene transcription, whereas RLRs activate Interferon Regulatory Factors 3 (IRF3). It is

5 therefore tempting to speculate that a common costimulatory factor associates to these

6 transcription factors when pyrimidine biosynthesis is impaired. Discovering this mechanism

7 remains a major challenge in our understanding of the mechanisms linking pyrimidine

8 metabolism to innate immunity.

9 Here, we showed that P1788 treatment was associated to the induction of a DNA

10 damage response as assessed by $\gamma \mathrm{H} 2 \mathrm{AX}$ staining. Furthermore, the enhanced response to IFN-

$11 \alpha$ was dependent on MRE11, ATR, CHK1, and P300/CBP. MRE11, ATR, and CHK1 are all

12 activated by single-stranded genomic DNA, in particular at stalled DNA replication forks which

13 likely accumulate when intracellular pyrimidine concentration drops below a certain threshold

14 [52]. This further supports the idea that the DNA damage response represents the functional

15 link between the inhibition of pyrimidine biosynthesis and the innate immune response. Most

16 interestingly, we and others have previously shown that Interferon Regulatory Factor 1 (IRF1)

17 is essential to ISG induction in cells treated with pyrimidine biosynthesis inhibitors alone,

18 double-stranded RNA, or both $[32,40]$. IRF1 is a transcription factor that is upregulated by the

19 DNA damage response and promotes the expression of ISGs, either alone or in association with

20 STATs and IRFs [59,60]. In addition, it was shown that IRF1-mediated transcription relies on

21 P300/CBP, two related histone acetyltransferases that we implicated in the signaling cascade

22 downstream of P1788 [61]. In a recent report by Luthra et al, it has been shown that DNA

23 damage associated with the inhibition of pyrimidine biosynthesis activate ATM (Ataxia

24 Telangiectasia Mutated), a kinase activated by double-stranded DNA breaks, which was

25 essential to the induction of ISGs by pyrimidine biosynthesis inhibitors [40]. In line with this 
1 work, we conclude from our observations that the DNA damage response links pyrimidine

2 deprivation to the innate immune response and to IRF1, and show that P300/CBP is also 3 involved in this phenomenon.

In conclusion, we have identified and characterized a new series of compounds inhibiting pyrimidine biosynthesis. Future work will aim at improving these compounds to

6 obtain more potent inhibitors with optimized pharmacological properties. These molecules

7 enhance cellular response to IFN- $\alpha / \beta$, and DNA damage response plays a key role in this

8 mechanism. Most importantly, we showed that cellular response to IFN- $\gamma$ is also enhanced in

9 the presence of P1788. This latter finding is opening exciting perspectives in cancer therapy as IFN- $\gamma$ contributes to the antitumoral activity of both NK cells and CD8+ T lymphocytes [62]. This suggests that the benefit of DHODH inhibitors relies not only on their cytostatic effects but also on their capacity to boost an antitumoral response. If confirmed in vivo this would represent a significant step toward the development of this new category of antitumoral drugs.

\section{ACKNOWLEDGMENTS}

We acknowledge the technical support of Stéphanie Dupuy from the Flow Cytometry Platform at Université Paris Descartes. We thank the chemical library UMR8601 of Paris Descartes University for preparing and providing access to Yerevan's complete database for virtual and physical screening. We thank Dr. Farah Hodeib and Dr. Yves Janin for proofreading the manuscript. This work was supported by the Agence Nationale de la Recherche (ChemInnate program to POV and SN), Campus France (Programme CEDRE), SantImmune from the

22 Fondation Paris Descartes, the Centre National de la Recherche Scientifique (CNRS; www.cnrs.fr), and the Institut National de la Santé Et de la Recherche Médicale (INSERM).

24 SH was supported by the National Council for Scientific Research (Lebanon) and the Université Saint-Esprit de Kaslik (USEK). 
Structures and DHODH-inhibitory activities of the original compounds described in this

manuscript have been patented.

\section{REFERENCES}

[1] H. Munier-Lehmann, P.-O. Vidalain, F. Tangy, Y.L. Janin, On dihydroorotate https://doi.org/10.1021/jm301848w.

[2] M.L. Lolli, S. Sainas, A.C. Pippione, M. Giorgis, D. Boschi, F. Dosio, Use of human Dihydroorotate Dehydrogenase (hDHODH) Inhibitors in Autoimmune Diseases and New Perspectives in Cancer Therapy, Recent Patents Anticancer Drug Discov. 13 (2018) 86-105. https://doi.org/10.2174/1574892812666171108124218.

[3] J.T. Madak, A. Bankhead, C.R. Cuthbertson, H.D. Showalter, N. Neamati, Revisiting the role of dihydroorotate dehydrogenase as a therapeutic target for cancer, Pharmacol. Ther. (2018). https://doi.org/10.1016/j.pharmthera.2018.10.012.

[4] E.F. O’Donnell, K.S. Saili, D.C. Koch, P.R. Kopparapu, D. Farrer, W.H. Bisson, L.K. Mathew, S. Sengupta, N.I. Kerkvliet, R.L. Tanguay, S.K. Kolluri, The anti-inflammatory drug leflunomide is an agonist of the aryl hydrocarbon receptor, PloS One. 5 (2010). https://doi.org/10.1371/journal.pone.0013128.

[5] D.B. Sykes, Y.S. Kfoury, F.E. Mercier, M.J. Wawer, J.M. Law, M.K. Haynes, T.A. Lewis, A. Schajnovitz, E. Jain, D. Lee, H. Meyer, K.A. Pierce, N.J. Tolliday, A. Waller, S.J. Ferrara, A.L. Eheim, D. Stoeckigt, K.L. Maxcy, J.M. Cobert, J. Bachand, B.A. Szekely, S. Mukherjee, L.A. Sklar, J.D. Kotz, C.B. Clish, R.I. Sadreyev, P.A. Clemons, A. Janzer, S.L. Schreiber, D.T. Scadden, Inhibition of Dihydroorotate Dehydrogenase Overcomes Differentiation Blockade in Acute Myeloid Leukemia, Cell. 167 (2016) 171-186.e15. https://doi.org/10.1016/j.cell.2016.08.057.

[6] T.A. Lewis, D.B. Sykes, J.M. Law, B. Muñoz, J.K. Rustiguel, M.C. Nonato, D.T. Scadden, S.L. Schreiber, Development of ML390: A Human DHODH Inhibitor That Induces Differentiation in Acute Myeloid Leukemia, ACS Med. Chem. Lett. 7 (2016) 1112-1117. https://doi.org/10.1021/acsmedchemlett.6b00316.

[7] D. Mathur, E. Stratikopoulos, S. Ozturk, N. Steinbach, S. Pegno, S. Schoenfeld, R. Yong, V.V. Murty, J.M. Asara, L.C. Cantley, R. Parsons, PTEN Regulates Glutamine Flux to Pyrimidine Synthesis and Sensitivity to Dihydroorotate Dehydrogenase Inhibition, Cancer Discov. 7 (2017) 380-390. https://doi.org/10.1158/2159-8290.CD-16-0612.

[8] S. Zhu, X. Yan, Z. Xiang, H.-F. Ding, H. Cui, Leflunomide reduces proliferation and induces apoptosis in neuroblastoma cells in vitro and in vivo, PloS One. 8 (2013) e71555. https://doi.org/10.1371/journal.pone.0071555.

[9] S. Arnould, G. Rodier, G. Matar, C. Vincent, N. Pirot, Y. Delorme, C. Berthet, Y. Buscail, J.Y. Noël, S. Lachambre, M. Jarlier, F. Bernex, H. Delpech, P.O. Vidalain, Y.L. Janin, C. Theillet, C. Sardet, Checkpoint kinase 1 inhibition sensitises transformed cells to dihydroorotate dehydrogenase inhibition, Oncotarget. $8 \quad$ (2017) 95206-95222. https://doi.org/10.18632/oncotarget.19199.

[10] M.J.G.W. Ladds, I.M.M. van Leeuwen, C.J. Drummond, S. Chu, A.R. Healy, G. 
Popova, A. Pastor Fernández, T. Mollick, S. Darekar, S.K. Sedimbi, M. Nekulova, M.C.C. Sachweh, J. Campbell, M. Higgins, C. Tuck, M. Popa, M.M. Safont, P. Gelebart, Z. Fandalyuk, A.M. Thompson, R. Svensson, A.-L. Gustavsson, L. Johansson, K. Färnegårdh, U. Yngve, A. Saleh, M. Haraldsson, A.C.A. D’Hollander, M. Franco, Y. Zhao, M. Håkansson, B. Walse, K. Larsson, E.M. Peat, V. Pelechano, J. Lunec, B. Vojtesek, M. Carmena, W.C. Earnshaw, A.R. McCarthy, N.J. Westwood, M. Arsenian-Henriksson, D.P. Lane, R. Bhatia, E. McCormack, S. Laín, A DHODH inhibitor increases p53 synthesis and enhances tumor cell killing by p53 degradation blockage, Nat. Commun. 9 (2018) 1107. https://doi.org/10.1038/s41467-01803441-3.

[11] M. Koundinya, J. Sudhalter, A. Courjaud, B. Lionne, G. Touyer, L. Bonnet, I. Menguy, I. Schreiber, C. Perrault, S. Vougier, B. Benhamou, B. Zhang, T. He, Q. Gao, P. Gee, D. Simard, M.P. Castaldi, R. Tomlinson, S. Reiling, M. Barrague, R. Newcombe, H. Cao, Y. Wang, F. Sun, J. Murtie, M. Munson, E. Yang, D. Harper, M. Bouaboula, J. Pollard, C. Grepin, C. GarciaEcheverria, H. Cheng, F. Adrian, C. Winter, S. Licht, I. Cornella-Taracido, R. Arrebola, A. Morris, Dependence on the Pyrimidine Biosynthetic Enzyme DHODH Is a Synthetic Lethal Vulnerability in Mutant KRAS-Driven Cancers, Cell Chem. Biol. 25 (2018) 705-717.e11. https://doi.org/10.1016/j.chembiol.2018.03.005.

[12] M. Bajzikova, J. Kovarova, A.R. Coelho, S. Boukalova, S. Oh, K. Rohlenova, D. Svec, S. Hubackova, B. Endaya, K. Judasova, A. Bezawork-Geleta, K. Kluckova, L. Chatre, R. Zobalova, A. Novakova, K. Vanova, Z. Ezrova, G.J. Maghzal, S. Magalhaes Novais, M. Olsinova, L. Krobova, Y.J. An, E. Davidova, Z. Nahacka, M. Sobol, T. Cunha-Oliveira, C. Sandoval-Acuña, H. Strnad, T. Zhang, T. Huynh, T.L. Serafim, P. Hozak, V.A. Sardao, W.J.H. Koopman, M. Ricchetti, P.J. Oliveira, F. Kolar, M. Kubista, J. Truksa, K. Dvorakova-Hortova, K. Pacak, R. Gurlich, R. Stocker, Y. Zhou, M.V. Berridge, S. Park, L. Dong, J. Rohlena, J. Neuzil, Reactivation of Dihydroorotate Dehydrogenase-Driven Pyrimidine Biosynthesis Restores Tumor Growth of Respiration-Deficient Cancer Cells, Cell Metab. 29 (2019) 399416.e10. https://doi.org/10.1016/j.cmet.2018.10.014.

[13] X. Wang, K. Yang, Q. Wu, L.J.Y. Kim, A.R. Morton, R.C. Gimple, B.C. Prager, Y. Shi, W. Zhou, S. Bhargava, Z. Zhu, L. Jiang, W. Tao, Z. Qiu, L. Zhao, G. Zhang, X. Li, S. Agnihotri, P.S. Mischel, S.C. Mack, S. Bao, J.N. Rich, Targeting pyrimidine synthesis accentuates molecular therapy response in glioblastoma stem cells, Sci. Transl. Med. 11 (2019). https://doi.org/10.1126/scitranslmed.aau4972.

[14] M. Hosseini, L. Dousset, P. Michon, W. Mahfouf, E. Muzotte, V. Bergeron, D. Bortolotto, R. Rossignol, F. Moisan, A. Taieb, A.-K. Bouzier-Sore, H.R. Rezvani, UVBinduced DHODH upregulation, which is driven by STAT3, is a promising target for chemoprevention and combination therapy of photocarcinogenesis, Oncogenesis. 8 (2019) 52. https://doi.org/10.1038/s41389-019-0161-z.

[15] S. Christian, C. Merz, L. Evans, S. Gradl, H. Seidel, A. Friberg, A. Eheim, P. Lejeune, K. Brzezinka, K. Zimmermann, S. Ferrara, H. Meyer, R. Lesche, D. Stoeckigt, M. Bauser, A. Haegebarth, D.B. Sykes, D.T. Scadden, J.-A. Losman, A. Janzer, The novel dihydroorotate dehydrogenase (DHODH) inhibitor BAY 2402234 triggers differentiation and is effective in the treatment of myeloid malignancies, Leukemia. (2019). https://doi.org/10.1038/s41375-0190461-5.

[16] L. Cao, M. Weetall, C. Trotta, K. Cintron, J. Ma, M.J. Kim, B. Furia, C. Romfo, J.D. Graci, W. Li, J. Du, J. Sheedy, J. Hedrick, N. Risher, S. Yeh, H. Qi, T. Arasu, S. Hwang, W. Lennox, R. Kong, J. Petruska, Y.-C. Moon, J. Babiak, T.W. Davis, A. Jacobson, N.G. Almstead, A. Branstrom, J.M. Colacino, S.W. Peltz, Targeting of Hematologic Malignancies with PTC299, A Novel Potent Inhibitor of Dihydroorotate Dehydrogenase with Favorable Pharmaceutical Properties, Mol. Cancer Ther. 18 (2019) 3-16. https://doi.org/10.1158/15357163.MCT-18-0863. 
[17] A. Bonavia, M. Franti, E. Pusateri Keaney, K. Kuhen, M. Seepersaud, B. Radetich, J. Shao, A. Honda, J. Dewhurst, K. Balabanis, J. Monroe, K. Wolff, C. Osborne, L. Lanieri, K. Hoffmaster, J. Amin, J. Markovits, M. Broome, E. Skuba, I. Cornella-Taracido, G. Joberty, T. Bouwmeester, L. Hamann, J.A. Tallarico, R. Tommasi, T. Compton, S.M. Bushell, Identification of broad-spectrum antiviral compounds and assessment of the druggability of their target for efficacy against respiratory syncytial virus (RSV), Proc. Natl. Acad. Sci. U. S. A. 108 (2011) 6739-6744. https://doi.org/10.1073/pnas.1017142108.

8 [18] Q.-Y. Wang, S. Bushell, M. Qing, H.Y. Xu, A. Bonavia, S. Nunes, J. Zhou, M.K. Poh,

9 P. Florez de Sessions, P. Niyomrattanakit, H. Dong, K. Hoffmaster, A. Goh, S. Nilar, W. Schul,

10 S. Jones, L. Kramer, T. Compton, P.-Y. Shi, Inhibition of dengue virus through suppression of

11 host pyrimidine biosynthesis, J. Virol. 85 (2011) 6548-6556.

12 https://doi.org/10.1128/JVI.02510-10.

13 [19] H.-H. Hoffmann, A. Kunz, V.A. Simon, P. Palese, M.L. Shaw, Broad-spectrum antiviral 14 that interferes with de novo pyrimidine biosynthesis, Proc. Natl. Acad. Sci. U. S. A. 108 (2011) 5777-5782. https://doi.org/10.1073/pnas.1101143108.

[20] M. Marschall, I. Niemann, K. Kosulin, A. Bootz, S. Wagner, T. Dobner, T. Herz, B. Kramer, J. Leban, D. Vitt, T. Stamminger, C. Hutterer, S. Strobl, Assessment of drug candidates for broad-spectrum antiviral therapy targeting cellular pyrimidine biosynthesis, Antiviral Res. 100 (2013) 640-648. https://doi.org/10.1016/j.antiviral.2013.10.003.

[21] C.-F. Yang, B. Gopula, J.-J. Liang, J.-K. Li, S.-Y. Chen, Y.-L. Lee, C.S. Chen, Y.-L. Lin, Novel AR-12 derivatives, P12-23 and P12-34, inhibit flavivirus replication by blocking host de novo pyrimidine biosynthesis, Emerg. Microbes Infect. 7 (2018) 187. https://doi.org/10.1038/s41426-018-0191-1.

[22] N.N. Cheung, K.K. Lai, J. Dai, K.H. Kok, H. Chen, K.-H. Chan, K.-Y. Yuen, R.Y.T. Kao, Broad-spectrum inhibition of common respiratory RNA viruses by a pyrimidine synthesis inhibitor with involvement of the host antiviral response, J. Gen. Virol. 98 (2017) 946-954. https://doi.org/10.1099/jgv.0.000758.

[23] F. Zeng, L. Quan, G. Yang, T. Qi, L. Zhang, S. Li, H. Li, L. Zhu, X. Xu, Structural Optimization and Structure-Activity Relationship of 4-Thiazolidinone Derivatives as Novel Inhibitors of Human Dihydroorotate Dehydrogenase, Mol. Basel Switz. 24 (2019). https://doi.org/10.3390/molecules24152780.

[24] T. Zeng, Z. Zuo, Y. Luo, Y. Zhao, Y. Yu, Q. Chen, A novel series of human dihydroorotate dehydrogenase inhibitors discovered by in vitro screening: inhibition activity and crystallographic binding mode, FEBS Open Bio. 9 (2019) 1348-1354. https://doi.org/10.1002/2211-5463.12658.

[25] V.K. Vyas, G. Qureshi, D. Oza, H. Patel, K. Parmar, P. Patel, M.D. Ghate, Synthesis of $2-, 4,-6-$, and/or 7-substituted quinoline derivatives as human dihydroorotate dehydrogenase (hDHODH) inhibitors and anticancer agents: 3D QSAR-assisted design, Bioorg. Med. Chem. Lett. 29 (2019) 917-922. https://doi.org/10.1016/j.bmcl.2019.01.038.

[26] S. Sainas, A.C. Pippione, E. Lupino, M. Giorgis, P. Circosta, V. Gaidano, P. Goyal, D. Bonanni, B. Rolando, A. Cignetti, A. Ducime, M. Andersson, M. Järvå, R. Friemann, M. Piccinini, C. Ramondetti, B. Buccinnà, S. Al-Karadaghi, D. Boschi, G. Saglio, M.L. Lolli, Targeting Myeloid Differentiation Using Potent 2-Hydroxypyrazolo[1,5- a]pyridine ScaffoldBased Human Dihydroorotate Dehydrogenase Inhibitors, J. Med. Chem. 61 (2018) 6034-6055. https://doi.org/10.1021/acs.jmedchem.8b00373.

[27] J.T. Madak, C.R. Cuthbertson, Y. Miyata, S. Tamura, E.M. Petrunak, J.A. Stuckey, Y. Han, M. He, D. Sun, H.D. Showalter, N. Neamati, Design, Synthesis, and Biological Evaluation of 4-Quinoline Carboxylic Acids as Inhibitors of Dihydroorotate Dehydrogenase, J. Med. Chem. 61 (2018) 5162-5186. https://doi.org/10.1021/acs.jmedchem.7b01862.

50 [28] M. Hosseini, L. Dousset, W. Mahfouf, M. Serrano-Sanchez, I. Redonnet-Vernhet, S. 
Mesli, Z. Kasraian, E. Obre, M. Bonneu, S. Claverol, M. Vlaski, Z. Ivanovic, W. Rachidi, T. Douki, A. Taieb, A.-K. Bouzier-Sore, R. Rossignol, H.R. Rezvani, Energy Metabolism Rewiring Precedes UVB-Induced Primary Skin Tumor Formation, Cell Rep. 23 (2018) 36213634. https://doi.org/10.1016/j.celrep.2018.05.060.

[29] T. Li, Z.J. Chen, The cGAS-cGAMP-STING pathway connects DNA damage to inflammation, senescence, and cancer, J. Exp. Med. 215 (2018) 1287-1299. https://doi.org/10.1084/jem.20180139.

[30] B.S. Parker, J. Rautela, P.J. Hertzog, Antitumour actions of interferons: implications for cancer therapy, Nat. Rev. Cancer. 16 (2016) 131-144. https://doi.org/10.1038/nrc.2016.14.

[31] R. Harvey, K. Brown, Q. Zhang, M. Gartland, L. Walton, C. Talarico, W. Lawrence, D. Selleseth, N. Coffield, J. Leary, K. Moniri, S. Singer, J. Strum, K. Gudmundsson, K. Biron, K.R. Romines, P. Sethna, GSK983: a novel compound with broad-spectrum antiviral activity, Antiviral Res. 82 (2009) 1-11. https://doi.org/10.1016/j.antiviral.2008.12.015. [32] M. Lucas-Hourani, D. Dauzonne, P. Jorda, G. Cousin, A. Lupan, O. Helynck, G. Caignard, G. Janvier, G. André-Leroux, S. Khiar, N. Escriou, P. Desprès, Y. Jacob, H. MunierLehmann, F. Tangy, P.-O. Vidalain, Inhibition of pyrimidine biosynthesis pathway suppresses viral growth through innate immunity, PLoS Pathog. 9 (2013) e1003678. https://doi.org/10.1371/journal.ppat.1003678.

[33] M. Lucas-Hourani, H. Munier-Lehmann, F. El Mazouni, N.A. Malmquist, J. Harpon, E.P. Coutant, S. Guillou, O. Helynck, A. Noel, A. Scherf, M.A. Phillips, F. Tangy, P.-O. Vidalain, Y.L. Janin, Original 2-(3-Alkoxy-1H-pyrazol-1-yl)azines Inhibitors of Human Dihydroorotate Dehydrogenase (DHODH), J. Med. Chem. 58 (2015) 5579-5598. https://doi.org/10.1021/acs.jmedchem.5b00606.

[34] K.L. Yeo, Y.-L. Chen, H.Y. Xu, H. Dong, Q.-Y. Wang, F. Yokokawa, P.-Y. Shi, Synergistic suppression of dengue virus replication using a combination of nucleoside analogs and nucleoside synthesis inhibitors, Antimicrob. Agents Chemother. 59 (2015) 2086-2093. https://doi.org/10.1128/AAC.04779-14.

[35] Y. Wang, W. Wang, L. Xu, X. Zhou, E. Shokrollahi, K. Felczak, L.J.W. van der Laan, K.W. Pankiewicz, D. Sprengers, N.J.H. Raat, H.J. Metselaar, M.P. Peppelenbosch, Q. Pan, Cross Talk between Nucleotide Synthesis Pathways with Cellular Immunity in Constraining Hepatitis E Virus Replication, Antimicrob. Agents Chemother. 60 (2016) 2834-2848. https://doi.org/10.1128/AAC.02700-15.

[36] D.-H. Chung, J.E. Golden, R.S. Adcock, C.E. Schroeder, Y.-K. Chu, J.B. Sotsky, D.E. Cramer, P.M. Chilton, C. Song, M. Anantpadma, R.A. Davey, A.I. Prodhan, X. Yin, X. Zhang, Discovery of a Broad-Spectrum Antiviral Compound That Inhibits Pyrimidine Biosynthesis and Establishes a Type 1 Interferon-Independent Antiviral State, Antimicrob. Agents Chemother. 60 (2016) 4552-4562. https://doi.org/10.1128/AAC.00282-16.

[37] E. Pery, A. Sheehy, N. Miranda Nebane, V. Misra, M.K. Mankowski, L. Rasmussen, E. Lucile White, R.G. Ptak, D. Gabuzda, Redoxal, an inhibitor of de novo pyrimidine biosynthesis, augments APOBEC3G antiviral activity against human immunodeficiency virus type 1, Virology. 484 (2015) 276-287. https://doi.org/10.1016/j.virol.2015.06.014.

[38] M. Lucas-Hourani, D. Dauzonne, H. Munier-Lehmann, S. Khiar, S. Nisole, J. Dairou, O. Helynck, P.V. Afonso, F. Tangy, P.-O. Vidalain, Original Chemical Series of Pyrimidine Biosynthesis Inhibitors That Boost the Antiviral Interferon Response, Antimicrob. Agents Chemother. 61 (2017). https://doi.org/10.1128/AAC.00383-17.

[39] K. Lee, D.-E. Kim, K.-S. Jang, S.-J. Kim, S. Cho, C. Kim, Gemcitabine, a broadspectrum antiviral drug, suppresses enterovirus infections through innate immunity induced by the inhibition of pyrimidine biosynthesis and nucleotide depletion, Oncotarget. 8 (2017) 115315-115325. https://doi.org/10.18632/oncotarget.23258.

50 [40] P. Luthra, J. Naidoo, C.A. Pietzsch, S. De, S. Khadka, M. Anantpadma, C.G. Williams, 
M.R. Edwards, R.A. Davey, A. Bukreyev, J.M. Ready, C.F. Basler, Inhibiting pyrimidine biosynthesis impairs Ebola virus replication through depletion of nucleoside pools and activation of innate immune responses, Antiviral Res. 158 (2018) 288-302. https://doi.org/10.1016/j.antiviral.2018.08.012.

[41] J. Zhou, D. Wang, B.H.-Y. Wong, C. Li, V.K.-M. Poon, L. Wen, X. Zhao, M.C. Chiu, X. Liu, Z. Ye, S. Yuan, K.-H. Sze, J.F.-W. Chan, H. Chu, K.K.-W. To, K.Y. Yuen, Identification and characterization of GLDC as host susceptibility gene to severe influenza, EMBO Mol. Med. 11 (2019). https://doi.org/10.15252/emmm.201809528.

[42] J. Costeira-Paulo, J. Gault, G. Popova, M.J.G.W. Ladds, I.M.M. van Leeuwen, M. Sarr, A. Olsson, D.P. Lane, S. Laín, E.G. Marklund, M. Landreh, Lipids Shape the Electron Acceptor-Binding Site of the Peripheral Membrane Protein Dihydroorotate Dehydrogenase, Cell Chem. Biol. 25 (2018) 309-317.e4. https://doi.org/10.1016/j.chembiol.2017.12.012.

[43] A. Hovhannisyan, T.H. Pham, D. Bouvier, L. Qin, G. Melikyan, M. Reboud-Ravaux, structure-activity relationships to optimize their inhibitory effect on $20 \mathrm{~S}$ proteasome, Bioorg. Med. Chem. Lett. 23 (2013) 2696-2703. https://doi.org/10.1016/j.bmcl.2013.02.079.

[44] A. Hovhannisyan, T.H. Pham, D. Bouvier, A. Piroyan, L. Dufau, L. Qin, Y. Cheng, G. Melikyan, M. Reboud-Ravaux, M. Bouvier-Durand, New C(4)- and C(1)-derivatives of furo[3,4-c]pyridine-3-ones and related compounds: evidence for site-specific inhibition of the constitutive proteasome and its immunoisoform, Bioorg. Med. Chem. Lett. 24 (2014) 15711580. https://doi.org/10.1016/j.bmcl.2014.01.072.

[45] T.H. Pham, A. Hovhannisyan, D. Bouvier, L. Tian, M. Reboud-Ravaux, G. Melikyan, M. Bouvier-Durand, A new series of N5 derivatives of the 1,1,5-trimethyl furo[3,4-c]pyridine3,4-dione (cerpegin) selectively inhibits the post-acid activity of mammalian $20 \mathrm{~S}$ proteasomes, Bioorg. Med. Chem. Lett. 22 (2012) 3822-3827. https://doi.org/10.1016/j.bmcl.2012.03.105.

[46] D. Villemin, N. Cheikh, L. Liao, N. Bar, J.-F. Lohier, J. Sopkova, N. ChoukchouBraham, B. Mostefa-Kara, Two versatile routes towards Cerpegin and analogues: applications of a one pot reaction to new analogues of Cerpegin, Tetrahedron. 68 (2012) 4906-4918. https://doi.org/10.1016/j.tet.2012.03.057.

[47] D.J. Diller, K.M. Merz, High throughput docking for library design and library prioritization, Proteins. 43 (2001) 113-124.

[48] S. Hayek, N. Bekaddour, L. Besson, R. Alves de Sousa, N. Pietrancosta, S. Viel, N. Smith, Y. Jacob, S. Nisole, R. Mandal, D.S. Wishart, T. Walzer, J.-P. Herbeuval, P.-O. Vidalain, Identification of Primary Natural Killer Cell Modulators by Chemical Library Screening with a Luciferase-Based Functional Assay, SLAS Discov. Adv. Life Sci. R D. 24 (2019) 25-37. https://doi.org/10.1177/2472555218797078.

[49] X. Deng, S. Kokkonda, F. El Mazouni, J. White, J.N. Burrows, W. Kaminsky, S.A. Charman, D. Matthews, P.K. Rathod, M.A. Phillips, Fluorine modulates species selectivity in the triazolopyrimidine class of Plasmodium falciparum dihydroorotate dehydrogenase inhibitors, J. Med. Chem. 57 (2014) 5381-5394. https://doi.org/10.1021/jm500481t.

[50] L.R. McLean, Y. Zhang, W. Degnen, J. Peppard, D. Cabel, C. Zou, J.T. Tsay, A. Subramaniam, R.J. Vaz, Y. Li, Discovery of novel inhibitors for DHODH via virtual screening and X-ray crystallographic structures, Bioorg. Med. Chem. Lett. 20 (2010) 1981-1984. https://doi.org/10.1016/j.bmcl.2010.01.115.

[51] F. Coquel, C. Neumayer, Y.-L. Lin, P. Pasero, SAMHD1 and the innate immune response to cytosolic DNA during DNA replication, Curr. Opin. Immunol. 56 (2018) 24-30. https://doi.org/10.1016/j.coi.2018.09.017.

[52] F. Coquel, M.-J. Silva, H. Técher, K. Zadorozhny, S. Sharma, J. Nieminuszczy, C. Mettling, E. Dardillac, A. Barthe, A.-L. Schmitz, A. Promonet, A. Cribier, A. Sarrazin, W. Niedzwiedz, B. Lopez, V. Costanzo, L. Krejci, A. Chabes, M. Benkirane, Y.-L. Lin, P. Pasero, 
SAMHD1 acts at stalled replication forks to prevent interferon induction, Nature. 557 (2018) 57-61. https://doi.org/10.1038/s41586-018-0050-1.

[53] J. Lee, W.G. Dunphy, The Mre11-Rad50-Nbs1 (MRN) complex has a specific role in the activation of Chk1 in response to stalled replication forks, Mol. Biol. Cell. 24 (2013) 13431353. https://doi.org/10.1091/mbc.E13-01-0025.

[54] T. Herz, K. Wolf, J. Kraus, B. Kramer, 4SCan/vADME: intelligent library screening as a shortcut from hits to lead compounds, Expert Opin. Drug Metab. Toxicol. 2 (2006) 471-484. https://doi.org/10.1517/17425255.2.3.471.

9 [55] Y. Diao, W. Lu, H. Jin, J. Zhu, L. Han, M. Xu, R. Gao, X. Shen, Z. Zhao, X. Liu, Y.

$10 \mathrm{Xu}, \mathrm{J}$. Huang, H. Li, Discovery of diverse human dihydroorotate dehydrogenase inhibitors as 11 immunosuppressive agents by structure-based virtual screening, J. Med. Chem. 55 (2012) 12 8341-8349. https://doi.org/10.1021/jm300630p.

13 [56] V.K. Vyas, M. Ghate, Development of docking-based 3D QSAR models for the design 14 of substituted quinoline derivatives as human dihydroorotate dehydrogenase (hDHODH) 15 inhibitors, SAR QSAR Environ. Res. 24 (2013) 625-645. 16 https://doi.org/10.1080/1062936X.2013.792871.

17 [57] M. Sucharita, B. Poorani, P. Swaminathan, An insilico workflow that yields 18 experimentally comparable inhibitors for human DiHydroOrotate DeHydrogenase, Curr. 19 Comput. Aided Drug Des. (2019). https://doi.org/10.2174/1573409915666190528114703.

20 [58] I. Fritzson, B. Svensson, S. Al-Karadaghi, B. Walse, U. Wellmar, U.J. Nilsson, D. da 21 Graça Thrige, S. Jönsson, Inhibition of human DHODH by 4-hydroxycoumarins, fenamic 22 acids, and $\mathrm{N}$-(alkylcarbonyl)anthranilic acids identified by structure-guided fragment selection, ChemMedChem. 5 (2010) 608-617. https://doi.org/10.1002/cmdc.200900454.

[59] M. Frontini, M. Vijayakumar, A. Garvin, N. Clarke, A ChIP-chip approach reveals a novel role for transcription factor IRF1 in the DNA damage response, Nucleic Acids Res. 37 (2009) 1073-1085. https://doi.org/10.1093/nar/gkn1051.

[60] M. Abou El Hassan, K. Huang, Z. Xu, T. Yu, R. Bremner, Frequent interferon regulatory factor 1 (IRF1) binding at remote elements without histone modification, J. Biol. Chem. 293 (2018) 10353-10362. https://doi.org/10.1074/jbc.RA118.002889.

[61] D. Dornan, M. Eckert, M. Wallace, H. Shimizu, E. Ramsay, T.R. Hupp, K.L. Ball, Interferon regulatory factor 1 binding to p300 stimulates DNA-dependent acetylation of p53, Mol. Cell. Biol. 24 (2004) 10083-10098. https://doi.org/10.1128/MCB.24.22.1008310098.2004.

[62] M.R. Zaidi, G. Merlino, The two faces of interferon- $\gamma$ in cancer, Clin. Cancer Res. Off. J. Am. Assoc. Cancer Res. 17 (2011) 6118-6124. https://doi.org/10.1158/1078-0432.CCR-110482 . 
2 Figure 1. In silico screening procedure for the identification of novel DHODH inhibitors.

3 (A) DHODH structure was retrieved from PDB (3KVJ), showing orotate (red), FMN (green), 4 and Arg136 (blue). The DHODH inhibitor present in the ubiquinone-binding site of the structure was removed and replaced by a ubiquinone analog without the hydrophobic tail to facilitate the in silico docking (yellow). Ubiquinone structure is shown in the upper left panel as a reference. (B) Schematic 2-D diagrams of small molecule inhibitors as bound to DHODH in PDB structures 4OQV, 3KVJ and 4RR4. For each inhibitor, the RMSD value estimates the position overlap between structural data and results of the in silico docking. (C) Venn diagram showing the results of the screenings performed on DHODH structures from $4 \mathrm{OQV}, 3 \mathrm{KVJ}$, and 4RR4. We selected the 11 hit compounds identified in more than one screen for further evaluation. (D-E) Schematic 2-D diagrams of P2703 and P1788 bound to DHODH as determined by in silico docking.

Figure 2. Cellular response to IFN- $\alpha$ is amplified by P1788 and P2703. (A) HEK-293 cells with the ISRE-Luc reporter gene were treated with P1788, P2703 or DMSO alone in the absence or presence of IFN- $\alpha(150 \mathrm{IU} / \mathrm{ml})$. Expression of the ISRE-Luc reporter gene was determined $24 \mathrm{~h}$ later, and results were normalized using cells treated with IFN- $\alpha$ alone as reference. (B) Cells were treated with DMSO or P1788 at different concentrations, and the number of viable cells was determined using the CellTiter-Glo reagent after 24, 48 and $72 \mathrm{~h}$ of culture. Results were expressed as a percentage relative to untreated cells at $t=0 \mathrm{~h}$. Data represent means +/- SD of three (A) or two (B) independent experiments. ${ }^{*} \mathrm{p}<0.05$; ${ }^{*} \mathrm{p}<0.01$; $* * * \mathrm{p}<0.001$ as calculated by one-way analysis of variance (ANOVA) with Bonferroni's post hoc test.

Figure 3. Structure/activity relationships. Chemical analogs of P1788 and P2703 were tested for their ability to boost cellular response to IFN- $\alpha$ in HEK-293 cells with the ISRE-Luc reporter gene. Teriflunomide, vidofludimus and brequinar were tested as reference DHODH inhibitors in the same cellular assay. pEC50s, corresponding to $-\log _{10}$ of the half maximal effective molar concentrations, were computed from a four-parameter fitting curve using Prism software (GraphPad). Binding energies were also computed by in silico docking for comparison with pEC50s. FTD ("failed to determine") is indicated when binding energies could not be computed. The chemical structure of cerpegin is shown as a reference. 
2 Figure 4. $\mathbf{P 1 7 8 8}$ is inhibiting pyrimidine biosynthesis. (A) Cells were treated with DMSO or 3 increasing concentrations of P1788. 24 h later, cells were harvested and intracellular levels of 4 purine $(\mathrm{G} / \mathrm{A})$ and pyrimidine $(\mathrm{C} / \mathrm{U})$ were determined by HPLC-coupled spectrophotometry. 5 Results were normalized using DMSO-treated cells as a reference. (B) Cells were treated with 6 increasing concentrations of IFN- $\alpha$ with DMSO, P1788 $(80 \mu \mathrm{M})$ or P1788 $(80 \mu \mathrm{M})$ and uridine $7 \quad(125 \mu \mathrm{M}) .24 \mathrm{~h}$ later, expression of the ISRE-Luc reporter gene was determined. Results were normalized using cells treated with DMSO + IFN- $\alpha$ at $250 \mathrm{IU} / \mathrm{ml}$ as a reference. (C) Same experiment as in (A), but culture medium was supplemented with $3 \mathrm{mM}$ of orotate or DHO instead of uridine. Data represent means $+/-\mathrm{SD}$ of three independent experiments. ${ }^{* * *} \mathrm{p}<0.001$ as calculated by two-way ANOVA.

Figure 5. ISG induction by IFN- $\alpha$ is enhanced in the presence of P1788. (A) HEK cells with the ISRE-Luc reporter gene were cultured with increasing concentrations of IFN- $\alpha$ and cotreated with DMSO or P1788 $(80 \mu \mathrm{M}) .16 \mathrm{~h}$ later, induction levels of indicated ISGs were determined by RT-qPCR, and expressed as fold changes relative to control cells (DMSO alone). Results highlighted in bold correspond to statistically significant values when comparing untreated to P1788-treated cells from three independent experiments $(\mathrm{p}<0.05$ determined by two-way ANOVA with Bonferroni's post hoc test). (B) Corresponding data for Mx2 mRNA expression were displayed as a bar chart showing mean values $+/-$ SD.

Figure 6. Cellular response to IFN- $\gamma$ is amplified by P1788. (A) HEK-293 cells with the ISRE-Luc reporter gene were treated with DMSO or P1788 $(80 \mu \mathrm{M})$ in the absence or presence of recombinant IFN- $\gamma(150 \mathrm{IU} / \mathrm{ml})$. Luciferase activity in culture wells was determined $24 \mathrm{~h}$ later. Results were normalized using cells treated with DMSO + IFN- $\gamma$ as reference. ${ }^{* *} \mathrm{p}<0.01$ as calculated by two-tailed t-test. (B) Same experiment as in (A), but cells were stimulated with different dilutions ranging from 1/8 to $1 / 64$ of conditioned supernatants from activated PBMCs. Results were normalized using cells treated with 1/8 diluted supernatants as reference. Data represent means $+/$ - SD of three independent experiments. ${ }^{*} \mathrm{p}<0.05$; $* * * \mathrm{p}<0.001$ determined by two-way ANOVA with Bonferroni's post hoc test. 
$1 \quad$ stalled DNA replication forks. (B) Cells were treated with DMSO, P1788 (80 $\mu$ M), P1788 +

2 uridine (Uri.; $125 \mu \mathrm{M}$ ), teriflunomide (Ter.; $50 \mu \mathrm{M}$ ) or mitoxantrone (Mit.; $50 \mathrm{nM}$ ). 24 h later,

3 cells were harvested and $\gamma \mathrm{H} 2 \mathrm{AX}$ level was determined by immunostaining and flow cytometry

4 analysis. Data represent means $+/-$ SD of three independent experiments. $* * p<0.01$;

$5 \quad * * * p<0.001$ as calculated by two-tailed t-test. (C-F) HEK-293 cells with the ISRE-Luc reporter

6 gene were treated with DMSO, IFN- $\alpha(150 \mathrm{IU} / \mathrm{ml})$ or IFN- $\alpha+\mathrm{P} 1788(80 \mu \mathrm{M})$, in the absence

7 or presence of mirin (C), AZD6738 (D), PF477736 (E) or C636 (F) to inhibit MRE11, ATR,

8 CHK1 and P300/CBP, respectively. Luciferase activity in culture wells was determined $24 \mathrm{~h}$

9 later, and results were normalized using cells treated with IFN- $\alpha$ alone as reference. Data

10 represent means $+/-\mathrm{SD}$ of at least three independent experiments $(\mathrm{B}-\mathrm{F}) .{ }^{*} \mathrm{p}<0.05 ;{ }^{* *} \mathrm{p}<0.01$;

$11 * * * p<0.001$ as calculated by standard Student's t-test (B) or one-way ANOVA with

12 Bonferroni's post hoc test (C-F).

13

14 Supplementary Figure 1. Cell counts in cultures treated with mirin, AZD6738, PF477736

15 or C636. The number of viable cells was determined in culture conditions from Fig. 7C, D, E 16 and D using the CellTiter-Glo reagent. Results were expressed as a percentage relative to cells

17 treated with IFN- $\alpha$ alone. Data represent means +/- SD of three (A/C/D) or two independent

18 (B) experiments. 
Scheme 1. Synthesis of cerpegin derivatives.<smiles>[R3]NC(=O)C1=C(C)C([R1])([R2])OC1=O</smiles>

(P2708)<smiles>[R15]Nc1ccccc1COCC</smiles>

(I)<smiles>[R]C1([R2])OC(=O)C(C(=O)OCC)=C1/C=C/N(C)C</smiles>

(II)<smiles>[R3]NC1([R2])OC(=O)c2c1ccn([R3])c2=O</smiles>

(III)

\begin{tabular}{|c|c|c|c|c|c|c|c|c|c|c|c|c|c|c|c|}
\hline $\mathbf{R}_{1}, \mathbf{R}_{2} \mathbf{R}_{3}$ & Norcerpegin & P2701 & P2702 & P2718 & P2717 & P1788 & P2703 & P2512 & P1781 & P2705 & P2707 & P1792 & P1793 & P2706 & P2708 \\
\hline $\mathrm{H}$ & $R_{3}$ & & & & & & & $R_{3}$ & & & & & & & \\
\hline Me & $\mathbf{R}_{1,} \mathbf{R}_{2}$ & $\mathbf{R}_{1}, \mathbf{R}_{2}$ & $R_{1}$ & & & & $\mathbf{R}_{1}$ & & $R_{3}$ & & & & & & \\
\hline ethyl & & & $\mathrm{R}_{2}$ & $\mathbf{R}_{1}, \mathbf{R}_{2}$ & & & & & & $R_{3}$ & & & & & \\
\hline \multicolumn{16}{|l|}{ isopropyl } \\
\hline cyclopropyl & & $\mathrm{R}_{3}$ & $\mathrm{R}_{3}$ & $\mathrm{R}_{3}$ & $\mathrm{R}_{3}$ & $R_{3}$ & $R_{3}$ & & & & & & & & $R_{3}$ \\
\hline cyclobutyl & & & & & & & & & & & $\mathrm{R}_{3}$ & & & & \\
\hline cyclopentyl & & & & & $\mathbf{R}_{1}, \mathbf{R}_{2}$ & & & & & & & $R_{3}$ & & & \\
\hline cyclohexyl & & & & & & $R_{1}, R_{2}$ & & $R_{1}, R_{2}$ & $R_{1}, R_{2}$ & $\mathrm{R}_{1}, \mathrm{R}_{2}$ & $\mathrm{R}_{1}, \mathrm{R}_{2}$ & $R_{1}, R_{2}$ & $\mathbf{R}_{1}, \mathbf{R}_{2}, \mathbf{R}_{3}$ & $R_{1}, R_{2}$ & $\mathrm{R}_{1}, \mathrm{R}_{2}$ \\
\hline cyclopropylmethyl & & & & & & & & & & & & & & $R_{3}$ & \\
\hline benzyl & & & & & & & $R_{2}$ & & & & & & & & \\
\hline
\end{tabular}



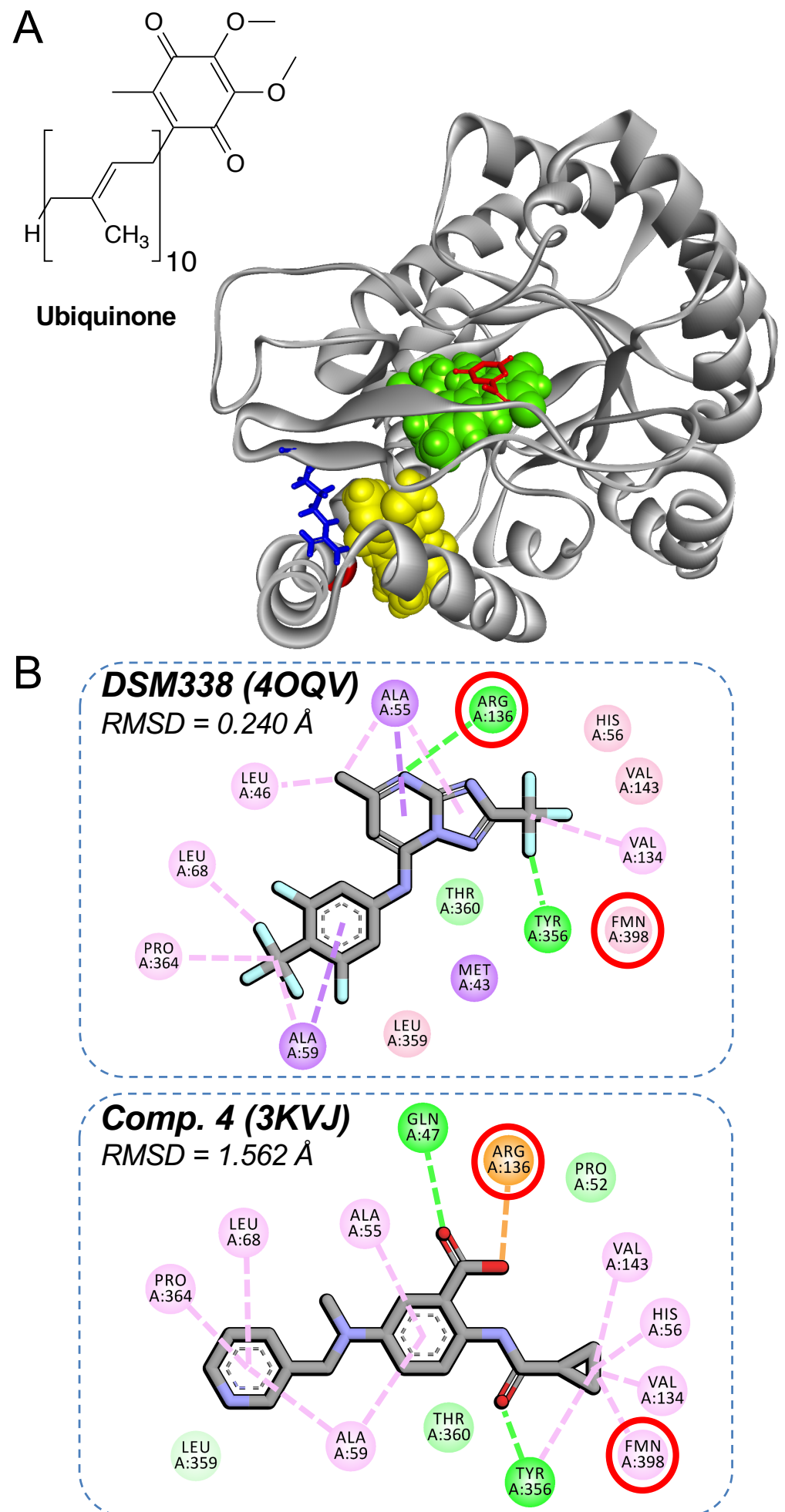

DH03A367 (4RR4) RMSD $=3.259 \AA$

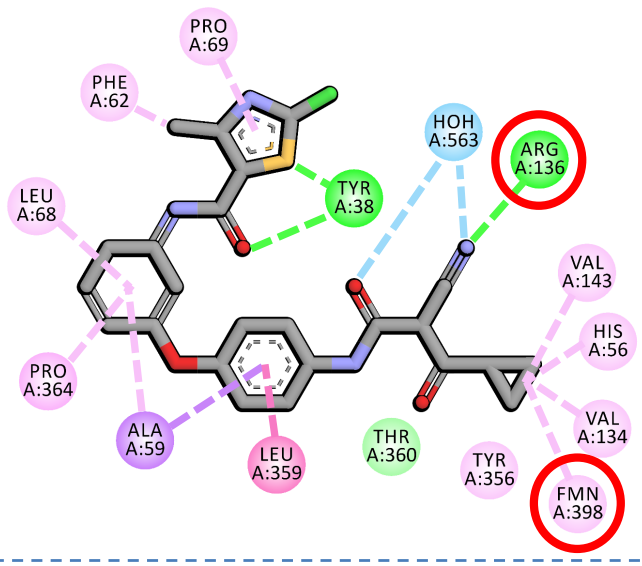

C

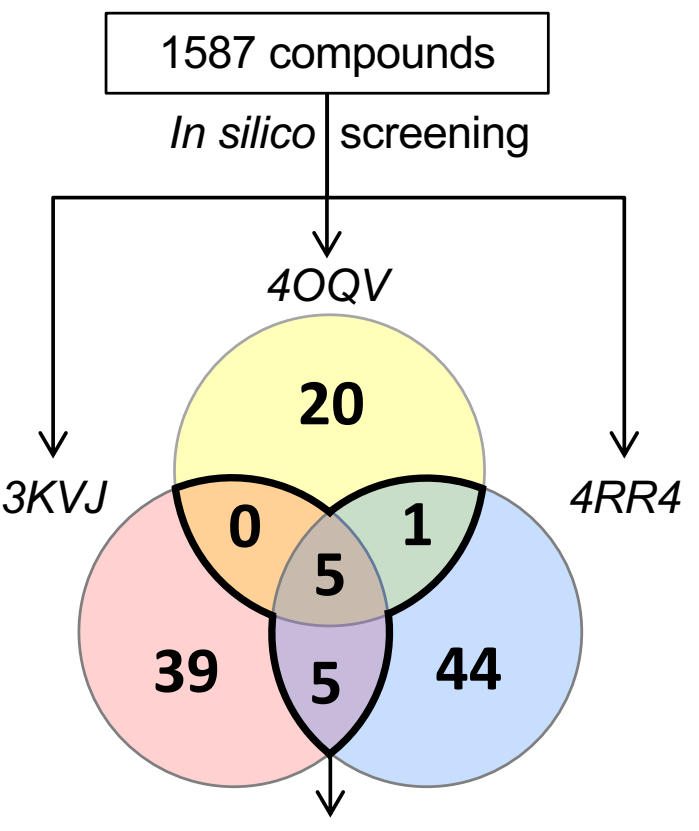

Hit selection and validation

D

\section{P2703}
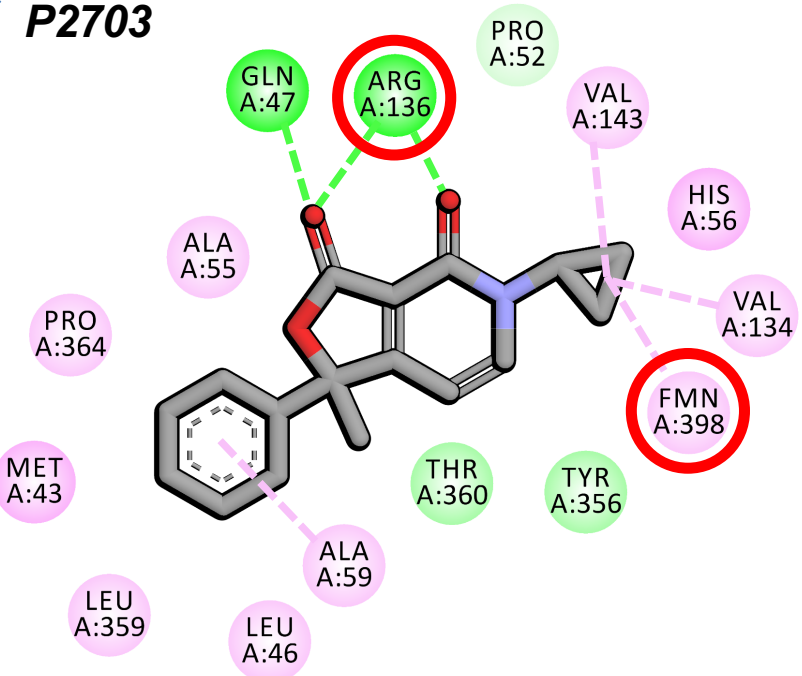

E

\section{P1788}

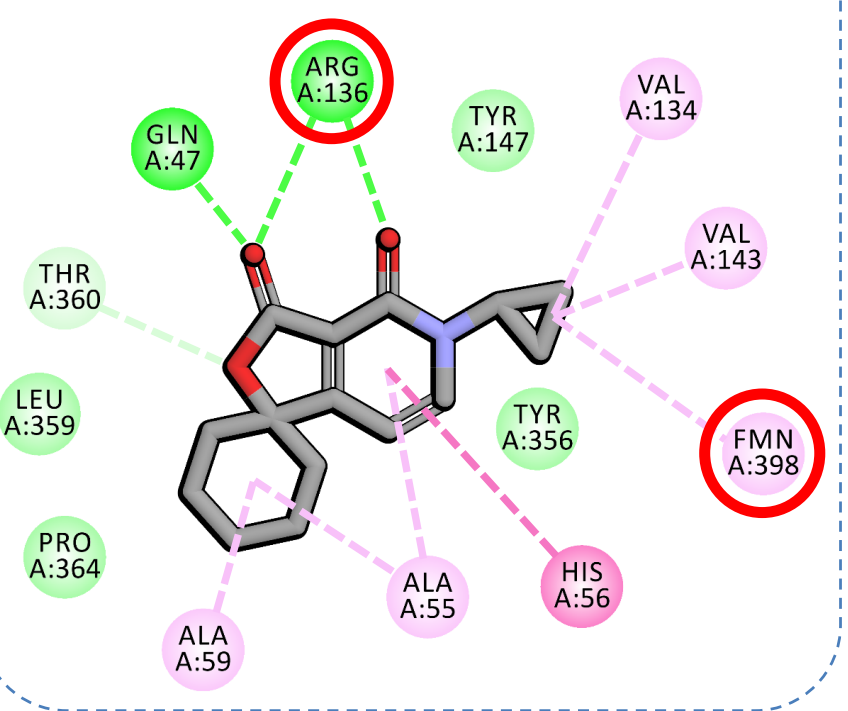


A
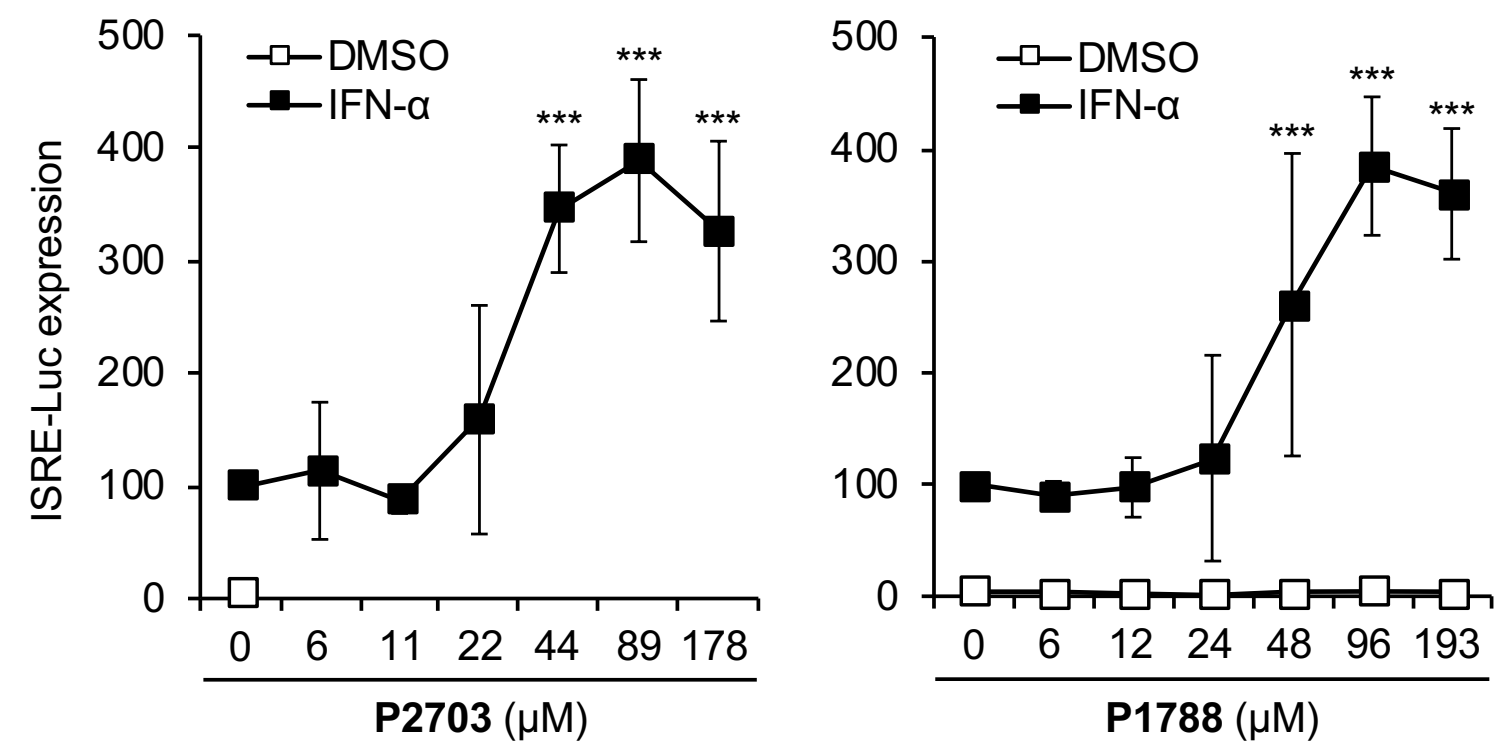

B

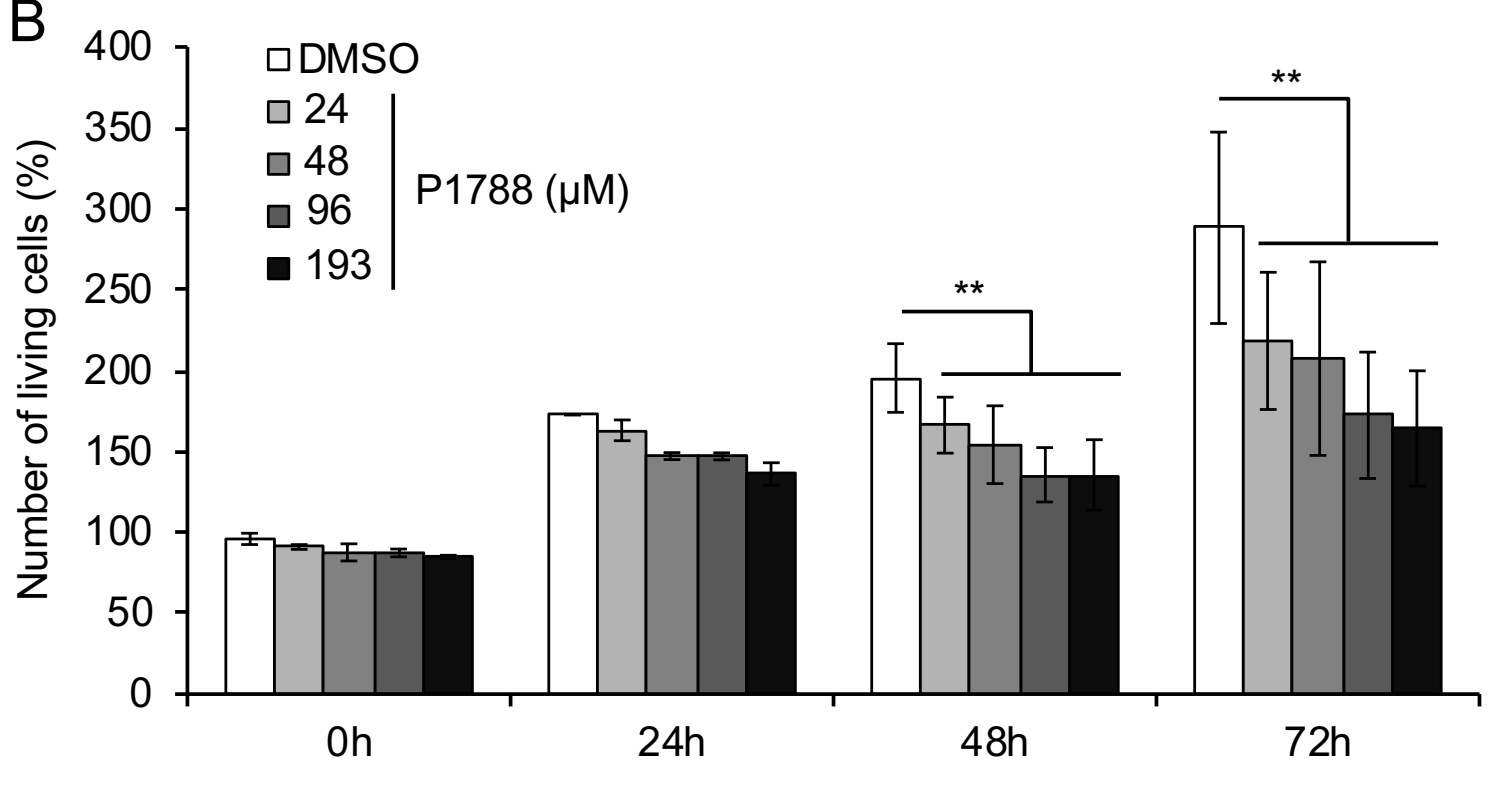


<smiles>Cn1ccc2c(c1=O)C(=O)OC2(C)C</smiles>

Cerpegin<smiles>CC1(C)OC(=O)c2c1cc[nH]c2=O</smiles><smiles>O=C1OC2(CCCCC2)c2cc[nH]c(=O)c21</smiles>

P2512

pEC50 < 3.8

FTD<smiles>O=C1OC2(CCCCC2)c2ccn(C3CCCC3)c(=O)c21</smiles>

pEC50 < 3.8

FTD<smiles>CC1(C)OC(=O)c2c1ccn(C1CC1)c2=O</smiles>

P2701

$$
\text { pEC50<3.8 }
$$

$E=-34.7 \mathrm{kcal} / \mathrm{mol}$<smiles>C/C(O)=C(/C#N)C(=O)Nc1ccc(C(F)(F)F)cc1</smiles>

$$
\begin{gathered}
\text { Teriflunomide } \\
p E C 50=5.05 \\
E=-61.6 \mathrm{kcal} / \mathrm{mol}
\end{gathered}
$$

Norcerpegin

pEC50 $<3.8$

FTD<smiles>CC1(c2ccccc2)OC(=O)c2c1ccn(C1CC1)c2=O</smiles>

P2703

$p E C 50=4.57$

$E=-41.9 \mathrm{kcal} / \mathrm{mol}$

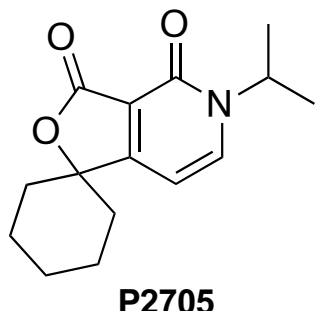

pEC50 $<3.8$

$E=-42.7 \mathrm{kcal} / \mathrm{mol}$

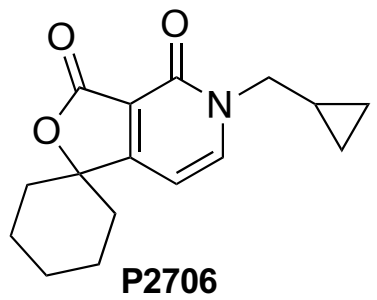

pEC50 $<3.8$

FTD<smiles>CCC1(CC)OC(=O)c2c1ccn(C1CC1)c2=O</smiles>

pEC50 $<3.8$

FTD
P2718<smiles>CNC1CC1</smiles>

pEC50 $<3.8$

$E=-40.6 \mathrm{kcal} / \mathrm{mol}$<smiles>O=C1OC2(CCCCC2)c2ccn(C3CC3)c(=O)c21</smiles>

P1788

pEC50 $=4.35$

$E=-41.2 \mathrm{kcal} / \mathrm{mol}$<smiles>O=C1OC2(CCCCC2)c2ccn(C3CCC3)c(=O)c21</smiles>

pEC50<3.8

$E=-42.3 \mathrm{kcal} / \mathrm{mol}$

\section{P2708}

$$
p E C 50<3.8
$$

$E=-40.6 \mathrm{kcal} / \mathrm{mol}$<smiles>O=C1OC2(CCCC2)c2ccn(C3CC3)c(=O)c21</smiles>

P2717

$$
\text { pEC50 }=4.28
$$

$E=-41.7 \mathrm{kcal} / \mathrm{mol}$<smiles>COc1cccc(-c2ccc(NC(=O)C3=C(C(=O)O)CCC3)c(F)c2)c1</smiles>

\section{Vidofludimus}

$p E C 50=5.56$

$E=-62.3 \mathrm{kcal} / \mathrm{mol}$
Brequinar sodium salt pEC50 $=7.26$ $E=-47.3 \mathrm{kcal} / \mathrm{mol}$ 

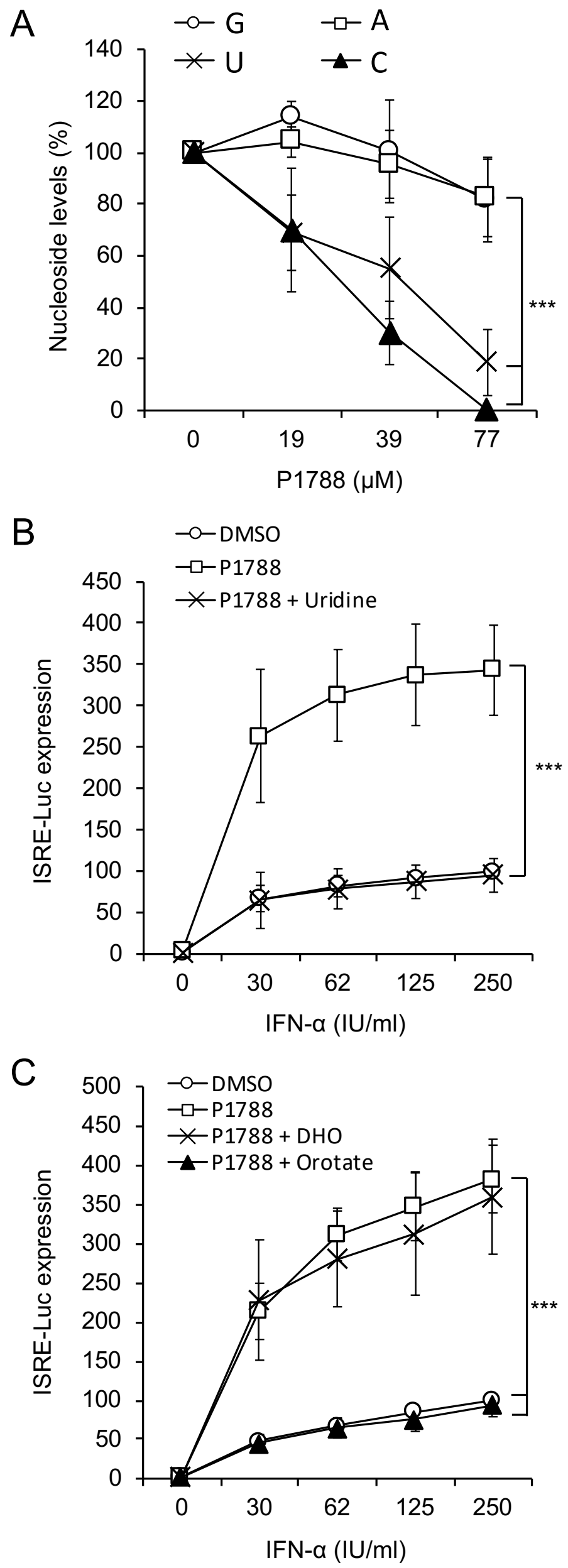
Figure 5

A

\begin{tabular}{|c|c|c|c|c|c|c|c|c|c|c|}
\hline & \multicolumn{5}{|c|}{ DMSO } & \multicolumn{5}{|c|}{ P1788 } \\
\hline $\begin{array}{l}\text { IFN-a } \\
\text { (IU/mI) }\end{array}$ & 0 & 30 & 60 & 125 & 250 & 0 & 30 & 60 & 125 & 250 \\
\hline ISG15 & 1 & 49 & 66 & 70 & 76 & 2 & 123 & 163 & 200 & 226 \\
\hline IFIT3 & 1 & 21 & 44 & 56 & 69 & 2 & 39 & 69 & 99 & 129 \\
\hline IFIT1 & 1 & 24 & 37 & 49 & 65 & 1 & 51 & 85 & 115 & 145 \\
\hline IFIT2 & 1 & 6 & 15 & 28 & 45 & 2 & 26 & 61 & 112 & 165 \\
\hline IFI6 & 1 & 4 & 18 & 25 & 33 & 2 & 47 & 64 & 80 & 91 \\
\hline IFI27 & 1 & 2 & 14 & 23 & 33 & 3 & 44 & 83 & 117 & 143 \\
\hline IFITM3 & 1 & 2 & 11 & 13 & 16 & 1 & 6 & 12 & 14 & 15 \\
\hline DDX58 & 1 & 2 & 8 & 11 & 14 & 2 & 16 & 23 & 31 & 38 \\
\hline$M \times 2$ & 1 & 1 & 2 & 4 & 7 & 2 & 7 & 13 & 20 & 28 \\
\hline IFIT5 & 1 & 2 & 3 & 3 & 3 & 1 & 3 & 3 & 4 & 5 \\
\hline PKR & 1 & 1 & 2 & 3 & 3 & 1 & 2 & 3 & 3 & 4 \\
\hline PML & 1 & 1 & 2 & 2 & 3 & 1 & 3 & 4 & 5 & 5 \\
\hline
\end{tabular}

B

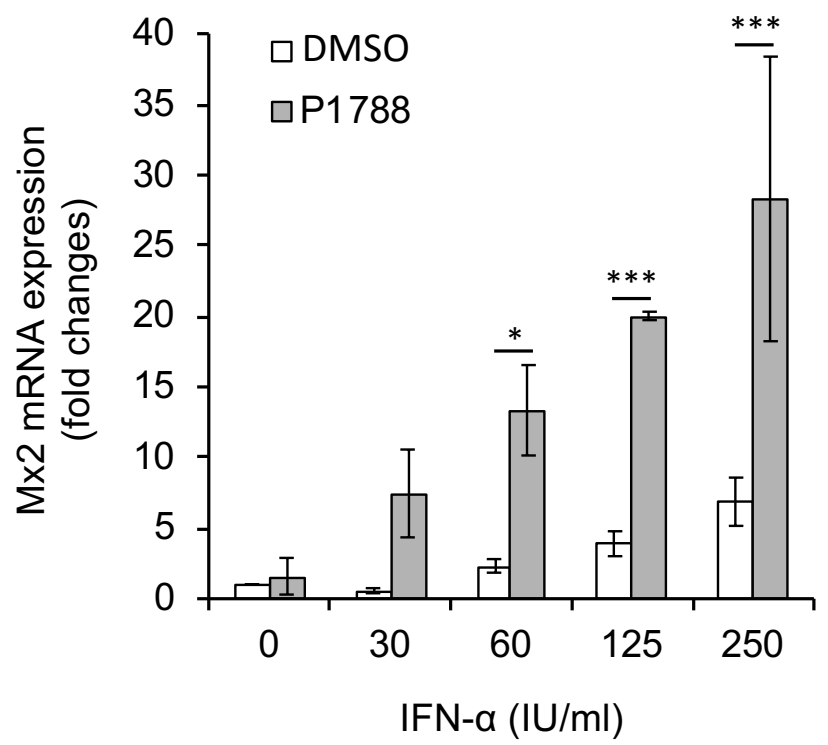


A

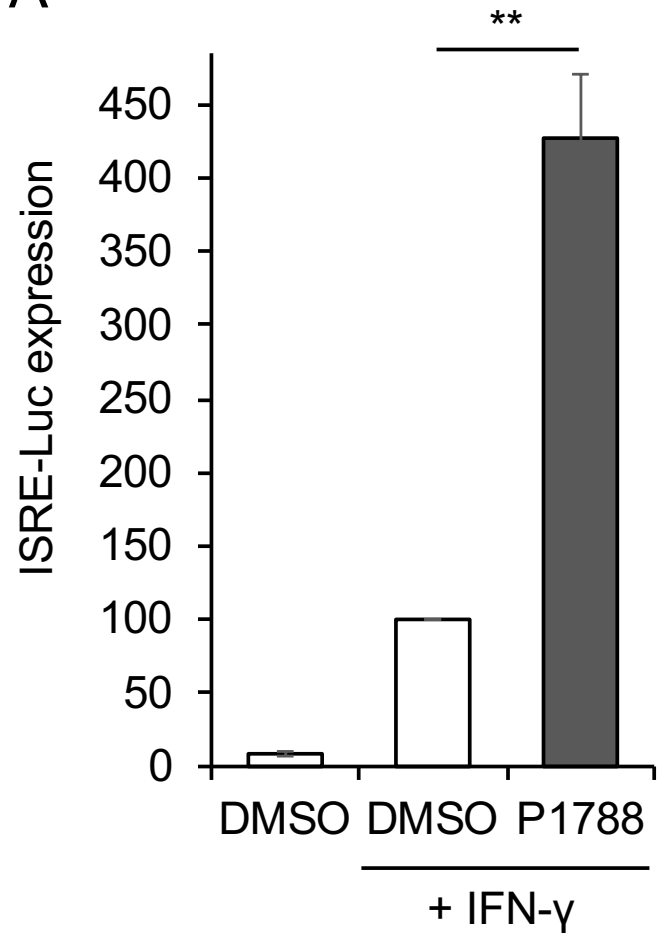

B

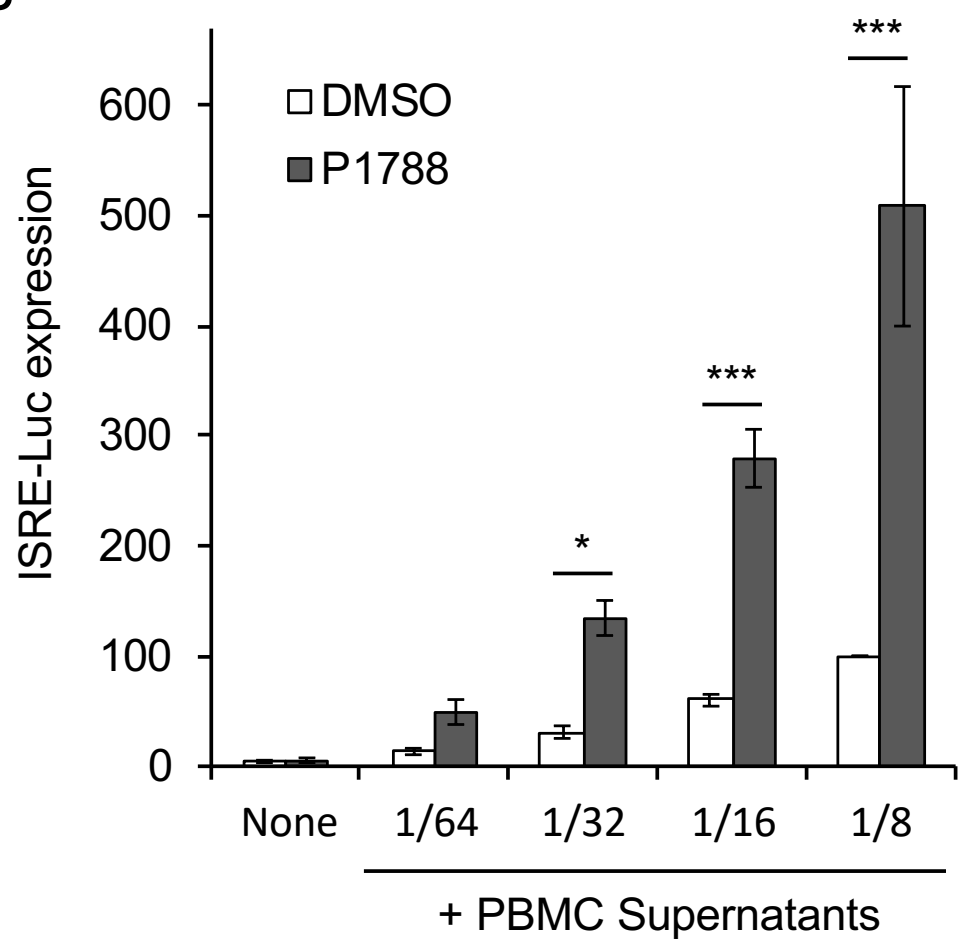


A

Pyrimidine deprivation

DNA replication is impaired

DNA damage response is induced

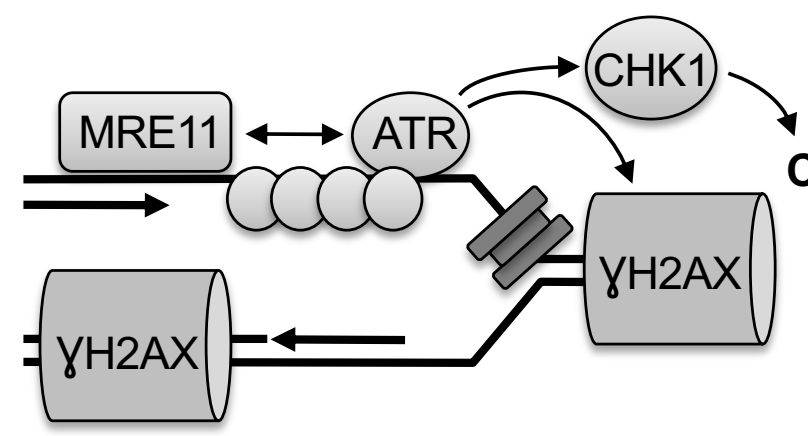

C

-DMSO aIFNa aP1788 + IFNa

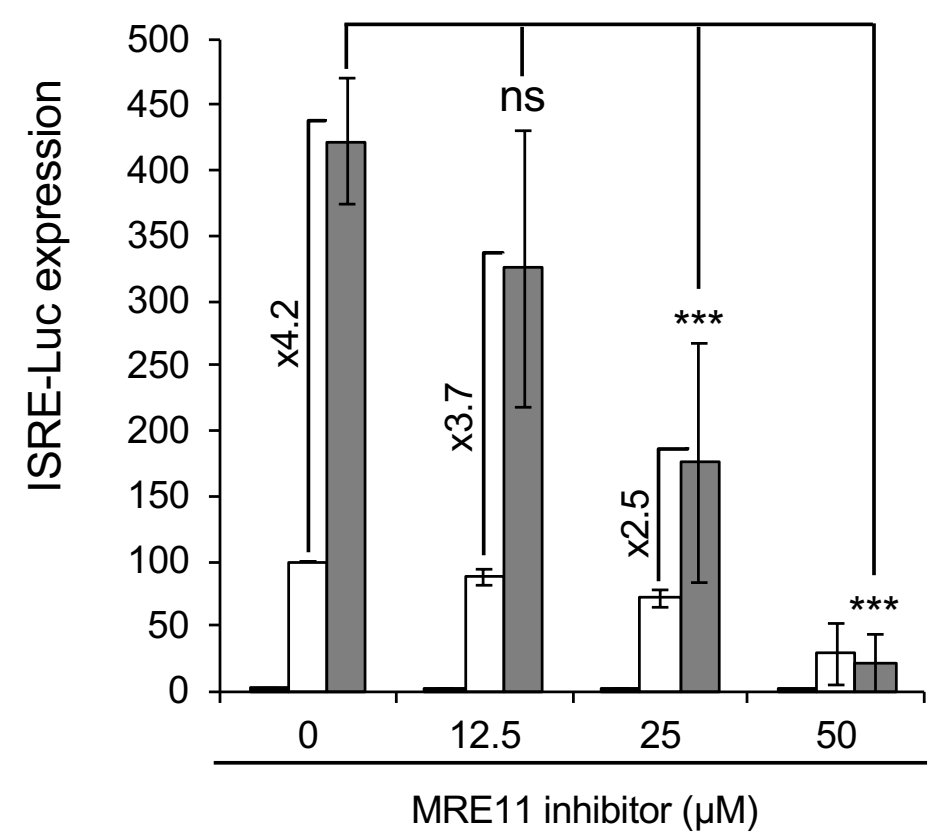

E -DMSO 口IFNa 口P1788 + IFNa

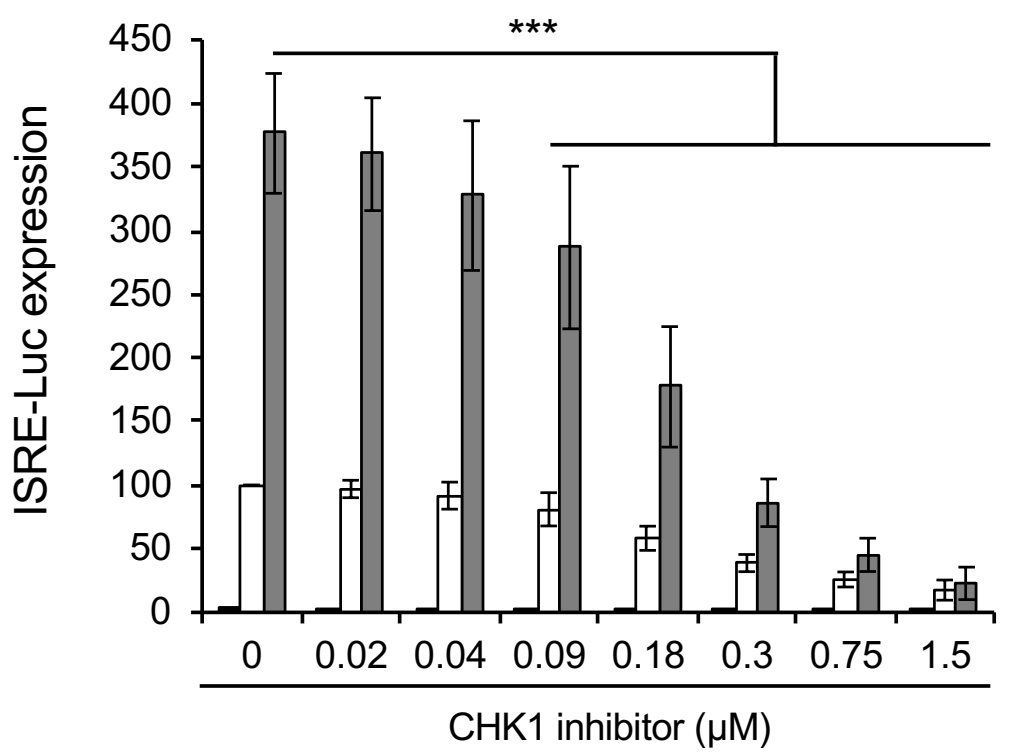

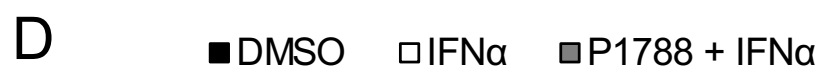

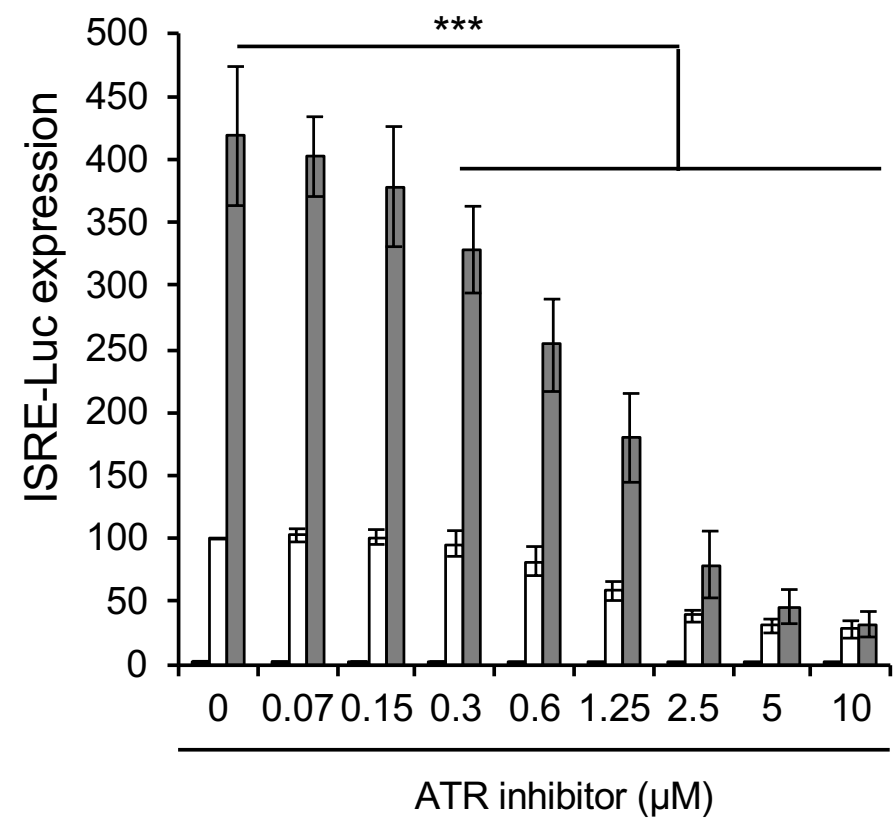

F

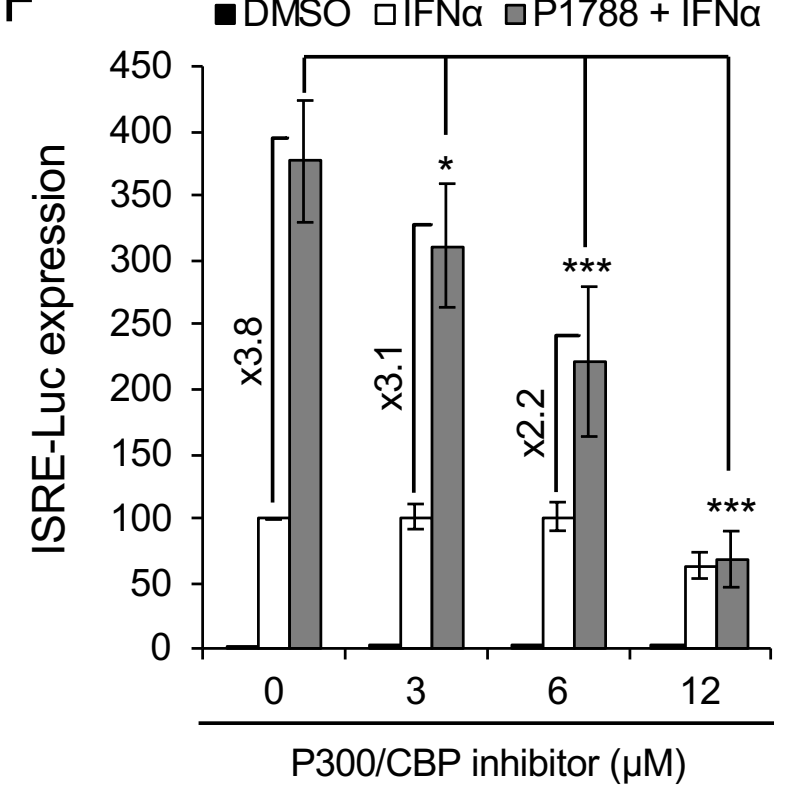



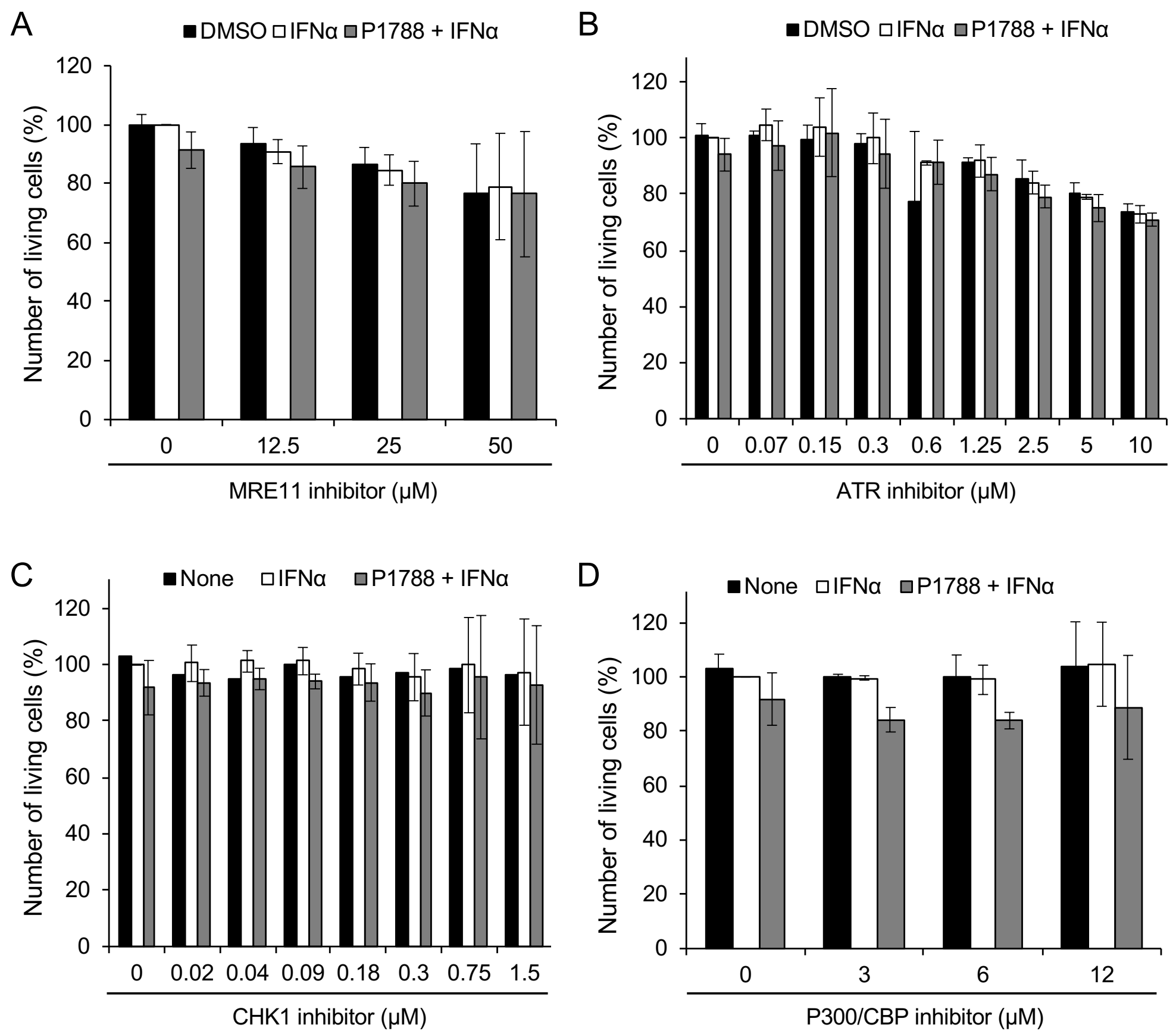


\section{Metabolite analysis}

4

The protocol we used for nucleoside/nucleotide quantification in HEK-293 cells was previously described in detail [25]. Briefly, cells were plated in 6-well plates at $1 \times 10^{6}$ cells per well and after $24 \mathrm{~h}, \mathrm{P} 1788$ (80 $\mu \mathrm{M}$ final concentration) or DMSO alone was added. $24 \mathrm{~h}$ later, cells were washed with PBS and cellular pellets were deproteinized by adding an equal volume of $6 \%$ perchloric acid. After $10 \mathrm{~min}$ of incubation on ice and clearing of the extracts by centrifugation $\left(13,000 \mathrm{rpm}\right.$ for $10 \mathrm{~min}$ at $\left.4^{\circ} \mathrm{C}\right)$, supernatants were supplemented with doubledistilled water $(\mathrm{v} / \mathrm{v})$ and neutralized by the addition of $2 \mathrm{M} \mathrm{Na}_{2} \mathrm{CO}_{3}$. Extracts were analyzed by HPLC onto a C18 Supelco 5 - $\mu \mathrm{m}\left(250\right.$ by $4.6 \mathrm{~mm}$ ) column (Sigma) at $45^{\circ} \mathrm{C}$ using a mobile phase delivered at a flow rate of $1 \mathrm{ml} / \mathrm{min}$. Buffer A contained $10 \mathrm{mM}$ tetrabutylammonium hydroxide, $10 \mathrm{mM} \mathrm{KH}_{2} \mathrm{PO}_{4}$, and $0.25 \% \mathrm{MeOH}$ and was adjusted to $\mathrm{pH} 6.9$ with $1 \mathrm{M} \mathrm{HCl}$. Buffer B contained 5.6 mM tetrabutylammonium hydroxide, $50 \mathrm{mM} \mathrm{KH}_{2} \mathrm{PO}_{4}$, and $30 \% \mathrm{MeOH}$ and was neutralized to $\mathrm{pH} 7.0$ with $1 \mathrm{M} \mathrm{NaOH}$. The following stepwise gradient elution program was used: $A$ to $B$ at 60:40 at $0 \mathrm{~min}, 40: 60$ at $30 \mathrm{~min}$, and 40:60 at $60 \mathrm{~min}$. Products were monitored spectrophotometrically at $254 \mathrm{~nm}$ with a diode array detector (PDA) and quantified by integration of the peak absorbance area. Calibration curves were generated with reference nucleosides. Finally, raw data were normalized to the total number of viable cells present in the well in order to take into account minor differences between culture conditions. 
1 Supplementary Table I. Cytokine expression levels in culture supernatants of human $2 \quad$ PBMC activated with $\mathbf{R 8 4 8 .}$

\begin{tabular}{|c|c|c|}
\hline Cytokine & PBMC alone & PBMC + R848 \\
\hline IL-1 $\beta$ & ND & $12 \mathrm{ng} / \mathrm{ml}$ \\
\hline IL-6* & ND & $11 \mathrm{ng} / \mathrm{ml}$ \\
\hline TNF- $\alpha$ & ND & $0.028 \mathrm{ng} / \mathrm{ml}$ \\
\hline IP10 & $0.002 \mathrm{ng} / \mathrm{ml}$ & $0.016 \mathrm{ng} / \mathrm{ml}$ \\
\hline IFN- $\lambda 1$ & $0.002 \mathrm{ng} / \mathrm{ml}$ & $214 \mathrm{ng} / \mathrm{ml}$ \\
\hline IL-8* & $0.149 \mathrm{ng} / \mathrm{ml}$ & $0.009 \mathrm{ng} / \mathrm{ml}$ \\
\hline IL-12p70 & ND & $0.097 \mathrm{ng} / \mathrm{ml}$ \\
\hline IFN- $\alpha 2$ & ND & $\mathrm{ND}$ \\
\hline IFN- $\lambda 2 / 3$ & ND & $0.043 \mathrm{ng} / \mathrm{ml}$ \\
\hline GM-CSF & ND & $0.015 \mathrm{ng} / \mathrm{ml}$ \\
\hline IFN- $\beta$ & ND & $0.283 \mathrm{ng} / \mathrm{ml}$ \\
\hline IL-10 & ND & $\mathbf{4 . 2} \mathbf{n g} / \mathbf{m l}$ \\
\hline IFN- $\gamma$ & ND & \\
\hline
\end{tabular}

3 ND stands for "Not Detected". All concentrations were measured on raw PBMC supernatants, 4 except for IL-6 and IL-8 where supernatants were diluted 12 times (*). 
1 Supplementary Table II: List of RT-qPCR primers

\begin{tabular}{|c|c|c|c|}
\hline Primer ID & GenBank ID & $\begin{array}{c}\text { Amplicon size } \\
\text { (nt) }\end{array}$ & Sequence 5' to 3' \\
\hline RPL13A-F & \multirow{2}{*}{23521} & \multirow{2}{*}{82} & AACAGCTCATGAGGCTACGG \\
\hline RPL13A-R & & & TGGGTCTTGAGGACCTCTGT \\
\hline ISG15-F & \multirow{2}{*}{9636} & \multirow{2}{*}{117} & CAGCGAACTCATCTTTGCCAG \\
\hline ISG15-R & & & GACACCTGGAATTCGTTGCC \\
\hline IFIT3-F & \multirow{2}{*}{3437} & \multirow{2}{*}{94} & AACAGATGTCCTCCGCAGTG \\
\hline IFIT3-R & & & TGTGGATTCCAACACCCGTT \\
\hline IFIT1-F & \multirow{2}{*}{3434} & \multirow{2}{*}{84} & ATGCGATCTCTGCCTATCGC \\
\hline IFIT1-R & & & CCTGCCTTAGGGGAAGCAAA \\
\hline IFIT2-F & \multirow{2}{*}{3433} & \multirow{2}{*}{84} & AATAGGACACGCTGTGGCTC \\
\hline IFIT2-R & & & AGGCTGGCAAGAATGGAACA \\
\hline IFI6-F & \multirow{2}{*}{2537} & \multirow{2}{*}{83} & GGGTGGAGGCAGGTAAGAAA \\
\hline IFI6-R & & & GACGGCCATGAAGGTCAGG \\
\hline IFI27-F & \multirow{2}{*}{3429} & \multirow{2}{*}{106} & ATCAGCAGTGACCAGTGTGG \\
\hline IFI27-R & & & GGCCACAACTCCTCCAATCA \\
\hline IFITM3-F & \multirow{2}{*}{10410} & \multirow{2}{*}{118} & GAAGATGGTTGGCGACGTGA \\
\hline IFITM3-R & & & CACTGGGATGACGATGAGCA \\
\hline DDX58-F & \multirow{2}{*}{23586} & \multirow{2}{*}{152} & ATCCAAACCAGAGGCAGAGGAA \\
\hline DDX58-R & & & ACTGCTTCGTCCCATGTCTGAA \\
\hline $\mathrm{MxA}-\mathrm{F}$ & \multirow{2}{*}{4599} & \multirow{2}{*}{74} & AAGCTGATCCGCCTCCACTT \\
\hline MxA-R & & & TGCAATGCACCCCTGTATACC \\
\hline IFIT5-F & \multirow{2}{*}{24138} & \multirow{2}{*}{99} & CACTATGGCCGCTTTCAGGA \\
\hline IFIT5-R & & & GCGAAGGGGTGATCTGTCTT \\
\hline PKR-F & \multirow{2}{*}{5610} & \multirow{2}{*}{102} & GTGGACCTCTACGCTTTGGG \\
\hline PKR-R & & & GATGCCATCCCGTAGGTCTG \\
\hline PML-F & \multirow{2}{*}{5371} & \multirow{2}{*}{97} & AGTGAGCTCAAGTGCGACAT \\
\hline PML-R & & & CAAAGGCACTATCCTGCTCCT \\
\hline
\end{tabular}




\section{Characterization of synthetized molecules}

Norcerpegin. 1,1-dimethylfuro[3,4-c]pyridine-3,4(1H,5H)-dione was previously described in $[1]$.

P2703. 5-cyclopropyl-1-methyl-1-phenylfuro[3,4-c]pyridine-3,4(1H,5H)-dione. Yield 73\%, mp. $186^{\circ} \mathrm{C} .{ }^{1} \mathrm{H}$ NMR $\left(300 \mathrm{MHz}, \mathrm{DMSO}-\mathrm{d} 6 / \mathrm{CCl}_{4}\right) \delta(\mathrm{ppm}): 0.98(\mathrm{~m}, 4 \mathrm{H}), 1.96(\mathrm{~s}, 3 \mathrm{H}), 2.49(\mathrm{~m}$, 1H), $6.42(\mathrm{~d}, J=6.8 \mathrm{~Hz}, 1 \mathrm{H}), 7.37(\mathrm{~m}, 5 \mathrm{H}), 7.88(\mathrm{~d}, J=6.9 \mathrm{~Hz}, 1 \mathrm{H}) .{ }^{13} \mathrm{C}$ NMR $(75 \mathrm{MHz}$, DMSO-d6/CCl 4$) \delta$ (ppm): 6.31, 6.38, 24.92, 31.71, 38.67, 38.94, 39.22, 39.49, 39.77, 40.05, 40.33, 95.48, 124.61, 127.81, 128.23, 139.00, 145.39, 157.07, 159.42, 165.52, 170.03. MS $[\mathrm{ESI}+, \mathrm{MeOH}]:[\mathrm{M}+\mathrm{H}]^{+} 282.11(32 \%),[\mathrm{M}+\mathrm{Na}]^{+} 304.09(76 \%),[2 \mathrm{M}+\mathrm{Na}]^{+} 585.20(100 \%)$. HRMS [ESI $\left.{ }^{+}, \mathrm{MeOH}\right]$ : calcd for $\mathrm{C}_{17} \mathrm{H}_{16} \mathrm{O}_{3} \mathrm{~N}[\mathrm{M}+\mathrm{H}]^{+} 282.1125$ found 282.1125.

P1788. 5'-cyclopropyl-3'H-spiro[cyclohexane-1,1'-furo[3,4-c]pyridine]-3',4'(5'H)-dione. Yield 76\%, mp. 235-236 ${ }^{\circ} \mathrm{C} .{ }^{1} \mathrm{H}$ NMR, (500 MHz, DMSO-d6) $\delta(\mathrm{ppm}): 0.88$ (m, 2H), $1.02(\mathrm{~m}, 2 \mathrm{H})$, $1.36(\mathrm{~m}, 1 \mathrm{H}), 1.57(\mathrm{~m}, 4 \mathrm{H}), 1.72(\mathrm{~m}, 3 \mathrm{H}), 1.89(\mathrm{dt}, J=4.0,13.1 \mathrm{~Hz}, 2 \mathrm{H}), 3.3(\mathrm{~m}, 1 \mathrm{H}), 6.56(\mathrm{~d}$, $J=6.8 \mathrm{~Hz}, 1 \mathrm{H}), 8.01(\mathrm{~d}, J=6.8 \mathrm{~Hz}, 1 \mathrm{H}) .{ }^{13} \mathrm{C} \mathrm{NMR},(125 \mathrm{MHz}, \mathrm{DMSO}-\mathrm{d} 6) \delta(\mathrm{ppm}): 6.4\left(2 \mathrm{CH}_{2}\right)$, $21.6\left(2 \mathrm{CH}_{2}\right), 23.8,32.1,33.7\left(2 \mathrm{CH}_{2}\right), 83.4,98.4,110.1,146,157.9,166.3,171.3 . \mathrm{MS}$ [ESI+, $\mathrm{MeOH}]:[\mathrm{M}+\mathrm{H}]^{+} 260.1(70 \%),[2 \mathrm{M}+\mathrm{Na}]^{+}$541.2(100\%). El. anal. calcd. for $\mathrm{C}_{15} \mathrm{H}_{17} \mathrm{NO}_{3}: \mathrm{C}$ 69.48; H 6.61; N 5.40; Found: C 69.66; H 6.63; N 5.40.

P2512. 3' $H$-spiro[cyclohexane-1,1'-furo[3,4-c]pyridine]-3', $4^{\prime}\left(5^{\prime} H\right)$-dione was previously described in [3][4].

P1781. 5'-methyl-3'H-spiro[cyclohexane-1,1'-furo[3,4-c]pyridine]-3',4'(5'H)-dione, previously described in [4], was obtained from the general procedure described above.

P2705. 5'-isopropyl-3'H-spiro[cyclohexane-1,1'-furo[3,4-c]pyridine]-3',4'(5'H)-dione. Yield 61\%, mp. 199-200 ${ }^{\circ} \mathrm{C} .{ }^{1} \mathrm{H}$ NMR (300 MHz, DMSO-d6/CCl 4 ) $\delta(\mathrm{ppm}): 1.38$ (m. 1H),1.38 (d, $J$ $=6.8 \mathrm{~Hz}, 6 \mathrm{H}), 1.61(\mathrm{~m}, 2 \mathrm{H}), 1.81(\mathrm{~m}, 7 \mathrm{H}), 5.16(\mathrm{~m}, 1 \mathrm{H}), 6.46(\mathrm{~d}, J=6.9 \mathrm{~Hz}, 1 \mathrm{H}), 8.03(\mathrm{~d}, J=$ $6.9 \mathrm{~Hz}, 1 \mathrm{H}) .{ }^{13} \mathrm{C}$ NMR (75 MHz, DMSO-d6/CCl 4$) \delta$ (ppm): 21.29, 21.36, 23.84, 33.96, 45.85, 82.33, 95.46, 110.40, 141.67, 155.83, 165.31, 169.92. HRMS [ESI $\left.{ }^{+}, \mathrm{MeOH}\right]$ : calcd for $\mathrm{C}_{15} \mathrm{H}_{20} \mathrm{O}_{3} \mathrm{~N}[\mathrm{M}+\mathrm{H}]^{+} 262.1438$ found 262.1439 . 
1 P2707. 5'-cyclobutyl-3'H-spiro[cyclohexane-1,1'-furo[3,4-c]pyridine]-3',4'(5'H)-dione. Yield $259 \%$, mp. 214-215 C. ${ }^{1} \mathrm{H}$ NMR, (500 MHz, DMSO-d6) $\delta$ (ppm): 1.37 (m, 1H), 1.57 (m, 4H), $31.74(\mathrm{~m}, 5 \mathrm{H}), 1.90(\mathrm{~m}, 2 \mathrm{H}), 2.26(\mathrm{~m}, 2 \mathrm{H}), 2.34(\mathrm{~m}, 2 \mathrm{H}), 5.0(\mathrm{~m}, \mathrm{~J}=8.6 \mathrm{~Hz}, 1 \mathrm{H}), 6.65(\mathrm{~d}, \mathrm{~J}=$ $4 \quad 6.8 \mathrm{~Hz}, 1 \mathrm{H}), 8.23(\mathrm{~d}, \mathrm{~J}=6.8 \mathrm{~Hz}, 1 \mathrm{H}) .{ }^{13} \mathrm{C}$ NMR, (125 MHz, DMSO-d6) $\delta$ (ppm): 14.3, 21.6 $5 \quad\left(2 \mathrm{CH}_{2}\right), 23.8,29.3\left(2 \mathrm{CH}_{2}\right), 33.7\left(2 \mathrm{CH}_{2}\right), 50.8,83.4,98.7,109.9,143.5,156.7,166.4,171.1$. 6 HRMS [ESI $\left.{ }^{+}, \mathrm{MeOH}\right]$ : calcd for $\mathrm{C}_{16} \mathrm{H}_{20} \mathrm{O}_{3} \mathrm{~N}[\mathrm{M}+\mathrm{H}]^{+} 274.1438$ found 274.1440.

P1792. 5'-cyclopentyl-3'H-spiro[cyclohexane-1,1'-furo[3,4-c]pyridine]-3',4'(5'H)-dione. Yield 86\%, mp. $233^{\circ} \mathrm{C} .{ }^{1} \mathrm{H}$ NMR, (500 MHz, DMSO-d6) $\delta(\mathrm{ppm}): 1.36$ (m, 1H), 1.57 (m, 4H), 1.65 (m, 3H), $1.71(\mathrm{~m}, 4 \mathrm{H}), 1.83(\mathrm{~m}, 2 \mathrm{H}), 1.9(\mathrm{~m}, 2 \mathrm{H}), 2.02(\mathrm{~m}, 2 \mathrm{H}), 5.11(\mathrm{~m}, \mathrm{~J}=7.8 \mathrm{~Hz}, 1 \mathrm{H}), 6.64$ $(\mathrm{d}, \mathrm{J}=6.8 \mathrm{~Hz}, 1 \mathrm{H}), 8.16(\mathrm{~d}, \mathrm{~J}=6.8 \mathrm{~Hz}, 1 \mathrm{H}) .{ }^{13} \mathrm{C} \mathrm{NMR},(125 \mathrm{MHz}, \mathrm{DMSO}-\mathrm{d} 6) \delta(\mathrm{ppm}): 21.6$ $\left(2 \mathrm{CH}_{2}\right), 23.7\left(2 \mathrm{CH}_{2}\right), 23.8,31.5\left(2 \mathrm{CH}_{2}\right), 33.7\left(2 \mathrm{CH}_{2}\right), 56.2,83.3,99.1,109.9,143.5,156.8$, 166.4, 170.8. HRMS [ESI $\left.{ }^{+}, \mathrm{MeOH}\right]$ : calcd for $\mathrm{C}_{17} \mathrm{H}_{22} \mathrm{O}_{3} \mathrm{~N}[\mathrm{M}+\mathrm{H}]^{+} 288.1594$ found 288.1600.

P1793. 5'-cyclohexyl-3'H-spiro[cyclohexane-1,1'-furo[3,4-c]pyridine]-3',4'(5'H)-dione. Yield 59\%, mp. $>270^{\circ} \mathrm{C} .{ }^{1} \mathrm{H}$ NMR, $(500 \mathrm{MHz}, \mathrm{DMSO}-\mathrm{d} 6) \delta(\mathrm{ppm}): 1.21(\mathrm{~m}, 1 \mathrm{H}), 1.40(\mathrm{~m}, 3 \mathrm{H}), 1.58$ $(\mathrm{m}, 6 \mathrm{H}), 1.73(\mathrm{~m}, 6 \mathrm{H}), 1.84(\mathrm{~m}, 2 \mathrm{H}), 1.89(\mathrm{~m}, 2 \mathrm{H}), 4.72(\mathrm{~m}, 1 \mathrm{H}), 6.64(\mathrm{dd}, \mathrm{J}=2,6.8 \mathrm{~Hz}, 1 \mathrm{H})$, $8.20(\mathrm{dd}, \mathrm{J}=2,6.8 \mathrm{~Hz}, 1 \mathrm{H}) .{ }^{13} \mathrm{C} \mathrm{NMR},(125 \mathrm{MHz}, \mathrm{DMSO}-\mathrm{d} 6) \delta(\mathrm{ppm}): 21.6\left(2 \mathrm{CH}_{2}\right), 23.8$, 24.6, $25.4\left(2 \mathrm{CH}_{2}\right), 31.5\left(2 \mathrm{CH}_{2}\right), 33.7\left(2 \mathrm{CH}_{2}\right), 53.6,83.3,98.9,109.9,143.3,156.4,166.4,170.6$. HRMS [ESI $\left.{ }^{+}, \mathrm{MeOH}\right]$ : calcd for $\mathrm{C}_{18} \mathrm{H}_{24} \mathrm{O}_{3} \mathrm{~N}[\mathrm{M}+\mathrm{H}]^{+} 302.1751$ found 302.1755.

P2706. 5'-(cyclopropylmethyl)-3'H-spiro[cyclohexane-1,1'-furo[3,4-c]pyridine]-3',4'(5'H)dione. Yield 67\%, mp. 195-196 ${ }^{\circ} \mathrm{C} .{ }^{1} \mathrm{H}$ NMR (300 MHz, DMSO-d6/CCl $) \delta(\mathrm{ppm}): 0.50(\mathrm{~m}$, 4H), $1.25(\mathrm{~m}, 1 \mathrm{H}), 1.41(\mathrm{~m}, 1 \mathrm{H}), 1.77(\mathrm{~m}, 9 \mathrm{H}), 3.82(\mathrm{~d}, J=7.2 \mathrm{~Hz}, 2 \mathrm{H}), 6.39$ (d, $J=6.7 \mathrm{~Hz}$, $1 \mathrm{H}), 8.08(\mathrm{~d}, J=6.7 \mathrm{~Hz}, 1 \mathrm{H}) .{ }^{13} \mathrm{C} \mathrm{NMR}\left(75 \mathrm{MHz}, \mathrm{DMSO}-\mathrm{d} 6 / \mathrm{CCl}_{4}\right) \delta(\mathrm{ppm}): 170.67,165.30$, $156.27,145.82,110.49,95.45,52.34,40.04,39.76,39.49,39.21,38.93,34.00,23.84,21.35$, 10.41, 3.24. HRMS [ESI $\left.{ }^{+}, \mathrm{MeOH}\right]$ : calcd for $\mathrm{C}_{16} \mathrm{H}_{20} \mathrm{O}_{3} \mathrm{~N}[\mathrm{M}+\mathrm{H}]^{+} 274.1438$ found 274.1439.

P2708. N-cyclopropyl-4-methyl-2-oxo-1-oxaspiro[4.5]dec-3-ene-3-carboxamide. Yield 62\%, mp. $141-143^{\circ} \mathrm{C} .{ }^{1} \mathrm{H}$ NMR, (500 MHz, DMSO-d6) $\delta(\mathrm{ppm}): 0.51$ (m, 2H), $0.71(\mathrm{~m}, 2 \mathrm{H}), 1.29$ $(\mathrm{m}, 1 \mathrm{H}), 1.41(\mathrm{~m}, 2 \mathrm{H}), 1.54(\mathrm{~m}, 2 \mathrm{H}), 1.71(\mathrm{~m}, 3 \mathrm{H}), 1.82(\mathrm{~m}, 2 \mathrm{H}), 2.33(\mathrm{~s}, 3 \mathrm{H}), 2.76(\mathrm{~m}, 1 \mathrm{H})$, $8.09(\mathrm{~s}, 1 \mathrm{H}) .{ }^{13} \mathrm{C}$ NMR, (125 MHz, DMSO-d6) $\delta(\mathrm{ppm}): 5.9\left(2 \mathrm{CH}_{2}\right), 12.6,21.5\left(2 \mathrm{CH}_{2}\right), 22$, 23.7, $31.9\left(2 \mathrm{CH}_{2}\right), 87.9,118,161.6,170.2,178.3$. HRMS [ESI $\left.{ }^{+}, \mathrm{MeOH}\right]$ : calcd for $\mathrm{C}_{14} \mathrm{H}_{20} \mathrm{O}_{3} \mathrm{~N}$ 
2 P2701. 5-cyclopropyl-1,1-dimethylfuro[3,4-c]pyridine-3,4(1H,5H)-dione. Yield 66\%, mp. 224-225ㄷ. ${ }^{1} \mathrm{H}$ NMR, (500 MHz, DMSO-d6) $\delta$ (ppm): 0.89 (m, 2H), 1.03 (m, 2H), 1.53 (s, 6H), $3.33(\mathrm{~m}, 1 \mathrm{H}), 6.58(\mathrm{~d}, \mathrm{~J}=6.8 \mathrm{~Hz}, 1 \mathrm{H}), 8.04(\mathrm{~d}, \mathrm{~J}=6.8 \mathrm{~Hz}, 1 \mathrm{H}) .{ }^{13} \mathrm{C}$ NMR, (125 MHz, DMSOd6) $\delta$ (ppm): $6.5\left(2 \mathrm{CH}_{2}\right), 25.3\left(2 \mathrm{CH}_{2}\right), 32.1,82.1,98.2,109.9,146.2,157.8,166.2,171.6$. HRMS [ESI $\left.{ }^{+}, \mathrm{MeOH}\right]$ : calcd for $\mathrm{C}_{12} \mathrm{H}_{14} \mathrm{O}_{3} \mathrm{~N}[\mathrm{M}+\mathrm{H}]^{+} 220.0968$ found 220.0969 .

P2702. 5-cyclopropyl-1-ethyl-1-methylfuro[3,4-c]pyridine-3,4(1H,5H)-dione. Yield 61\%, mp. $158^{\circ} \mathrm{C} .{ }^{1} \mathrm{H}$ NMR $\left(300 \mathrm{MHz}, \mathrm{DMSO}-\mathrm{d} 6 / \mathrm{CCl}_{4}\right) \delta(\mathrm{ppm}): 0.78$ (t, $\left.J=7.4 \mathrm{~Hz}, 3 \mathrm{H}\right), 0.91(\mathrm{~m}, 2 \mathrm{H})$, $1.10(\mathrm{~m}, 2 \mathrm{H}), 1.53(\mathrm{~s}, 3 \mathrm{H}), 1.91(\mathrm{~m}, 2 \mathrm{H}), 3.36(\mathrm{~m}, 1 \mathrm{H}), 6.38(\mathrm{~d}, J=6.8 \mathrm{~Hz}, 1 \mathrm{H}), 7.91(\mathrm{~d}, J=$ $6.8 \mathrm{~Hz}, 1 \mathrm{H}) .{ }^{13} \mathrm{C}$ NMR $\left(75 \mathrm{MHz}, \mathrm{DMSO}-\mathrm{d} 6 / \mathrm{CCl}_{4}\right) \delta(\mathrm{ppm}): 6.28,6.38,7.15,23.85,30.63$, 31.63, 38.94, 39.22, 39.49, 39.77, 40.05, 95.45, 111.32, 144.94, 157.01, 165.44, 169.68. HRMS [ESI $\left.{ }^{+}, \mathrm{MeOH}\right]$ : calcd for $\mathrm{C}_{13} \mathrm{H}_{16} \mathrm{O}_{3} \mathrm{~N}[\mathrm{M}+\mathrm{H}]^{+} 234.1125$ found 234.1125.

P2718. 5-cyclopropyl-1,1-diethylfuro[3,4-c]pyridine-3,4(1H,5H)-dione. Yield 63\%, mp. 176$178^{\circ} \mathrm{C} .{ }^{1} \mathrm{H}$ NMR, (500 MHz, DMSO-d6) $\delta$ (ppm): 0.64 (t, J = 7.39 Hz, 6H), 0.9 (m, 2H), 1.03 $(\mathrm{m}, 2 \mathrm{H}), 1.88$ (q, J = 7.4 Hz, 2H), 1.94 (q, J = 7.4 Hz, 2H), 3.35 (tt, J=4.12, $7.43 \mathrm{~Hz}, 1 \mathrm{H}), 6.48$ $(\mathrm{d}, \mathrm{J}=6.8 \mathrm{~Hz}, 1 \mathrm{H}), 8.03(\mathrm{~d}, \mathrm{~J}=6.8 \mathrm{~Hz}, 1 \mathrm{H}) .{ }^{13} \mathrm{C}$ NMR, (125 MHz, DMSO-d6) $\delta$ (ppm): 5.7 $\left(2 \mathrm{CH}_{2}\right), 21.6\left(2 \mathrm{CH}_{2}\right), 24,29.2,36.3,91.7,97.2,100.8,143.3,154.3,158.4,171.7 . \mathrm{HRMS}^{2} \mathrm{ESI}^{+}$, $\mathrm{MeOH}]$ : calcd for $\mathrm{C}_{14} \mathrm{H}_{18} \mathrm{O}_{3} \mathrm{~N}[\mathrm{M}+\mathrm{H}]^{+} 248.1281$ found 248.1284 .

P2717. 5'-cyclopropyl-3'H-spiro[cyclopentane-1,1'-furo[3,4-c]pyridine]-3',4'(5'H)-dione. Yield 72\%, mp. 190-192 ${ }^{\circ} \mathrm{C} .{ }^{1} \mathrm{H}$ NMR, (500 MHz, DMSO-d6) $\delta(\mathrm{ppm}): 0.89$ (m, 2H), 1.02 (m, 2H), $1.89(\mathrm{~m}, 6 \mathrm{H}), 2.09(\mathrm{~m}, 2 \mathrm{H}), 3.33(\mathrm{~m}, 1 \mathrm{H}), 6.55(\mathrm{~d}, \mathrm{~J}=6.9 \mathrm{~Hz}, 1 \mathrm{H}), 8.03(\mathrm{~d}, \mathrm{~J}=6.9 \mathrm{~Hz}$, 1H). ${ }^{13} \mathrm{C}$ NMR, (125 MHz, DMSO-d6) $\delta(\mathrm{ppm}): 6.5\left(2 \mathrm{CH}_{2}\right), 24.5\left(2 \mathrm{CH}_{2}\right), 32.1,37.9\left(2 \mathrm{CH}_{2}\right)$, 91.8, 98.2, 110.9, 146.1, 157.5, 166.2, 169.5. $\left.\mathrm{MS}_{[\mathrm{ESI}}^{+}, \mathrm{MeOH}\right]:[\mathrm{M}+\mathrm{H}]^{+} 246.11(48 \%)$, $[\mathrm{M}+\mathrm{Na}]^{+} 268.09(52 \%),[2 \mathrm{M}+\mathrm{Na}]^{+} 513.20$ (100\%). HRMS [ESI $\left.{ }^{+}, \mathrm{MeOH}\right]:$ calcd for $\mathrm{C}_{14} \mathrm{H}_{16} \mathrm{O}_{3} \mathrm{~N}[\mathrm{M}+\mathrm{H}]+246.1125$ found 246.1128 .

\section{References}

[1] T.H. Pham, A. Hovhannisyan, D. Bouvier, L. Tian, M. Reboud-Ravaux, G. Melikyan, M. Bouvier-Durand, A new series of N5 derivatives of the 1,1,5-trimethyl furo[3,4-c]pyridine3,4-dione (cerpegin) selectively inhibits the post-acid activity of mammalian $20 \mathrm{~S}$ proteasomes, Bioorg. Med. Chem. Lett. 22 (2012) 3822-3827. doi:10.1016/j.bmcl.2012.03.105. 
[2] A. Hovhannisyan, T.H. Pham, D. Bouvier, L. Qin, G. Melikyan, M. Reboud-Ravaux, M. Bouvier-Durand, C1 and N5 derivatives of cerpegin: synthesis of a new series based on structure-activity relationships to optimize their inhibitory effect on $20 \mathrm{~S}$ proteasome, Bioorg. Med. Chem. Lett. 23 (2013) 2696-2703. doi:10.1016/j.bmcl.2013.02.079.

[3] A. Hovhannisyan, T.H. Pham, D. Bouvier, A. Piroyan, L. Dufau, L. Qin, Y. Cheng, G. Melikyan, M. Reboud-Ravaux, M. Bouvier-Durand, New C(4)- and C(1)-derivatives of furo[3,4-c]pyridine-3-ones and related compounds: evidence for site-specific inhibition of the constitutive proteasome and its immunoisoform, Bioorg. Med. Chem. Lett. 24 (2014) 1571-1580. doi:10.1016/j.bmcl.2014.01.072.

[4] D. Villemin, N. Cheikh, L. Liao, N. Bar, J.-F. Lohier, J. Sopkova, N. Choukchou-Braham, B. Mostefa-Kara, Two versatile routes towards Cerpegin and analogues: applications of a one pot reaction to new analogues of Cerpegin, Tetrahedron. 68 (2012) 4906-4918. doi:10.1016/j.tet.2012.03.057. 


\section{Supplementary material - NMR DATA}

NMR data P1788
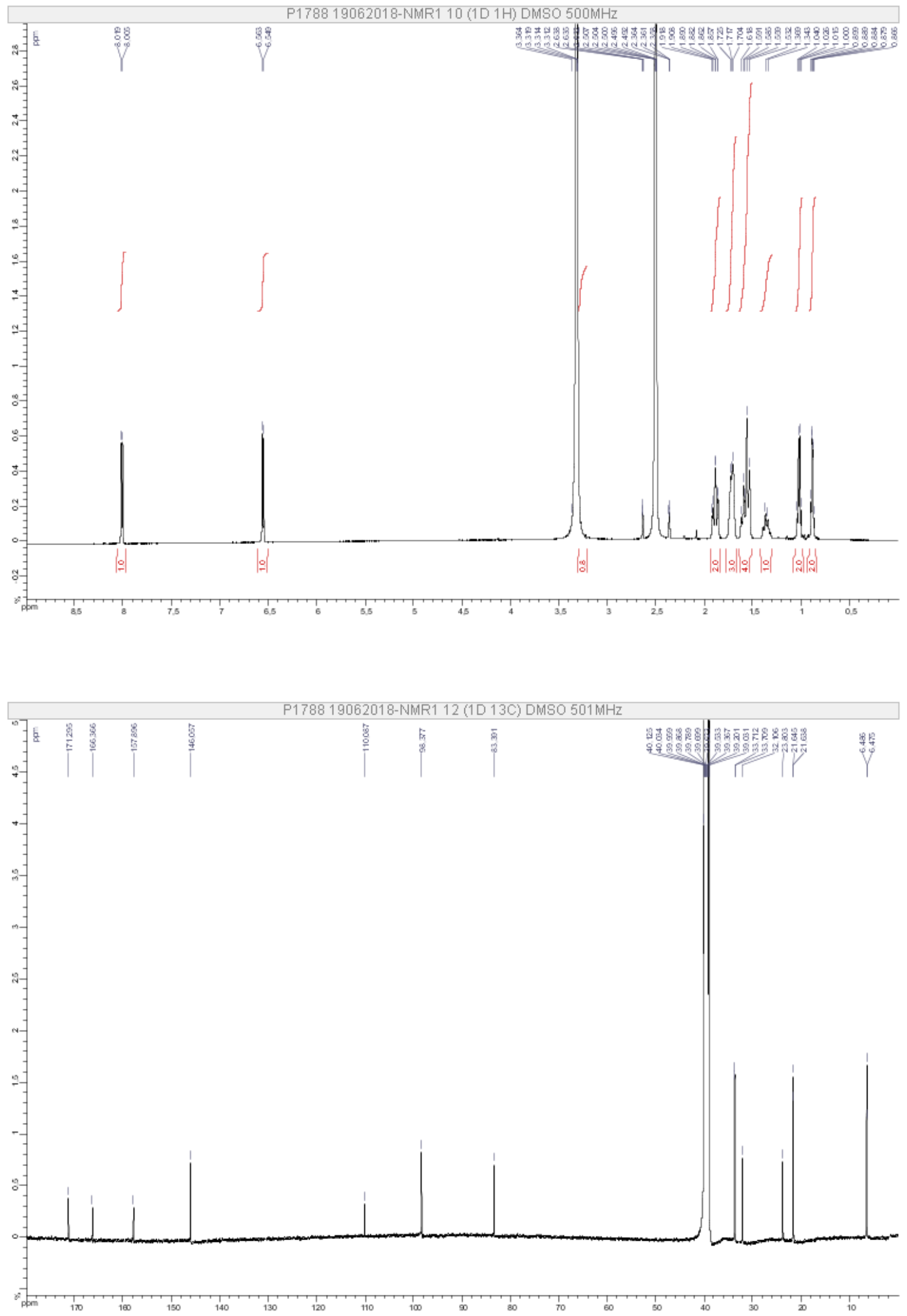
NMR data P1792
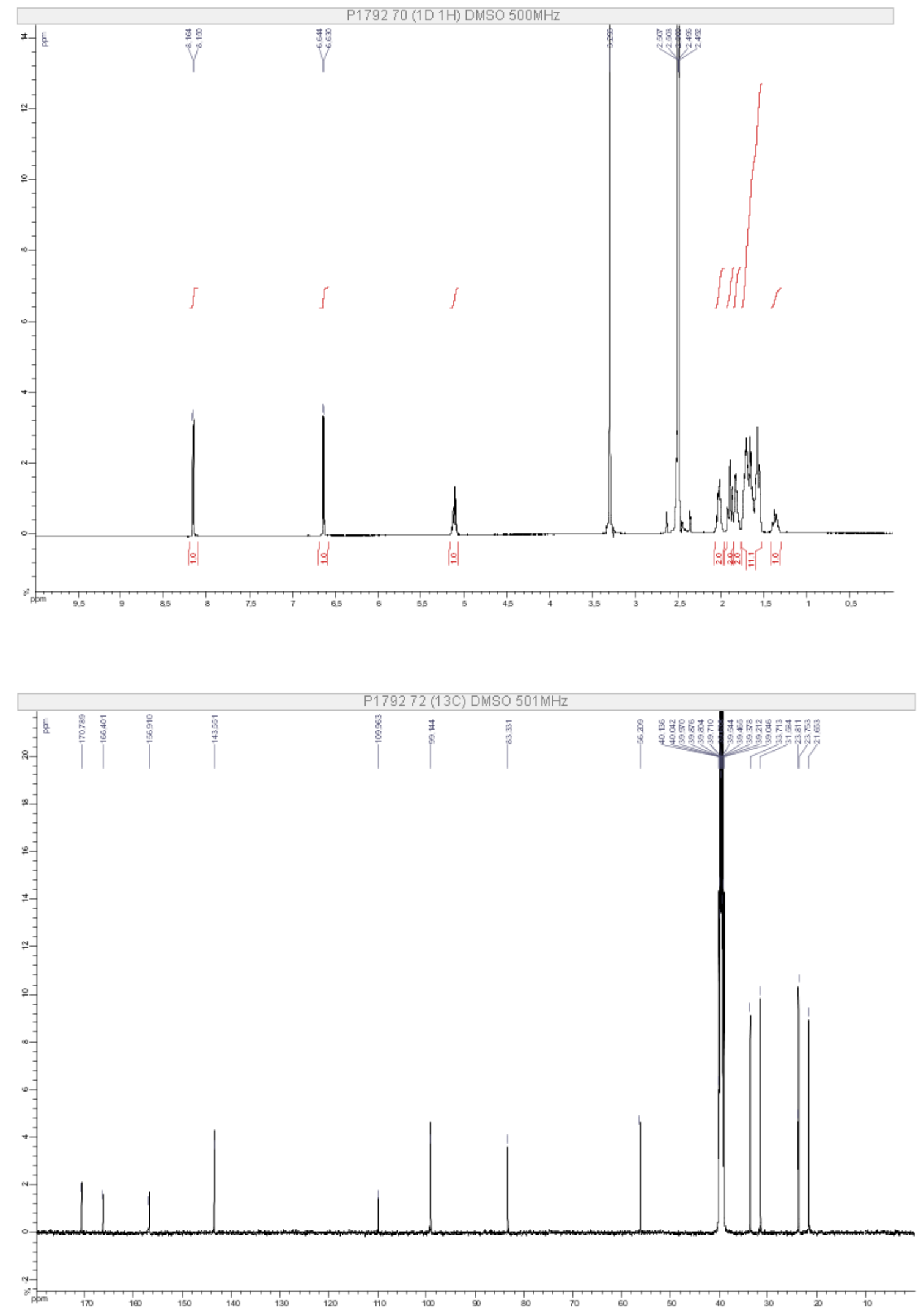
NMR data P1793
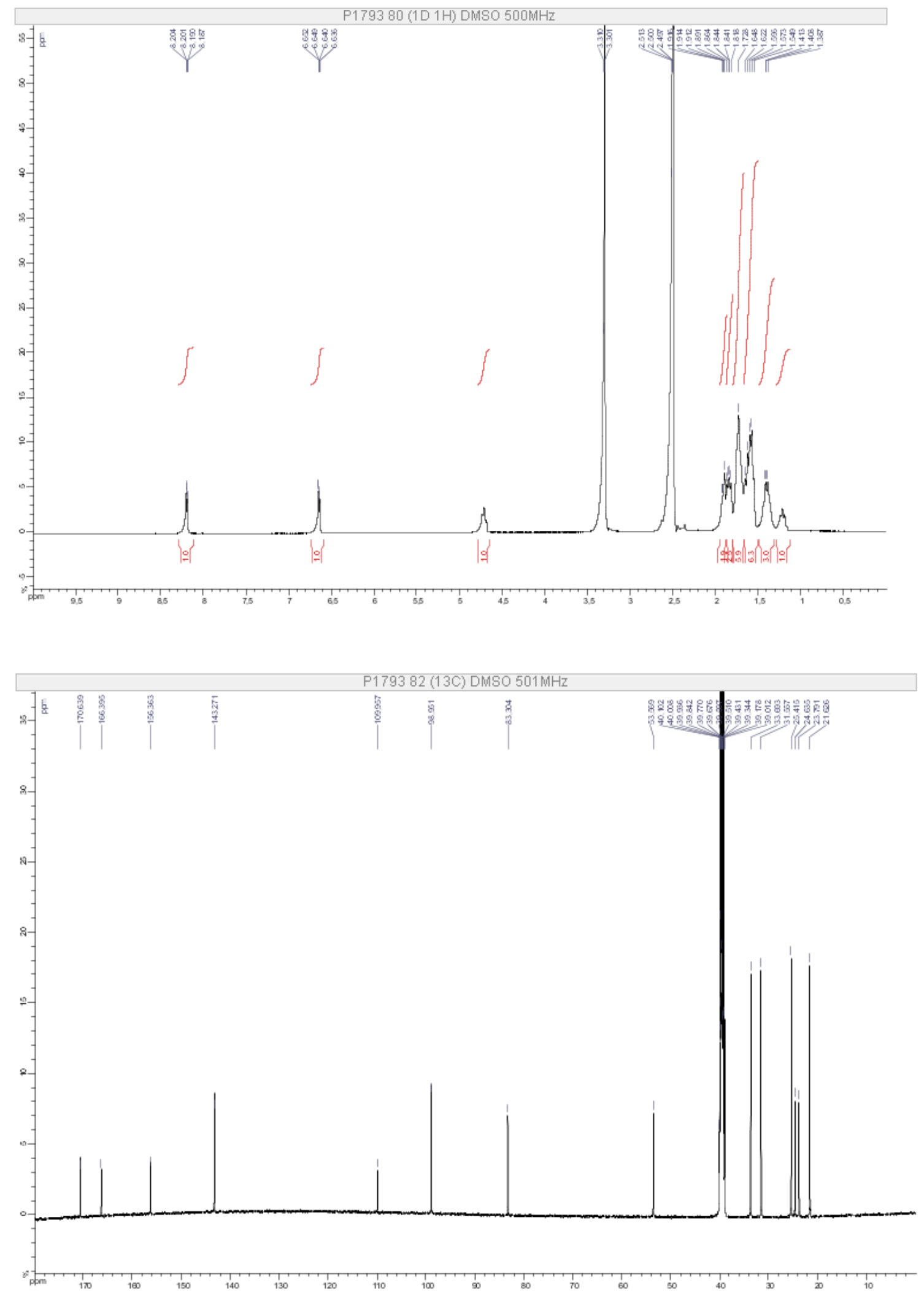
NMR data P2701
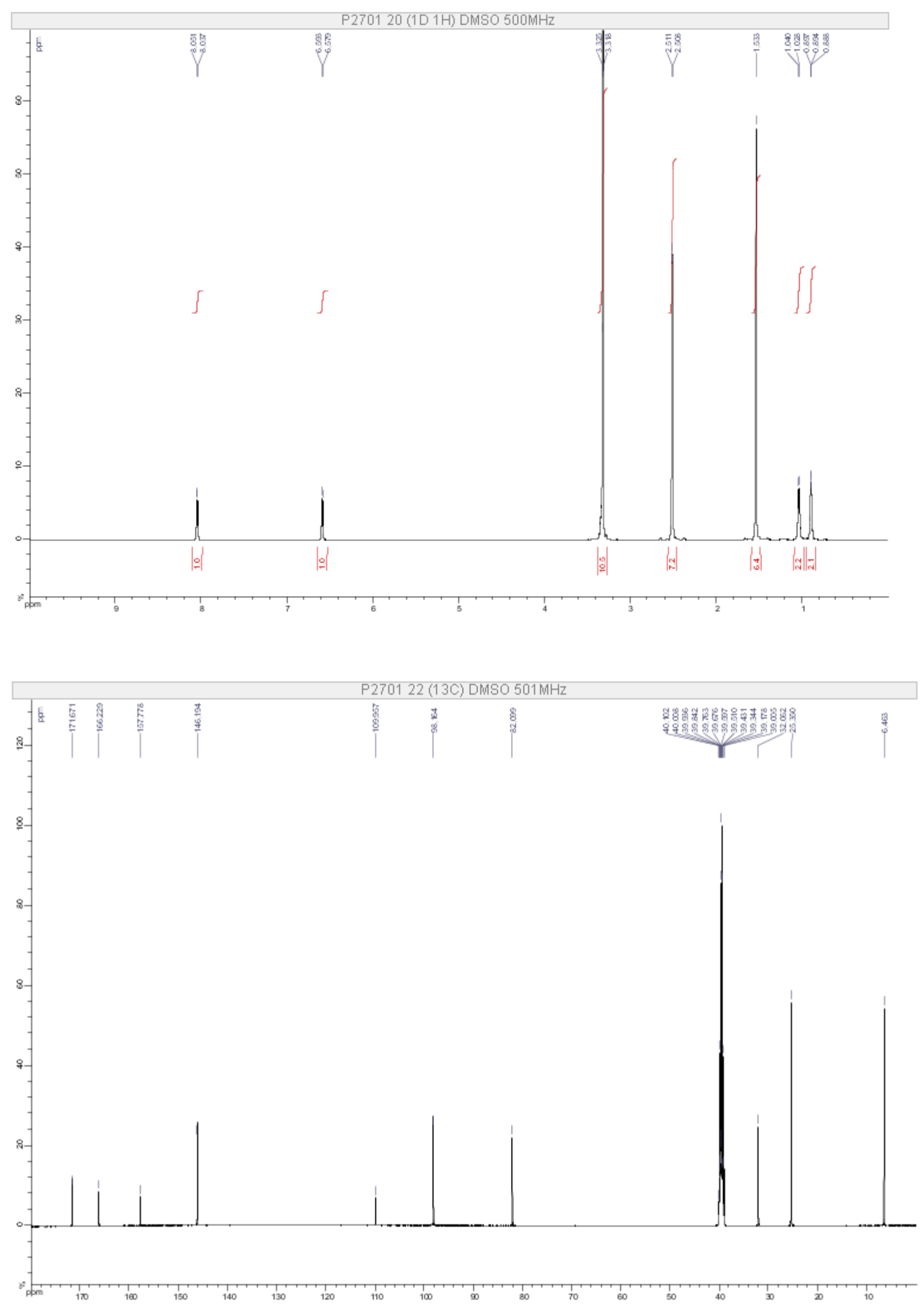
$\mathrm{P} 2702\{1 \mathrm{H})$

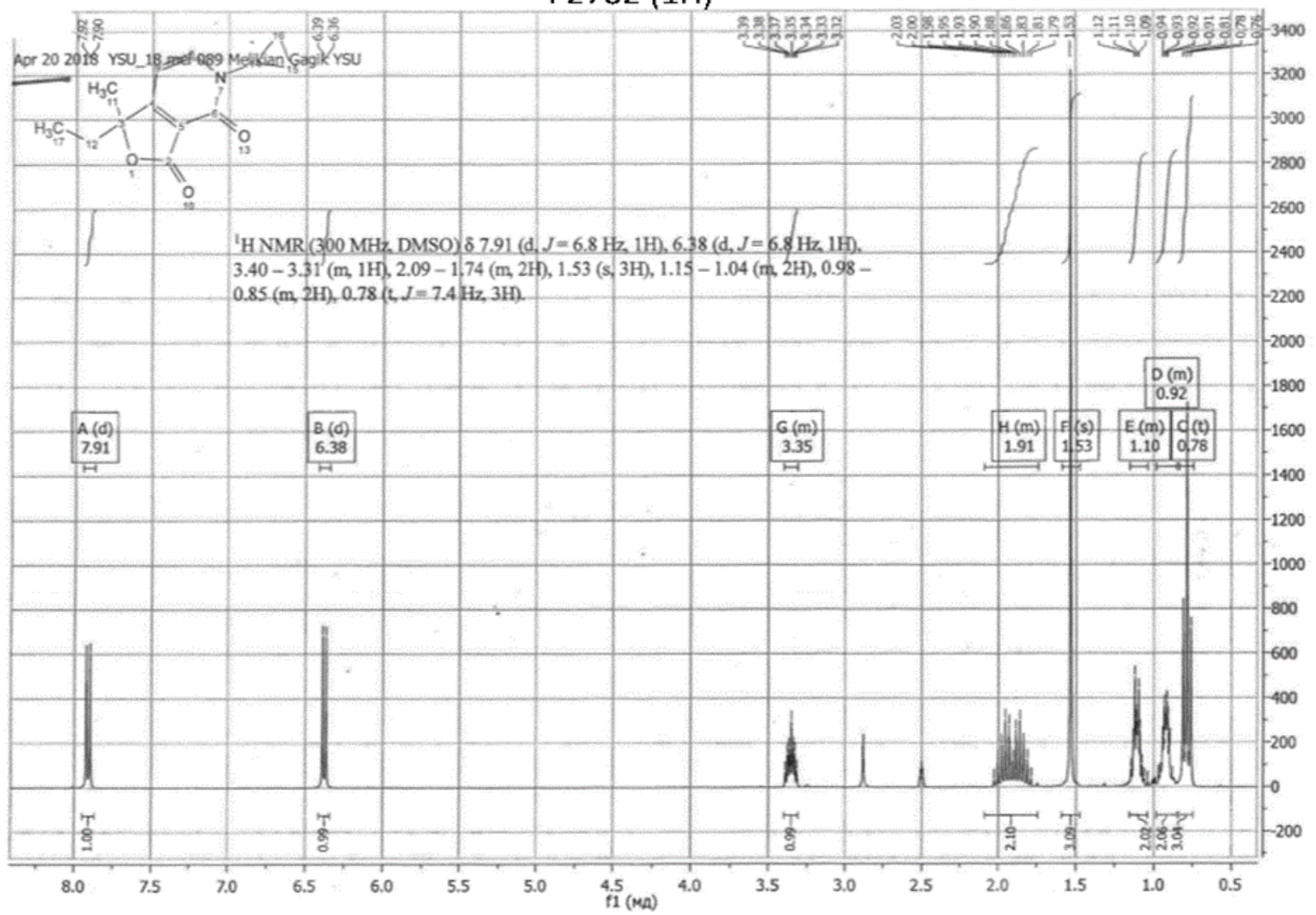

P2702 (13C)

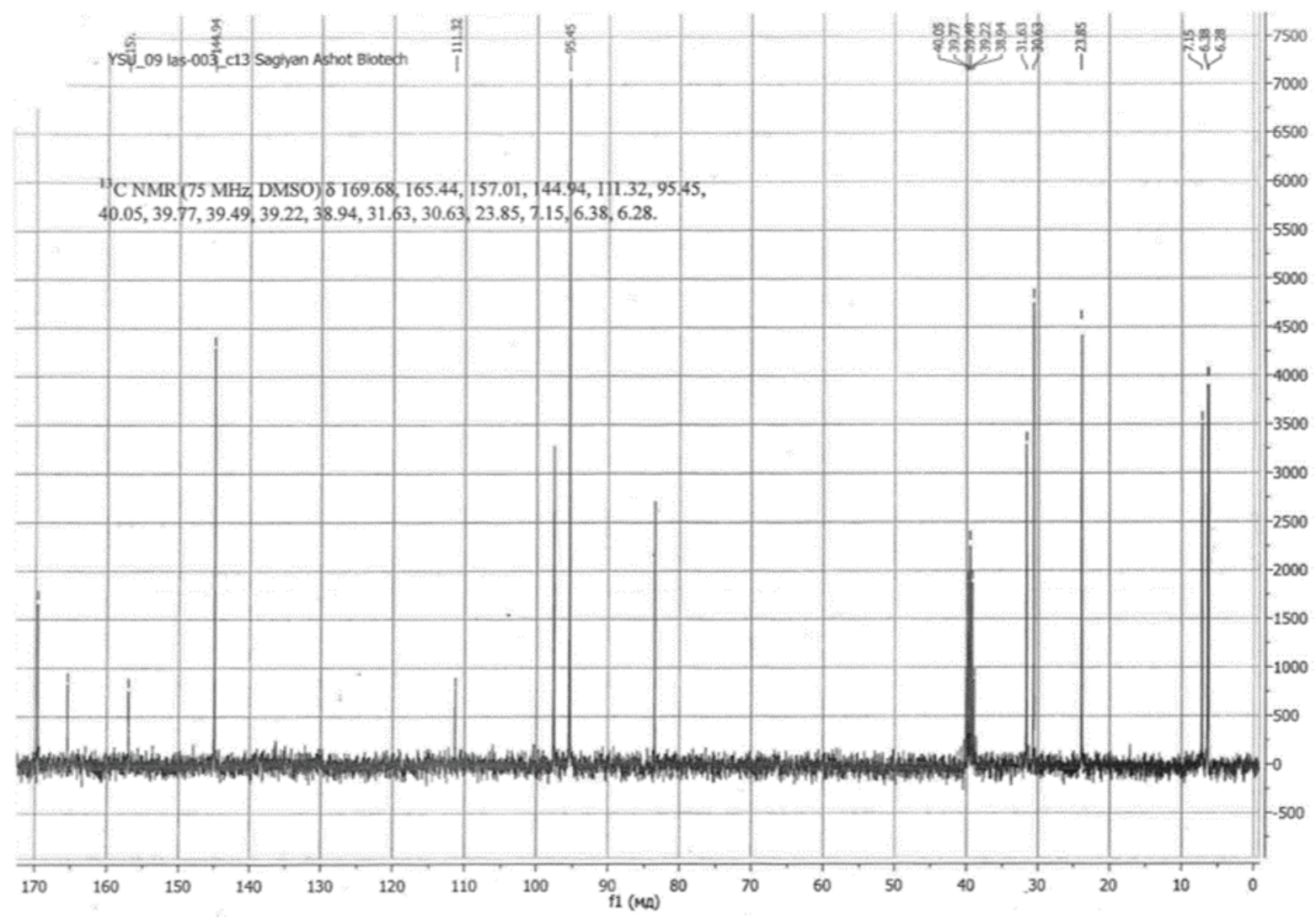




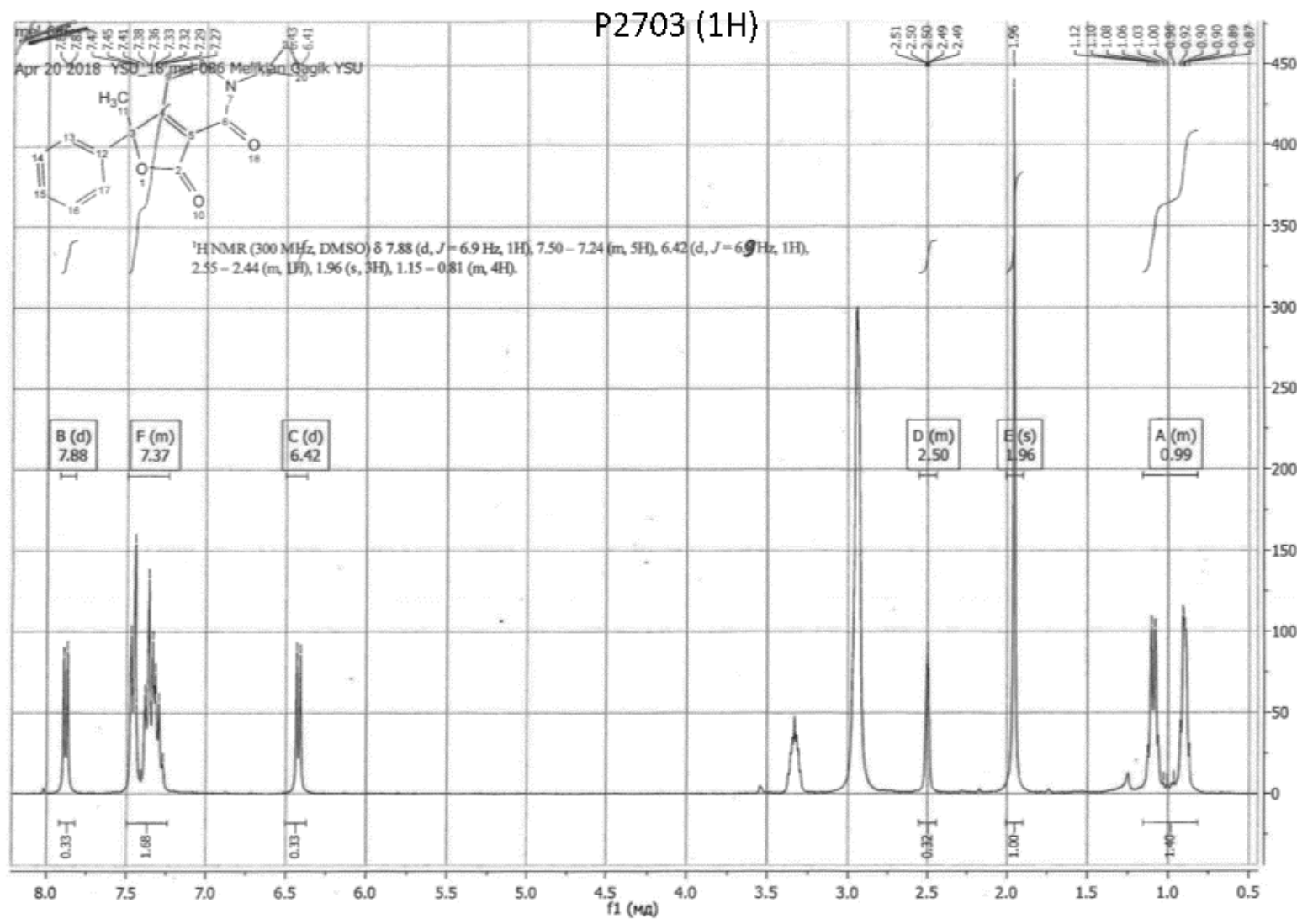

P2703 (13C)

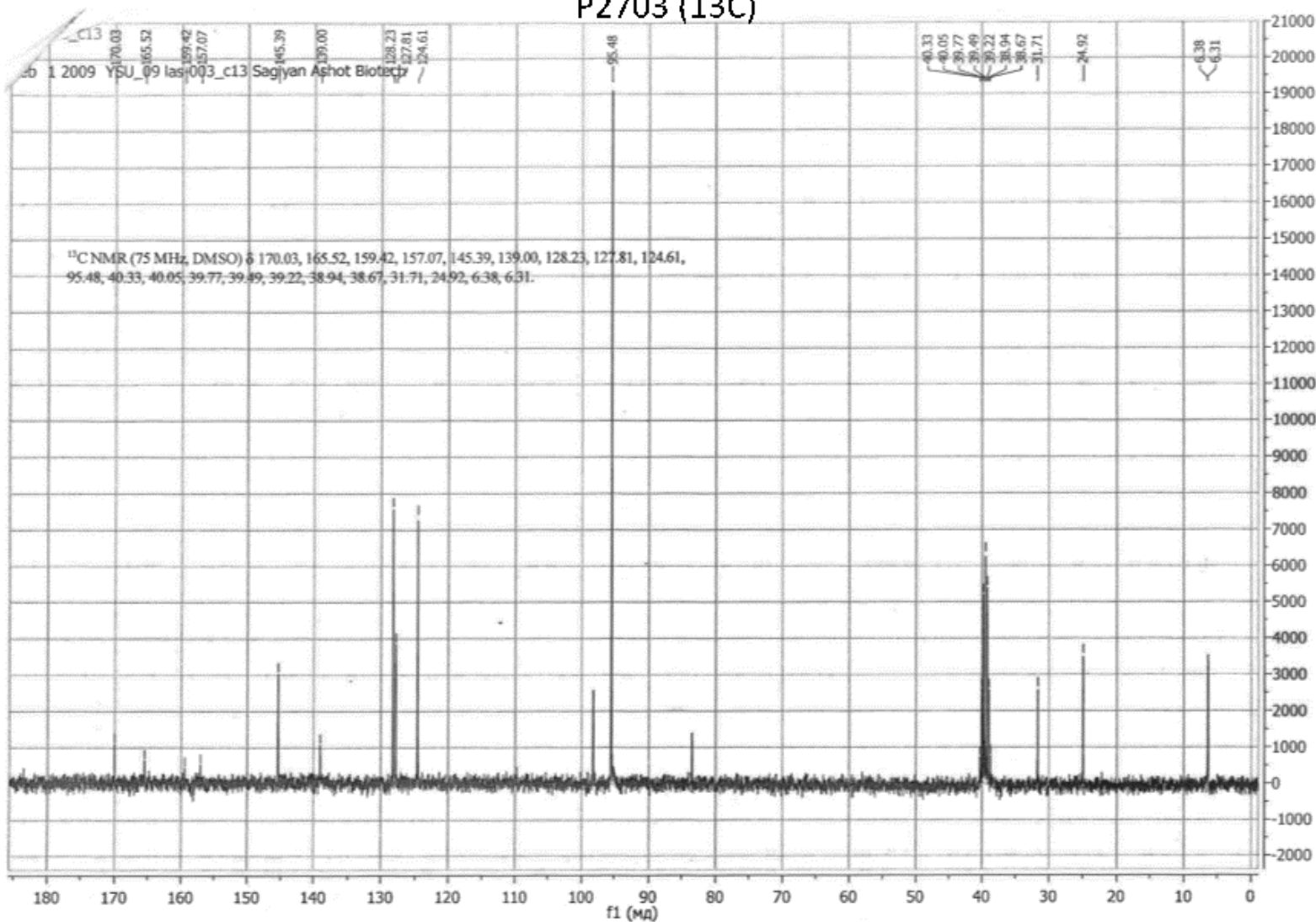




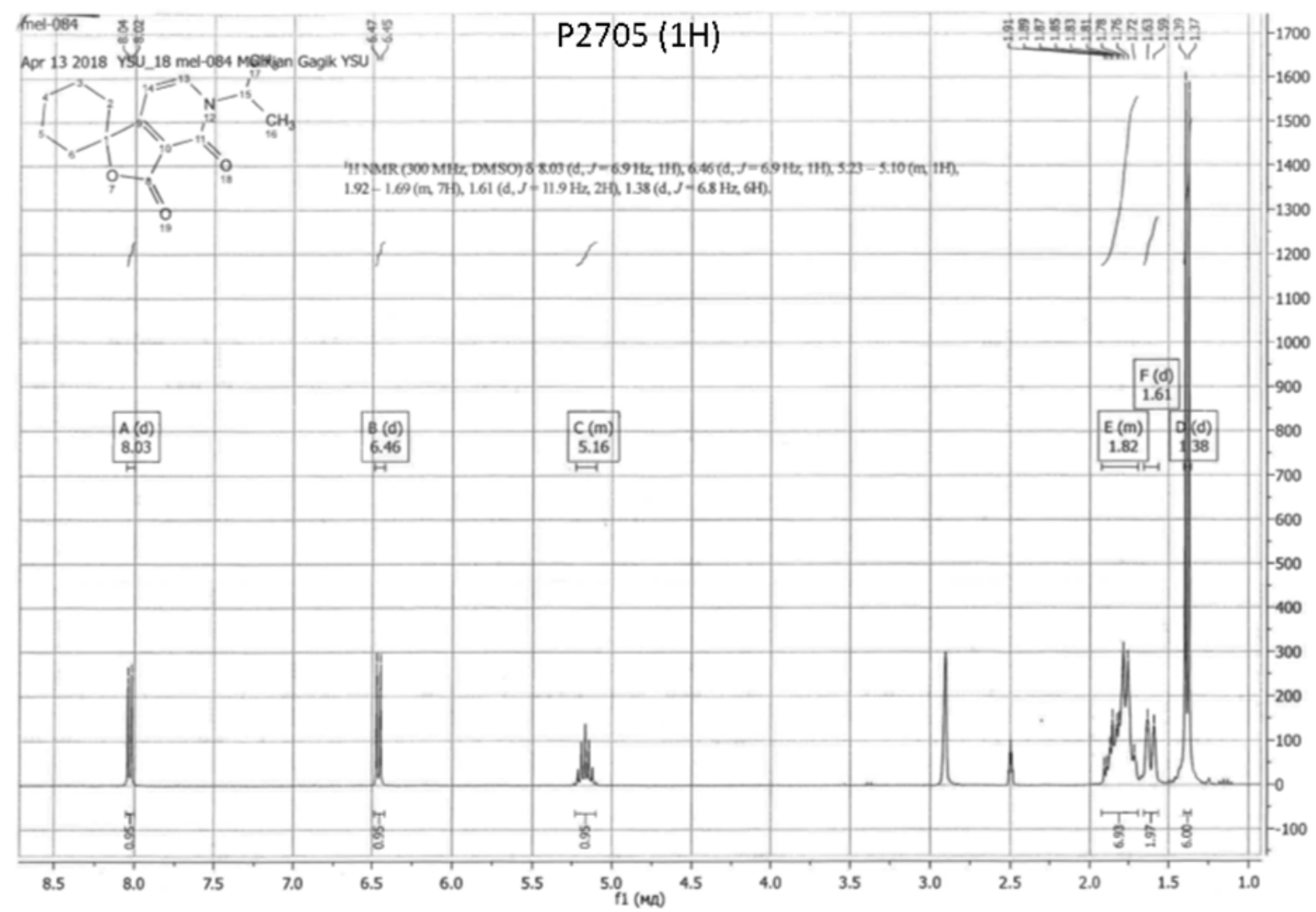

P2705 (13C)

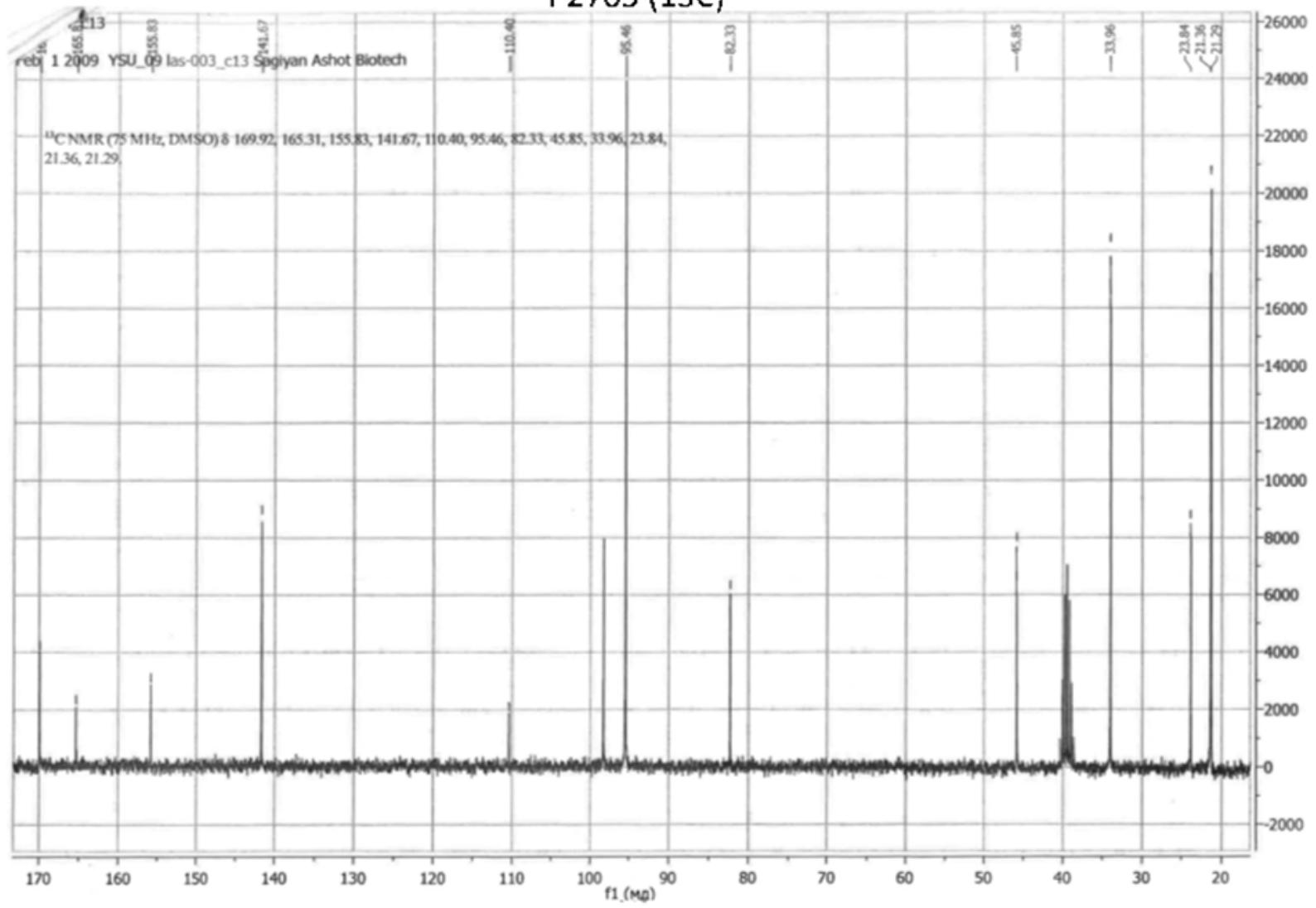


P2706 (1H)

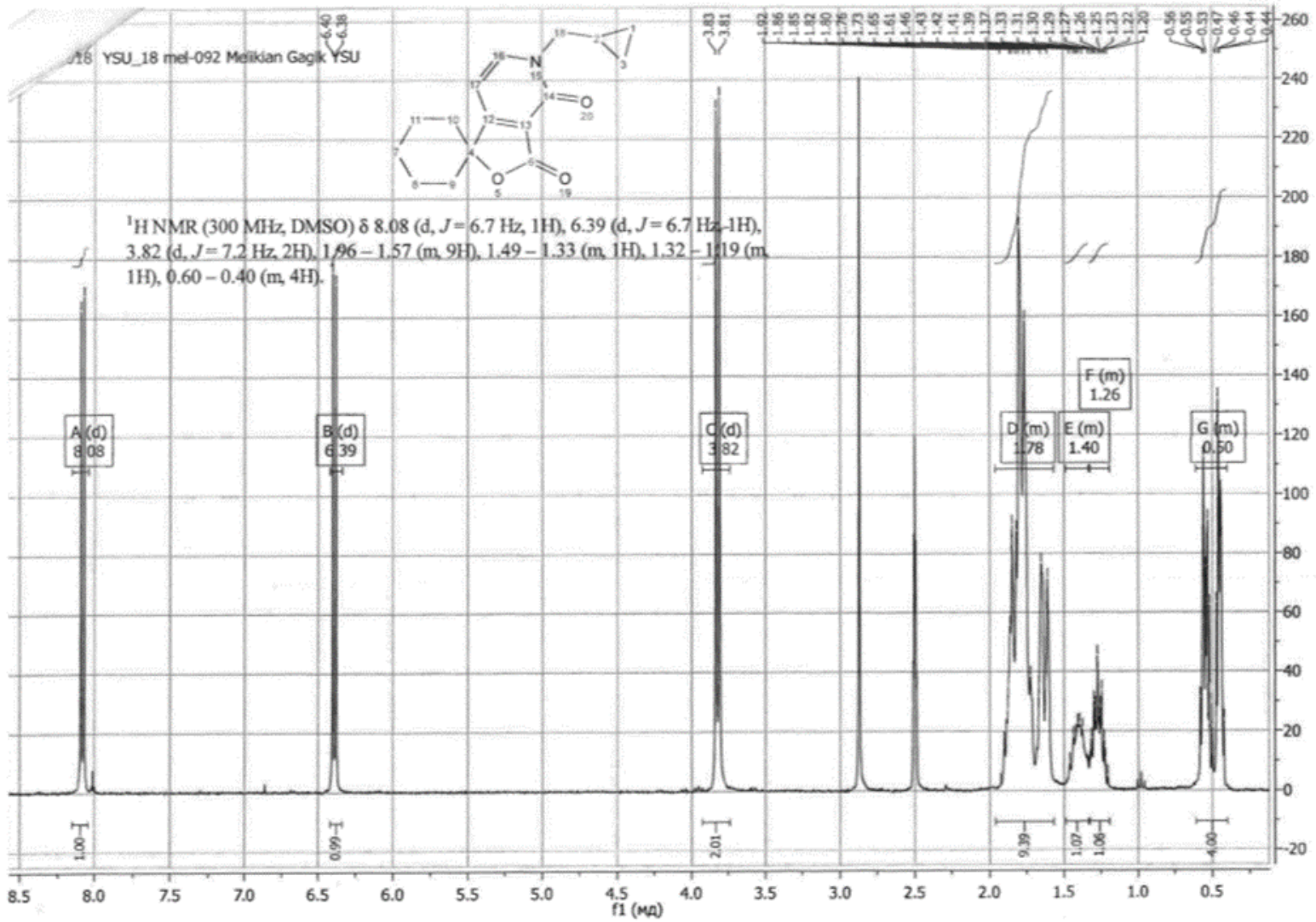

P2706 (13C)

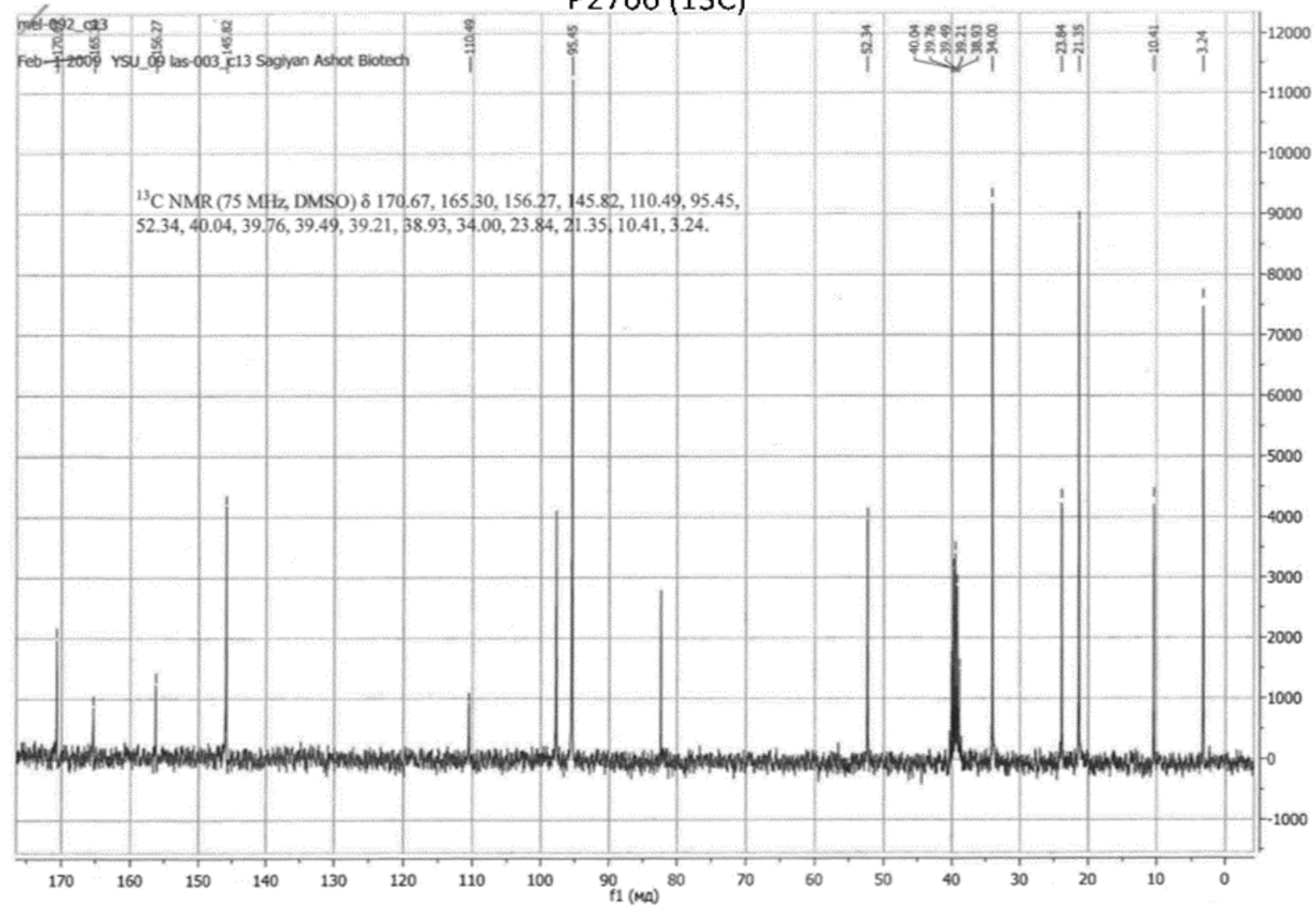


NMR data P2707
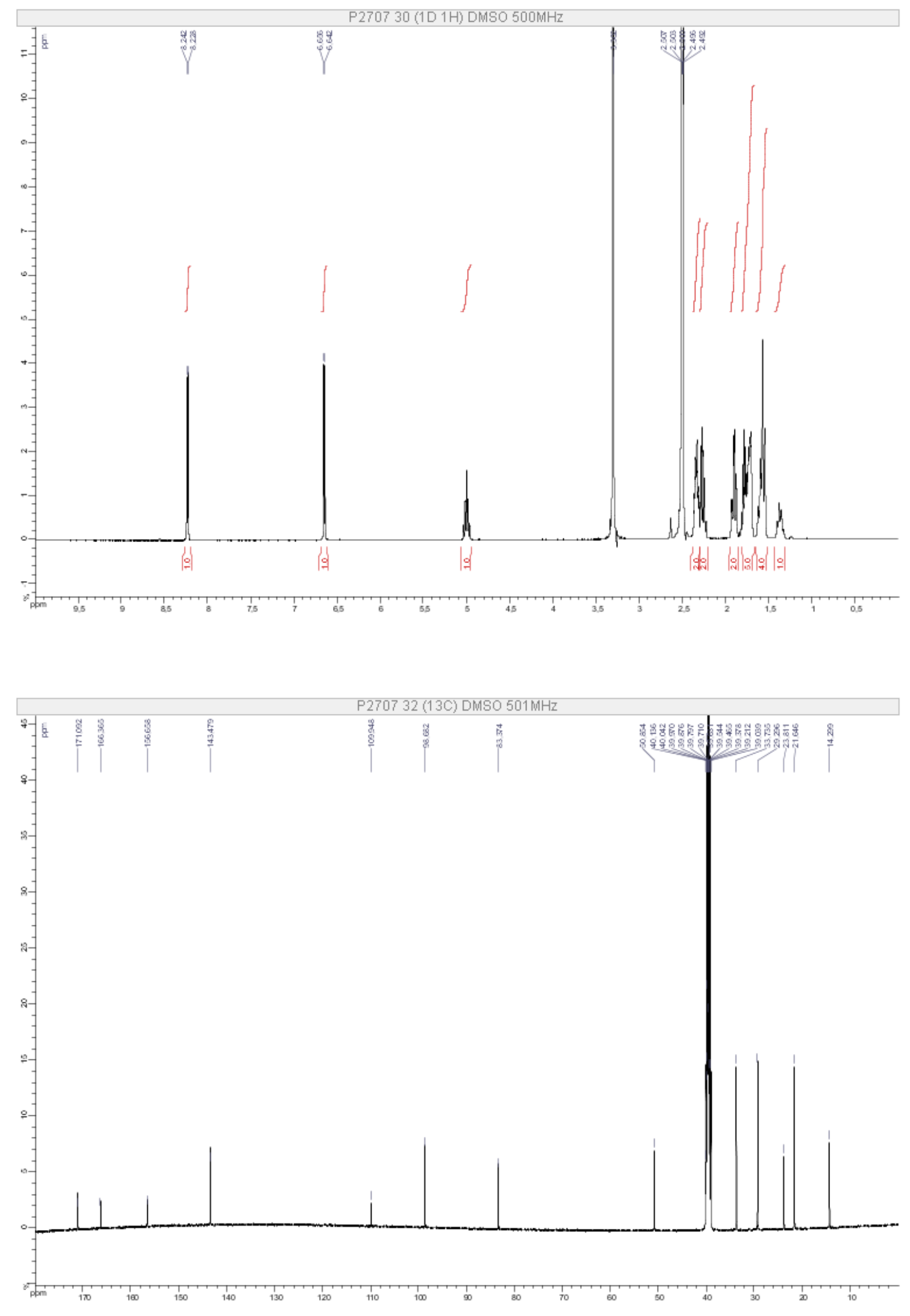
NMR data P2708
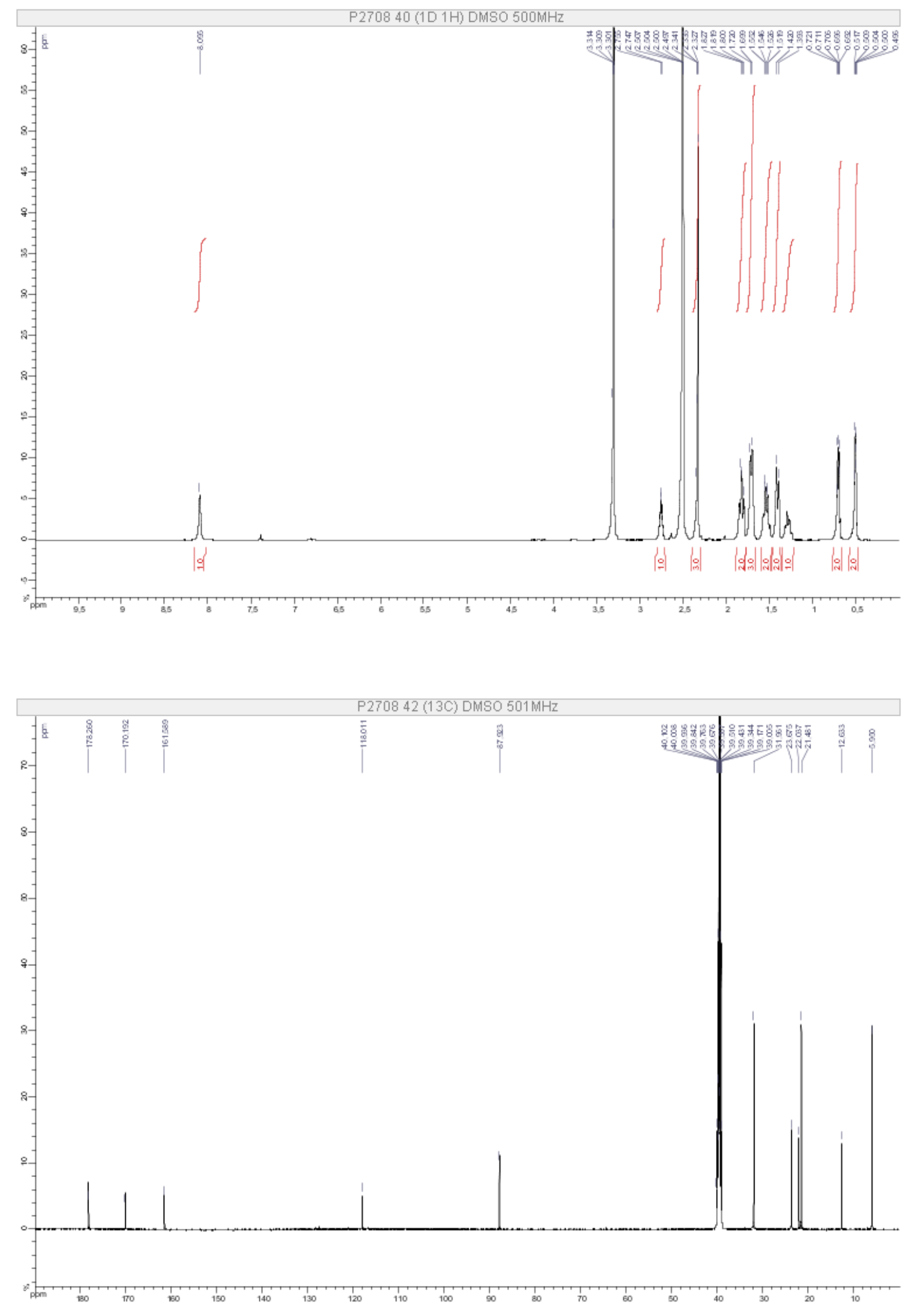
NMR data P2717
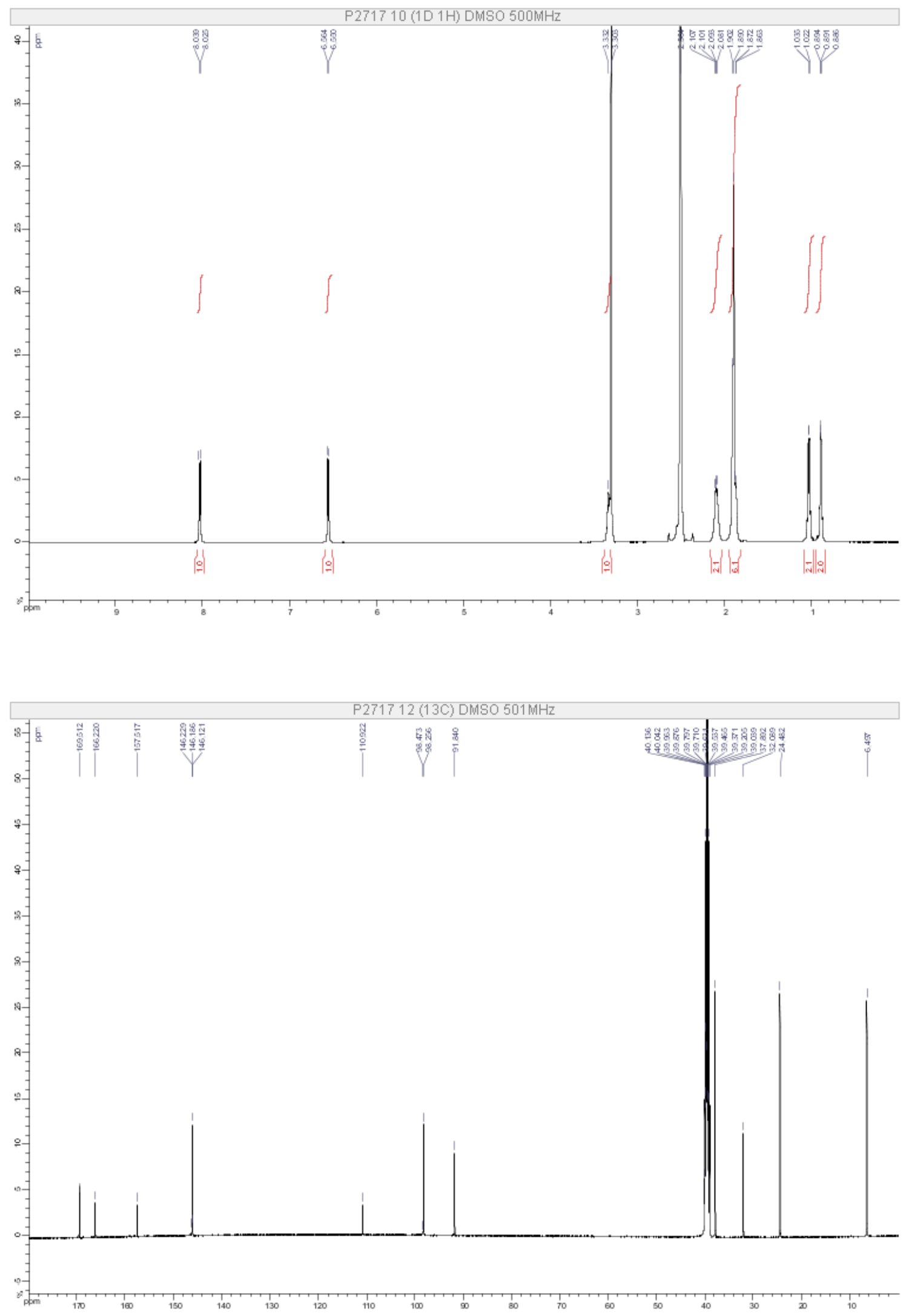
NMR data P2718
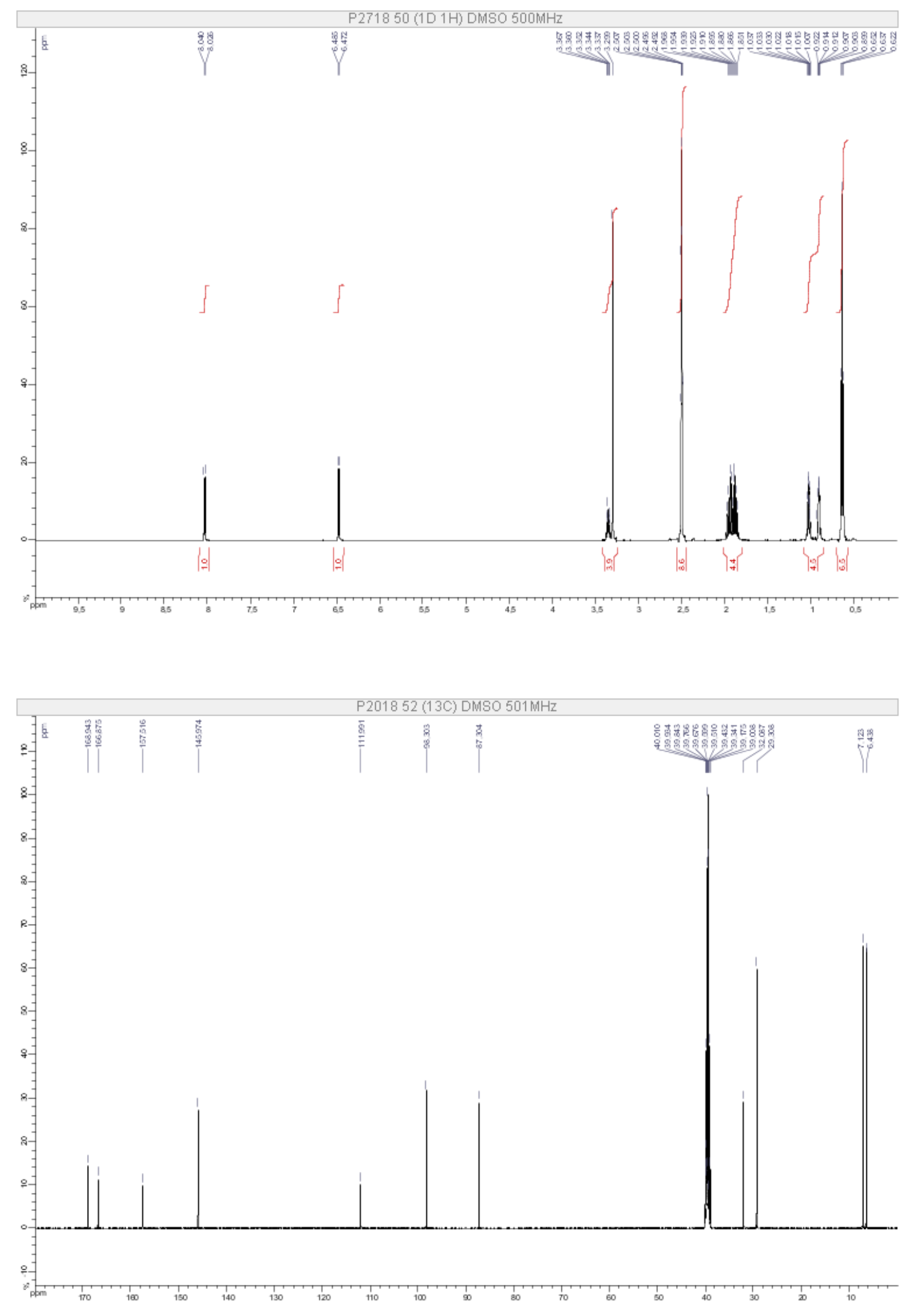